\title{
Apoio à Documentação de Engenharia Reversa de Software por meio de Hipertextos
}

\author{
Valéria Delisandra Feltrim
}

Orientação:

Prof $^{a}$. Dr ${ }^{a}$. Renata Pontin de Mattos Fortes

Dissertação ${ }^{1}$ apresentada ao Instituto de Ciências Matemáticas e de Computação - USP, como parte dos requisitos para a obtenção do título de Mestre em Ciências - Área de Ciências de Computação e Matemática Computacional.

USP - São Carlos

Novembro de 1999

\footnotetext{
${ }^{1}$ Trabalho realizado com o apoio financeiro da FAPESP, \#97/12999-8.
} 
“Aos meus pais, Feltrim e Lourdes, pelo amor e apoio incondicionais" 


\section{Agradecimentos}

À Profa. Renata Pontin de Mattos Fortes, minha orientadora, pelo apoio e pela confiança em mim depositada, e acima de tudo, pela sua amizade.

Ao João Caldas, por seu amor e apoio constantes.

Ao meu irmão Ricardo, pela confiança e pelo carinho que, de alguma forma, sempre existiram.

À amiga Gisele, por me ensinar a acreditar em mim.

Às minhas companheiras de república, Luciana, Tatiana e Thelma, por compartilharem comigo os bons e os maus momentos.

A todos os amigos do ICMC, pela amizade e pelos momentos de descontração vividos ao lado de cada um.

À Fapesp, pelo apoio financeiro.

A todos que, direta ou indiretamente, contribuíram para a conclusão deste trabalho. 



\section{Sumário}

\section{Lista de Figuras}

\section{Lista de Quadros}

\section{Resumo}

\section{Abstract}

1 Introdução 1

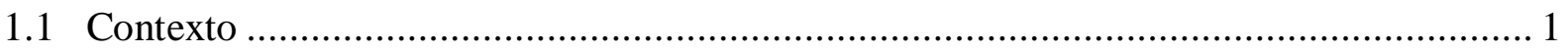

1.2 Motivação ....................................................................................................... 3

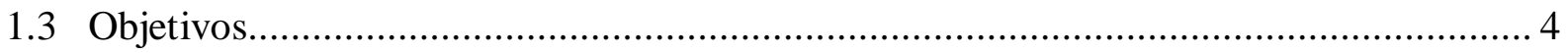

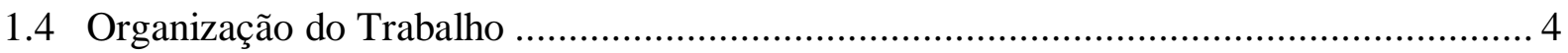

$\begin{array}{lll}2 & \text { Engenharia Reversa } & 7\end{array}$

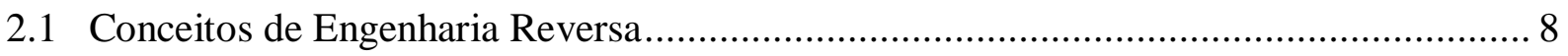

2.2 O Método Fusion-RE/I..................................................................................... 11

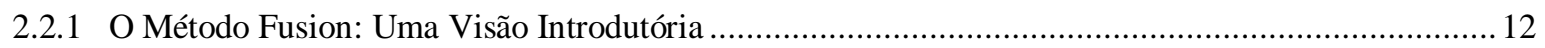

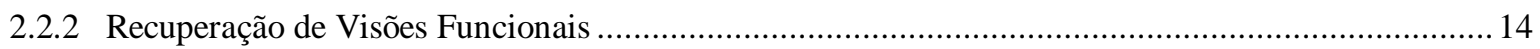

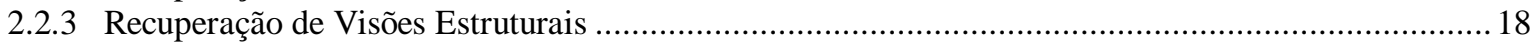

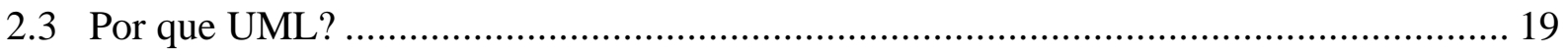

2.4 Representação dos Modelos do Método Fusion-RE/I em UML..................................... 22

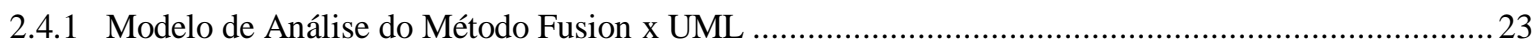

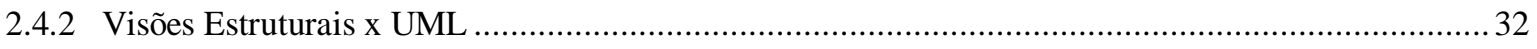

2.5 Considerações Finais......................................................................................... 38

3 O Suporte de Sistemas Hipermídia 41

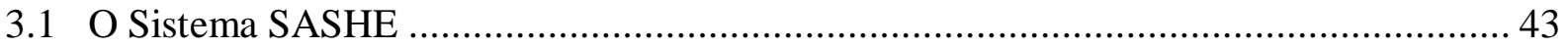

3.1.1 Modelo de Contextos Aninhados ........................................................................................ 47

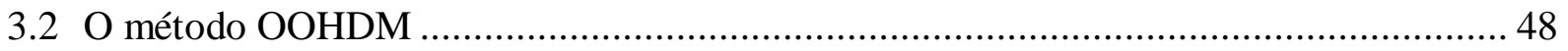

3.3 Modelagem hipermídia do domínio de Engenharia Reversa.................................... 49

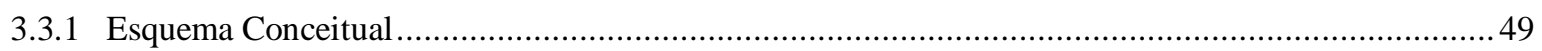




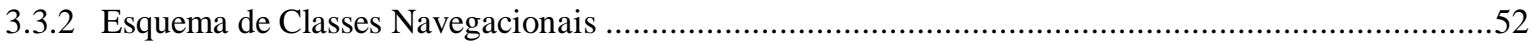

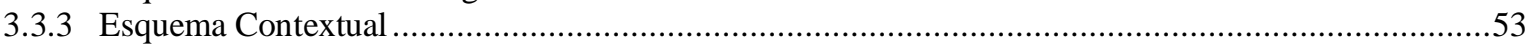

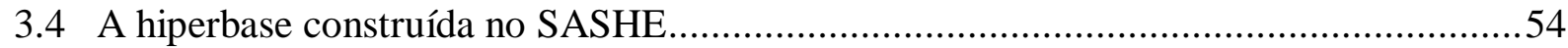

3.5 Proposta de adequação do SASHE para Engenharia Reversa ...................................59

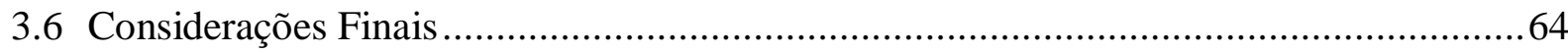

4 Engenharia Reversa aplicada ao Sistema SASHE

4.1 Resumo dos resultados da Engenharia Reversa ................................................66

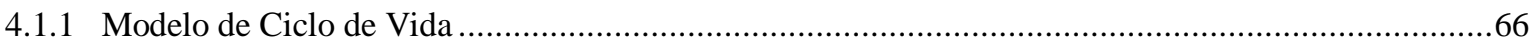

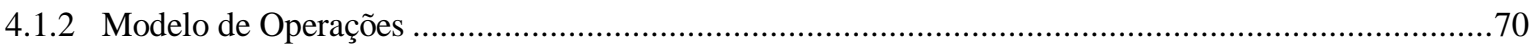

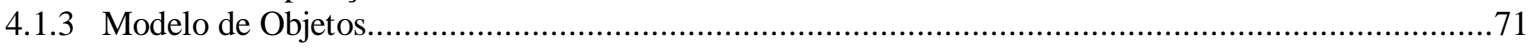

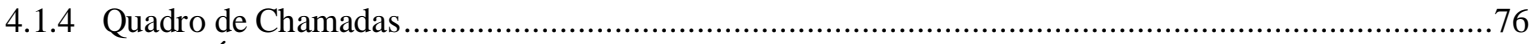

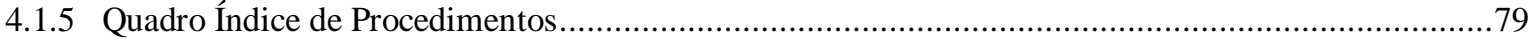

4.1.6 Quadro de Operações-Procedimentos de Implementação .............................................................80

4.2 Métricas do processo de Engenharia Reversa realizado ............................................81

4.3 Problemas encontrados na realização da Engenharia Reversa....................................83

4.4 Considerações Finais .................................................................................... 835

5 Avaliação geral do Fusion-RE/I $\quad 87$

5.1 Discussão dos pontos positivos e críticos da aplicação do método Fusion-RE/I............87

5.2 Validação dos Resultados obtidos com o Fusion-RE/I....................................... 96

5.3 Uma proposta de adequação do Fusion-RE/I a sistemas OO.....................................98

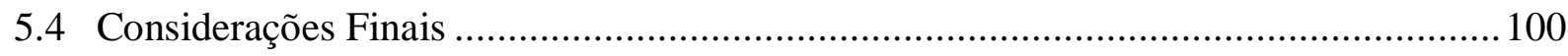

6 Conclusão $\quad 101$

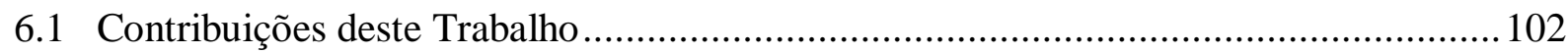

6.2 Sugestões para Futuras Pesquisas ................................................................. 103

$\begin{array}{ll}\text { Referências Bibliográficas } & 105\end{array}$ 


\section{Lista de Figuras}

Figura 2.1 - Processo de Engenharia Progressiva x Engenharia Reversa .............................. 9

Figura 2.2 - Visão Geral do Método Fusion-RE/I .............................................................. 11

Figura 2.3 - Visão Geral do Método Fusion (Masiero, 1995) ............................................. 12

Figura 2.4 - Resumo da notação UML para diagrama de classes e objetos ............................ 24

Figura 2.5 - Modelo de Objetos simplificado para o tema Autoria, em Fusion ...................... 25

Figura 2.6 - Modelo de Objetos simplificado para o tema Autoria, em $U M L \ldots \ldots \ldots \ldots \ldots \ldots \ldots \ldots . . . . . .25$

Figura 2.7 - Notação do Diagrama de Estado usado pela UML ........................................... 29

Figura 2.8 - Parte inicial do Modelo de Ciclo de Vida do SASHE...................................... 29

Figura 2.9 - Diagrama de estado representando as sentenças iniciais do ciclo de vida ............. 30

Figura 2.10 - Janela para especificação geral da transição de estado na Rational Rose ............. 31

Figura 2.11 - Janela para especificação detalhada da transição de estado na Rational Rose ...... 31

Figura 2.12 - Ícone utilizado pela Rational Rose para representar o corpo de um subprograma34

Figura 2.13 - Exemplo de diagrama de componente................................................. 34

Figura 2.14 - Diagrama de componentes para o arquivo ancora.cpp ................................... 37

Figura 3.1 - Arquitetura geral dos módulos funcionais de SASHE..................................... 44

Figura 3.2 - Controles de navegação disponíveis no sistema SASHE .................................. 46

Figura 3.3 - Esboço da Metodologia OOHDM (Rossi, 1996) ............................................ 48

Figura 3.4 - Modelo Conceitual do PER ........................................................................ 50

Figura 3.5 - Modelo de Classes Navegacionais ...................................................... 52

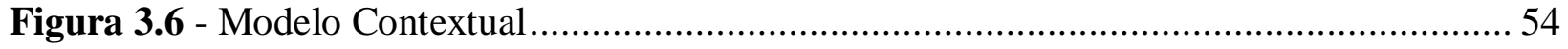

Figura 3.7 - Projeto dos contextos aninhados da hiperbase para documentar a engenharia reversa segundo o Fusion-RE/I.................................................................... 55

Figura 3.8 - Esquema contextual adaptado aos nós de contextos criados ............................. 56

Figura 3.9 - Parte do índice principal da hiperbase juntamente com o índice de operações....... 57

Figura 3.10 - Item de implementação Avança Histórico................................................... 58

Figura 3.11 - Janela apresentando a descrição da operação "Ativar Janela n”......................... 59

Figura 3.12 - Janela do SASHE para a criação de um nó terminal ........................................ 60

Figura 3.13 - Possível modificação de interface para a janela de criação de nó ...................... 61

Figura 3.14 - Possível modificação dos controles de navegação......................................... 62

Figura 4.1 - Parte inicial do Modelo de Ciclo de Vida do SASHE....................................... 67 
Figura 4.2 - Refinamento da opção "Hiperbase” e da operação "Abrir" ................................68

Figura 4.3 - Diagrama de transição de estado para a operação “Abrir Hiperbase”...................69

Figura 4.4 - Primeira tentativa de defini7ção de Temas para o SASHE .................................72

Figura 4.5 - Temas propostos para o SASHE .............................................................. 72

Figura 4.6 - Modelo de Objetos para o tema Autoria ........................................................74

Figura 4.7 - Modelo de Objetos para o tema Navegação..................................................75

Figura 4.8 - Modelo de Objetos recuperado a partir do código fonte do SASHE.....................76

Figura 5.1 - Aplicação do Fusion-RE/I a sistemas procedimentais .....................................8 88

Figura 5.2 - Aplicação do Fusion-RE/I a sistemas orientados a objetos ................................94

Figura 5.3a - O ambiente SASHE proposto (Nunes et al., 1996) ........................................96

Figura 5.3b - Arquitetura básica do Hip (Nunes et al., 1996) .......................................... 96

Figura 5.4a - Arquitetura recuperada do ambiente SASHE................................................97

Figura 5.4b - Arquitetura recuperada do Hip/Windows ............................................. 97 


\section{Lista de Quadros}

Quadro 2.1 - Representação do esquema para descrição das operações............................... 14

Quadro 2.2 - Descrição da operação "Criar Hiperbase” "...................................................... 30

Quadro 2.3 - Modelo de análise Fusion x UML ............................................................... 32

Quadro 2.4 - Quadro de Chamadas recuperado do arquivo ancora.cpp ............................... 35

Quadro 2.5 - Visões Estruturais Fusion-RE/I x UML...................................................... 38

Quadro 2.6 - Ordem das tarefas prescritas pelo Fusion-RE/I.............................................. 39

Quadro 3.1 - Parte do Modelo Operações-Procedimentos de Implementação.......................... 57

Quadro 4.1 - Esquema descrevendo a operação "Abrir" do menu "Hiperbase" ...................... 71

Quadro 4.2 - Quadro de Chamadas recuperado do arquivo elo.cpp .................................... 78

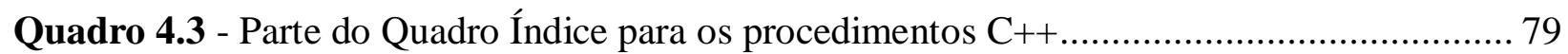

Quadro 4.4 - Parte do Quadro de Operações-Procedimentos de Implementação ..................... 81

Quadro 4.5 - Resumo dos produtos obtidos, em totais .................................................. 81

Quadro 5.1 - Informações sobre os estudos de caso realizados com o Fusion-RE/I ................. 90

Quadro 5.2 - Vantagens e desvantagens do Fusion-RE/I aplicado a sistemas OO................... 91

Quadro 5.3 - Modificações propostas para o Fusion-RE/I ................................................. 99 


\section{Resumo}

$\mathrm{O}$ crescimento do mercado de software a cada dia acarreta o aumento do uso de técnicas de desenvolvimento, muitas vezes informais. A manutenção de tais softwares torna-se problemática, uma vez que a documentação associada ao software, na maioria das vezes, não está de acordo com o código implementado. Dessa forma, quando diante da manutenção do produto, o engenheiro de software encontra uma documentação informal e incompleta, que não reflete o software existente. Nesse contexto é que se encontra a Engenharia Reversa de Software, com o propósito de recuperar as informações de projeto perdidas durante a fase de desenvolvimento, e de documentar o real estado do software. O principal objetivo deste trabalho de mestrado foi a investigação de uma estrutura adequada de hiperdocumento para apoiar a documentação requerida durante o processo de engenharia reversa de software. A partir de um levantamento dos requisitos desejáveis em um hiperdocumento, para que possua as habilidades de suporte à documentação de engenharia de reversa de software, um conjunto de links e estrutura de nós foi definido. Os requisitos, para a composição de tal hiperdocumento, foram investigados por meio de uma experiência: a autodocumentação do sistema hipermídia denominado SASHE (Sistema de Autoria e Suporte Hipermídia para Ensino), que já possui suporte ao tratamento de nós aninhados e outras características de aplicativo para ensino. A engenharia reversa foi desenvolvida baseando-se no método de engenharia reversa Fusion-RE/I, e os produtos obtidos foram inseridos em uma hiperbase no SASHE. 


\section{Abstract}

The growth of the software market has leading to an increasing use of development techniques, which are, sometimes, informal ones. The maintenance of such software is problematic, since its documentation rarely reflects the implemented code. In this context Reverse Engineering of Software can help by means of recovering the project information lost during the development phase and documenting the current software state. The main objective of this work was the investigation of an appropriate hypertext structure for supporting the documentation required through the software reverse engineering process. Starting from the survey of the desired requirements in a hyperdocument that has the abilities to support reverse engineering documents, we defined a set of links and nodes structures. The requirements for such hyperdocument were inquired by an experiment: the system SASHE's selfdocumentation that already treats nested contexts and has other educational characteristics. The reverse engineering process was developed based on the Fusion$\mathrm{RE} / \mathrm{I}$ method, and the resulting products were inserted in a hyperbase in the system SASHE. 



\section{Capítulo 1}

\section{Introdução}

Este capítulo apresenta o contexto no qual este trabalho está inserido, bem como as motivações que nos levaram ao seu desenvolvimento. Posteriormente também são descritos os objetivos do trabalho, assim como sua organização.

\subsection{Contexto}

A Engenharia de Software é tipicamente uma das áreas da Ciência de Computação que envolve, além de um grande volume de documentos, uma grande diversidade de tipos de documentos (diagramas, textos, códigos-fonte, executáveis, etc.). Tal característica, aliada ao fato de que tais documentos contêm informações bastante relacionadas, sugere naturalmente a utilização de hiperdocumentos (com nós e links) como meio adequado para o armazenamento e recuperação dessas informações (Bigelow, 1988), (Garg; Scacchi, 1989), (Meira; Cabral, 1994).

Dentro da engenharia de software, uma fase reconhecidamente problemática se refere à manutenção de software, responsável por custos de proporções superiores aos das demais fases do ciclo de vida de sistemas (Schach, 1994). A atividade de manutenção consiste de três etapas: entendimento, modificação e revalidação do sistema (Schneidewind, 1987). Notadamente, as etapas de entendimento e modificação estão muito relacionadas com a disponibilização das informações do software, ou seja, se apóiam na existência, consistência, completitude e atualização correta dos documentos que o compõem. A Engenharia Reversa é uma técnica 
utilizada para recuperar informações a partir dos documentos do software relativos ao produto ou código-fonte, visando a obtenção de sua representação em um nível mais alto de abstração. Dessa forma, visa facilitar o entendimento de sistemas de software.

Por sua vez, a tecnologia de hipermídia, servindo como um meio mais flexível para tornar disponível as informações aos usuários de aplicativos, está evoluindo rapidamente e possibilitando que novas formas de apresentação das informações também sejam investigadas. De fato, a base da tecnologia de sistemas hipermídia é a rede de informações que possui interconexões que devem estar facilmente acessíveis pelos usuários ${ }^{2}$. Essa rede de informações, onde os "nós" correspondem às unidades de informação e os "links" às interconexões entre eles, compõe um hiperdocumento.

Neste trabalho de mestrado, o principal interesse foi o tratamento de hiperdocumentos para dar o suporte necessário ao processo de engenharia reversa de software. Dessa forma, os estudos neste trabalho tiveram como alvo a construção de um hiperdocumento que possibilitasse a fidelidade do conteúdo da documentação com relação ao produto de software sendo documentado. Além disso, tivemos como meta obter a consistência entre as partes do hiperdocumento e os componentes do software com mais facilidade por meio dos links definidos. Por exemplo, o código-fonte de um programa é um documento que, se espera, tenha as respectivas documentações relacionadas ao seu projeto, análise, testes e outros, sendo, sempre que possível, consistentes e possuindo ligações de fácil acesso, a fim de refletir corretamente suas informações nos diversos níveis de abstração.

Deve-se ressaltar, ainda, que os links entre os diversos tipos de documentos devem ser representativos para que os mantenedores de software conheçam as repercussões das alterações realizadas e, principalmente, de forma que essas alterações sejam, sempre que possível, de fácil recuperação. Mas para uma definição desses links, de forma que eles atendam e auxiliem os mantenedores de software a entendê-lo, é necessário um estudo sistemático, pois, além de não se tratar de uma atividade simples, geralmente, muitos dos links e dos conteúdos de informação dos nós são estabelecidos conforme as premissas preconizadas pela metodologia utilizada.

Nesse contexto, este trabalho propõe um conjunto de links referentes ao domínio de informações relacionadas à documentação do processo de engenharia reversa de software. Para tanto, um ambiente de hipermídia, SASHE (Sistema de Autoria e Suporte Hipermídia para

\footnotetext{
${ }^{2} \mathrm{O}$ usuário de sistemas hipermídia pode ser: leitor e autor.
} 
Ensino), foi submetido à engenharia reversa, e tal processo foi suportado pela utilização do próprio SASHE para registrar o desenvolvimento das etapas envolvidas. Dessa forma, cada etapa de recuperação dos níveis de abstração e das relações entre os componentes de software implementados no SASHE, corresponde à definição de nós e links que o documentam, de forma hipertextual, no próprio SASHE.

\subsection{Motivação}

Com o desenvolvimento do ambiente de hipermídia SASHE em um projeto concluído no ICMC, e a partir dos primeiros experimentos obtidos com a criação de hiperdocumentos para ensino, pode-se observar que suas características constituem um recurso potencialmente utilizável por outros tipos de aplicação, que não somente as de ensino (Nunes et al., 1997a), (Nunes; Fortes, 1997). Neste sentido, a possível generalização para outro domínio de aplicação, o de Engenharia Reversa de Software, foi nossa principal motivação para o início deste trabalho, e foi investigada como contribuição ao projeto anteriormente realizado.

A experiência da utilização do SASHE para "documentar" o próprio SASHE, por meio da elaboração dos documentos referentes ao processo de engenharia reversa a que foi submetido foi, então, o exercício fundamental para o levantamento de requisitos que um engenheiro de software necessita para utilizar o SASHE como ferramenta de suporte à documentação do processo de engenharia reversa de software.

Outro ponto motivador das pesquisas deste trabalho de mestrado foi o de utilizar o método Fusion-RE/I (Costa, 1997) desenvolvido também no ICMC, que deve-se, principalmente, do fato de que a experiência prática conduzida neste projeto se constitui da aplicação da engenharia reversa a um ambiente de hipermídia, e esta aplicação foi registrada no próprio ambiente hipermídia. Como a utilização do Fusion-RE/I inicialmente considera a operacionalidade da interface usuário-computador do software, foi possível uma interação representativa para a própria "autodocumentação" realizada.

Além disso, a escolha do método Fusion-RE/I se orientou pelo fato de que o mesmo leva à produção das visões do sistema, ou seja, auxilia no entendimento e reconhecimento do seu modelo abstrato, sob o paradigma de Orientação a Objetos (OO). Deve-se ressaltar ainda que, mesmo com a escolha prévia por se aplicar o método Fusion-RE/I, este projeto o fez com uma 
particularidade inédita, que foi a de, ao final, produzir o modelos do sistema SASHE, na notação UML (Unified Modeling Language) (Rational, 1997a). A modelagem em UML possibilita uma abrangência de forma a não restringir a utilização de algum método de OO específico, como Fusion (Coleman, 1996) ou OMT (Object Modeling Technique) (Rumbaugh et al., 1991).

\subsection{Objetivos}

O principal objetivo desta pesquisa de mestrado foi elaborar uma proposta de adequação do sistema SASHE ao domínio da documentação de engenharia reversa de software, de forma que os links estabelecidos fossem representativos e proporcionassem agilidade para o acesso da documentação em questão.

Para tanto, a investigação e os estudos necessários para essa elaboração resultaram da análise de um experimento. Tal experimento consistiu da utilização e aplicação de engenharia reversa a um sistema hipermídia protótipo existente: SASHE, que foi desenvolvido no ICMC. Esse ambiente hipermídia SASHE, particularmente, provê um modelo interno de estruturação de nós do hiperdocumento que auxilia a organização dos nós: o MCA (Casanova et al., 1991), o qual também foi estudado de forma a fornecer os subsídios para o processo de entendimento do SASHE.

Além disso, para que a documentação atenda ao paradigma OO, a engenharia reversa orientou-se pela aplicação do método Fusion-RE/I. Finalmente, também foram obtidos conhecimentos sobre uma linguagem padrão de modelagem OO, a UML, cuja potencialidade de ser independente da utilização de qualquer método sob o paradigma de OO, pôde ser comprovada.

\subsection{Organização do Trabalho}

Este trabalho está organizado em seis capítulos, sendo que neste primeiro foi discutido o contexto em que este trabalho se encontra, as motivações para o seu desenvolvimento, e os objetivos almejados com sua realização.

O Capítulo 2 apresenta os conceitos de Engenharia Reversa de Software, abordando o método que foi utilizado para a realização da engenharia reversa no sistema SASHE, o Fusion- 
RE/I. Também nesse capítulo é discutido o porquê do uso da UML e uma breve descrição da sua notação, seguido da proposta para um mapeamento dos modelos gerados pelo método Fusion$\mathrm{RE} / \mathrm{I}$ para a UML, bem como exemplos de como esse mapeamento foi implementado.

No Capítulo 3 é abordado o suporte oferecido pelos sistemas hipermídia em vários domínios de aplicação, destacando-se a Engenharia de Software e a Engenharia Reversa. Em seguida, é descrito o ambiente hipermídia SASHE, ambiente que foi submetido à engenharia reversa, de forma a dar uma idéia geral da sua funcionalidade e das informações que estavam disponíveis no início do processo de engenharia reversa. Também nesse capítulo é mostrada a hiperbase construída com a documentação recuperada durante o processo de engenharia reversa, baseada em uma modelagem do domínio de engenharia reversa realizada, orientada pelo método OOHDM. Finalmente, nesse capítulo é apresentada uma proposta de adequação do sistema SASHE, a fim de tornar o ambiente mais propício à autoria e navegação de documentos de software.

Os documentos resultantes da aplicação do Fusion-RE/I ao SASHE são apresentados no Capítulo 4. Essa documentação é apresentada de forma resumida, devido ao grande volume de informações gerado.

No Capítulo 5, também como resultado da aplicação do Fusion-RE/I, são abordados os aspectos gerais que foram avaliados sobre o método. Como esse método ainda não havia sido aplicado a nenhum sistema com as características do SASHE, foi possível avaliar uma série de fatores, ressaltando vantagens e pontos críticos da aplicação do método. Encerrando esse capítulo é proposto um conjunto de mudanças ao método Fusion-RE/I, visando melhorar o desempenho do método para sua aplicação a sistemas OO.

Finalmente, as conclusões deste trabalho, bem como as possibilidades de trabalhos futuros, são apresentados no Capítulo 6. 
Capítulo 1 - Introdução 


\section{Capítulo 2}

\section{Engenharia Reversa}

Segundo Saleh e Boujarwah (1996), o mercado de software vem crescendo a cada dia e com ele o uso de técnicas de desenvolvimento, muitas vezes informais. Como resultado, a manutenção de tais softwares torna-se problemática, uma vez que a documentação associada ao software, na maioria das vezes, não está de acordo com o código implementado. Além disso, as constantes modificações e adições de novas características ao software acarreta efeitos colaterais inesperados, que não estão presentes na documentação.

Dessa forma, quando diante da manutenção do produto, o engenheiro de software encontra uma documentação informal e incompleta, que não reflete o software existente, tornando impossível o gerenciamento do processo de manutenção (Saleh; Boujarwah, 1996). Neste contexto, a Engenharia Reversa de Software, com o propósito de recuperar as informações de projeto perdidas durante a fase de desenvolvimento, e de documentar o real estado do software pode auxiliar o processo de gerenciamento da manutenção.

Rugaber (1992) afirma que a maior parte do esforço de desenvolvimento de software é gasto na manutenção de sistemas existentes e não no desenvolvimento de sistemas novos, e que grande parte do processo de manutenção é dirigido ao entendimento do sistema em manutenção. Sendo assim, se queremos melhorar o desenvolvimento de software, e necessário facilitar o processo de compreensão de sistemas existentes. A engenharia reversa ataca diretamente o problema de compreender o software. 
Neste trabalho, a engenharia reversa foi empregada com o objetivo de recuperar informações de análise do sistema SASHE, não registradas durante o desenvolvimento do software. A documentação recuperada poderá então facilitar a manutenção do sistema, uma vez que foi arquivada na forma de um hiperdocumento no próprio SASHE, e apoiar uma posterior reengenharia.

Na Seção 2.1 são discutidos alguns conceitos básicos sobre engenharia reversa, sendo apresentado em seguida, na Seção 2.2, o método de engenharia reversa Fusion-RE/I, utilizado como base para o desenvolvimento do processo de engenharia reversa. $\mathrm{Na}$ Seção 2.3 são apresentados os motivos pelos quais optamos por utilizar a notação UML neste trabalho, para a representação das informações recuperadas através da aplicação do Fusion-RE/I, bem como uma breve descrição da notação UML. Na Seção 2.4 é apresentada a proposta de mapeamento dos elementos de modelagem Fusion para a notação UML, seguida de exemplos de como o mapeamento dos documentos recuperados do sistema SASHE para a UML foi realizado.

\subsection{Conceitos de Engenharia Reversa}

Segundo Chikofsky e Cross II (1990) o termo "engenharia reversa" teve sua origem na análise de hardware, onde a prática de decifrar o projeto de produtos prontos é comum. O mesmo conceito pode ser aplicado a software, com uma diferença: enquanto a Engenharia Reversa de Hardware tem por objetivo reproduzir o sistema, a Engenharia Reversa de Software se destina a criar "visões" do sistema em diferentes níveis de abstração, facilitando seu entendimento com o principal objetivo de ajudar na manutenção do sistema.

Uma definição de abstração é dada como a habilidade de se ignorar os aspectos de assuntos não relevantes para o propósito em questão, tornando possível uma concentração maior nos assuntos principais (Oxford, 1986).

O ciclo de vida do software expressa bem a diferença entre níveis de abstração. Vale ainda ressaltar a existência de dois conceitos relativos a abstração: "nível de abstração" e "grau de abstração".

Diferentes níveis de abstração ocorrem entre diferentes etapas do desenvolvimento (por exemplo, as informações na etapa de projeto são outras além das informações da etapa de 
análise), enquanto diferenças no grau de abstração ocorrem dentro de uma mesma etapa (pode-se representar as informações de uma mesma etapa do desenvolvimento de forma geral ou de forma mais detalhada) (Chikofsky; Cross II, 1990).

Dessa forma, a engenharia reversa pode ser aplicada em qualquer etapa do ciclo de vida, seja para recuperar níveis de abstração ou para fornecer uma nova visão em um grau de abstração mais alto (é consenso de que quanto mais alto o grau de abstração, menos detalhes são fornecidos).

A engenharia reversa segue o sentido oposto ao da engenharia progressiva. A engenharia progressiva segue a seqüência que vai desde os requisitos, passa pelo projeto até a implementação. Na engenharia progressiva, o sistema é o resultado do processo de desenvolvimento. Na engenharia reversa, o sistema geralmente é o ponto inicial do processo (Chikofsky; Cross II, 1990). A Figura 2.1, adaptada de Chikofsky e Cross II (1990), representa esquematicamente, uma forma comparativa das direções inversas por quais se orientam as etapas envolvidas em cada uma das engenharias. O processo de engenharia reversa caracteriza-se pelas atividades retroativas do ciclo de vida, que partem de um baixo nível de abstração para um alto nível de abstração.

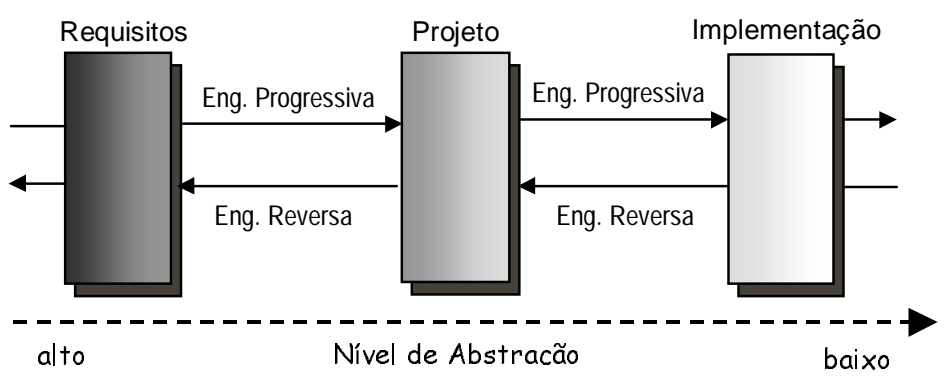

Figura 2.1 - Processo de Engenharia Progressiva x Engenharia Reversa

Existem várias definições de Engenharia Reversa. A de Pressman (1995) diz que é "o processo de análise num esforço de criar uma representação do programa em um nível de abstração mais alto que o código fonte”. Em Costa (1997) encontramos a definição de Engenharia Reversa como "o processo de exame e compreensão do sistema existente, para recapturar ou recriar os requisitos atualmente implementados pelo sistema, apresentando-os em um grau ou nível mais alto de abstração. Não envolve mudanças no sistema ou criação de um novo sistema". Segundo Chikofsky e Cross II (1990), Engenharia Reversa de Software é um processo de investigação, não um processo de mudança ou reprodução. Rugaber (1992) identifica o propósito da engenharia reversa como sendo entender um sistema de software com o 
objetivo de facilitar atividades como: expansão, correção, documentação, re-projeto ou reprogramação em outra linguagem de programação.

Chikofsky e Cross II (1990) também identificam duas importantes categorias da Engenharia Reversa: a redocumentação (visualização de código) e a recuperação de projeto (entendimento de programa).

A categoria redocumentação compreende a criação ou revisão de uma representação semanticamente equivalente dentro de um mesmo nível de abstração. Esse processo visa criar novas visões do sistema através da análise do código fonte, com o objetivo de melhorar a compreensão do sistema.

A criação dessas visões adicionais do código, geralmente gráficas, tem como objetivo recriar a documentação que já existiu ou que deveria ter existido sobre o sistema (Costa, 1997). No entanto, as informações recuperadas com esse tipo de análise fornecem apenas visões estruturais, de forma que informações como a função e os propósitos do sistema exigem um maior esforço de entendimento.

A Engenharia Reversa categorizada como recuperação de projeto é um subconjunto da Engenharia Reversa no qual o domínio de conhecimento, informação externa e dedução são adicionados às observações sobre o sistema para identificar abstrações de mais alto nível que sejam significativas, além daquelas obtidas diretamente pelo exame do sistema em si (Biggerstaff, 1989). Esse tipo de processo de entendimento visa recuperar todas as informações necessárias para se compreender melhor o que o sistema faz, como ele o faz e porque ele o faz.

Recuperação de projeto é a forma mais crítica de Engenharia Reversa porque tenta recuperar não só a funcionalidade do sistema, mas o processo no qual ele foi desenvolvido (Costa, 1997). Esse tipo de análise recupera mais do que visões estruturais, obtendo visões funcionais e até mesmo de domínio.

Visando a recuperação de projeto, neste trabalho de mestrado, nos apoiamos no método Fusion-RE/I, que é apresentado a seguir (Seção 2.2). O método de Engenharia Reversa FusionRE/I (Fusion - Reverse Engineering / Interface) - desenvolvido no ICMC-USP (Costa, 1997), baseia-se nos conceitos e idéias da Engenharia Reversa orientada a objetos, e fornece mecanismos para abstrair visões funcionais (modelos de análise de sistemas de acordo com o método Fusion de Coleman e outros (1996)) e visões estruturais partindo, inicialmente, dos aspectos operacionais e de dados disponíveis na interface usuário-computador. 


\subsection{O Método Fusion-RE/I}

O Fusion-RE/I constitui-se de um método de Engenharia Reversa que, visando facilitar o processo, parte da interface do sistema para a recuperação de informações úteis à manutenção de software. Através desse método é possível a recuperação de visões funcionais e visões estruturais do sistema. Dessa forma, parte-se de considerações lógicas obtidas via análise da interface para a recuperação de visões funcionais do sistema e, posteriormente, parte-se dessas visões recuperadas e de considerações físicas obtidas via análise do código fonte, para a recuperação de visões estruturais do sistema (Costa, 1997). A Figura 2.2 mostra uma visão geral do método, representando os elementos requeridos e os obtidos na realização do processo.

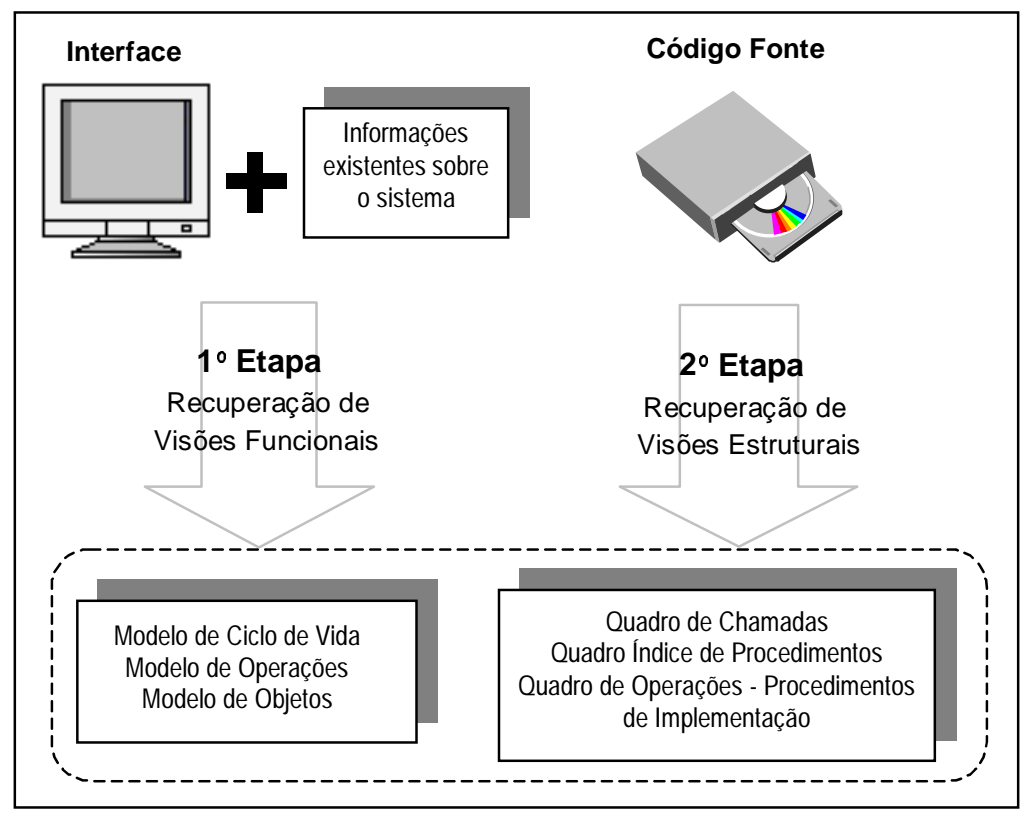

Figura 2.2 - Visão Geral do Método Fusion-RE/I

Sendo que o método Fusion-RE/I representa toda a informação recuperada da fase de análise do sistema através dos modelos de análise do método Fusion (Coleman et al., 1996), na subseção seguinte é feita uma breve introdução sobre o método, sendo descritos os modelos efetivamente utilizados pelo Fusion-RE/I.

Nas próximas subseções (2.2.2 e 2.2.3) são então descritas as duas fases que compõem o Fusion-RE/I: Recuperação de Visões Funcionais e Recuperação de Visões Estruturais, respectivamente. Durante a descrição dessas fases são discutidas as características do processo, as quais proporcionam que a estrutura de um hiperdocumento possa ser definida. 


\subsubsection{O Método Fusion : Uma Visão Introdutória}

O método Fusion foi criado por Coleman e outros (1996), na tentativa de reunir as melhores técnicas propostas pelos métodos então existentes. $\mathrm{O}$ método compreende três fases distintas: análise, projeto e implementação. A Figura 2.3 apresenta uma visão geral do método e da interação entre as fases, além de apresentar os documentos gerados em cada uma delas.

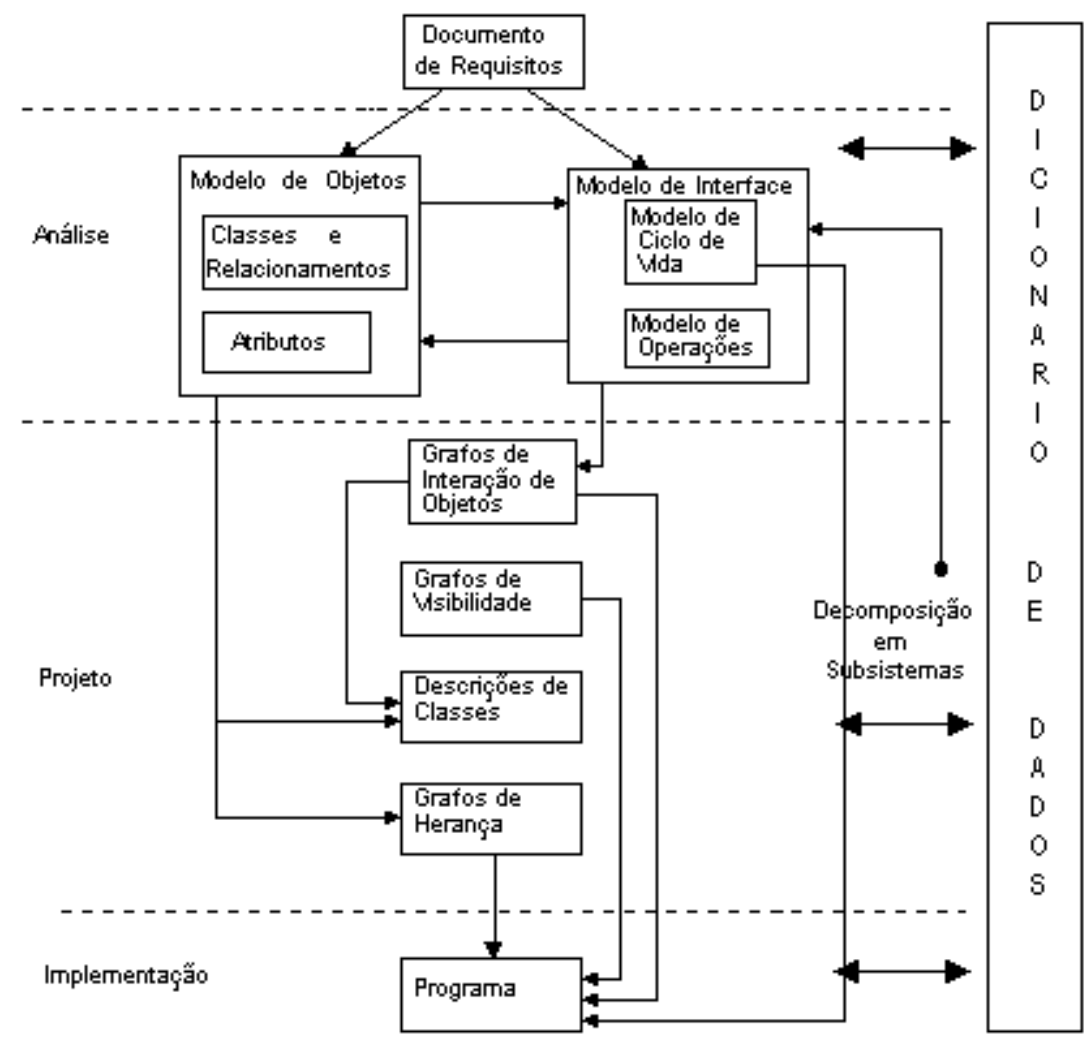

Figura 2.3 - Visão Geral do Método Fusion (Masiero, 1995)

Durante a fase de análise do método Fusion são gerados dois modelos do sistema: o Modelo de Objetos, que descreve a estrutura do sistema e o modelo de interface, que descreve o comportamento do sistema. Por sua vez, o modelo de interface é composto de dois modelos que capturam diferentes aspectos do comportamento: o Modelo de Ciclo de Vida, o qual caracteriza sequiências permitidas de operações e eventos do sistema e o Modelo de Operações, o qual caracteriza o efeito de cada operação do sistema em termos de mudanças de estado e eventos gerados (Coleman et al., 1996).

O ponto de partida e fonte de informações para a fase de análise é um documento de requisitos informalmente especificado, contendo os requisitos necessários para o sistema (Penteado, 1996). 
A análise deve iniciar em um alto nível de abstração, recomendando-se que os detalhes sejam inseridos só depois que a estrutura geral for considerada satisfatória. Os objetos, na fase de análise, não incluem a definição de métodos, ou procedimentos inerentes às classes, os quais serão incorporados na fase de projeto (Masiero, 1995).

O Modelo de Objetos tem como objetivo representar conceitos existentes no domínio do sistema e o relacionamento entre eles (Masiero, 1995). A notação é derivada da notação do modelo entidade-relacionamento estendido, sendo composta por classes, relacionamentos entre classes, atributos de classes e de relacionamentos e possíveis agregações, especializações e generalizações (Coleman et al., 1996). A notação é bastante semelhante a do Modelo de Objetos do método OMT (Penteado, 1996).

O Modelo de Ciclo de Vida é composto por expressões regulares que definem a seqüência de eventos a que o sistema pode interagir durante toda a sua vida. Ele descreve o comportamento completo de como o sistema se comunica com o ambiente, desde sua criação até o seu término (Masiero, 1995), (Penteado, 1996).

As expressões do ciclo de vida são simples extensões de expressões regulares ou gramaticais (Costa, 1997). As expressões regulares definem a sequiência de eventos aceita pelo sistema do mesmo modo que nas gramáticas elas definem as seqüências de símbolos da linguagem que podem ser aceitas pelo compilador (Coleman et al., 1996).

O Modelo de Ciclo de Vida possui a seguinte sintaxe geral (Masiero, 1995):

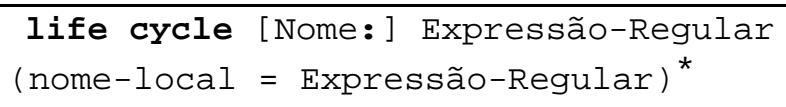

onde Nome especifica o nome do sistema, e uma vez que a expressão regular seja composta por "nome-local", são fornecidas na seqüência as expressões de sua formação.

O Modelo de Operações é decorrente do Modelo de Ciclo de Vida. Este modelo especifica o comportamento de uma operação de forma declarativa em termos das mudanças de estado do sistema e eventual geração de eventos de saída (Masiero, 1995).

Cada operação identificada no Modelo de Ciclo de Vida é descrita individualmente através de um formulário textual contendo as seguintes informações: nome da operação, descrição informal, dados de entrada, objetos acessados ${ }^{3}$ e modificados, eventos de saída e os agentes que

\footnotetext{
${ }^{3}$ Embora o termo "acessar" não seja uma palavra encontrada nos dicionários da Língua Portuguesa, é amplamente utilizado pela comunidade da área de Ciência da Computação.
} 
os recebem, pré-condições e resultados da operação, descritos como pós-condições (Penteado, 1996), seguindo o esquema mostrado na Quadro 2.1. Dessa forma, o Modelo de Operações será expresso por uma série de esquemas, sendo que existirá, no mínimo, um esquema para cada operação do sistema (Coleman et al., 1996).

Nesse modelo também são indicados quais valores são parâmetros da operação, através da palavra supplied antecedendo os itens acessados (valores lidos pela operação). A criação de novos objetos é indicada através da palavra new antecedendo o nome do objeto.

Finalizando a etapa de análise é feita uma verificação de consistência e completitude do modelo. Um modelo é dito consistente quando não existem contradições, implícita ou explicitamente, entre as partes do modelo. Um modelo é dito completo se todas as abstrações significativas do domínio tiverem sido captadas e se o modelo de análise for condizente com as expectativas do usuário descritas no documento de requisitos (Penteado, 1996).

Quadro 2.1 - Representação do esquema para descrição das operações

\begin{tabular}{|ll|}
\hline Operação: & nome \\
Descrição: & texto \\
\hline Lê: & itens \\
Modifica: & itens \\
Envia: & agentes e eventos \\
Assume: & condição \\
Resultado: & estado \\
\hline
\end{tabular}

Como o método Fusion-RE/I utiliza apenas os modelos de análise do método Fusion, neste trabalho não abordaremos as fases de projeto e implementação que complementam o método. Assim, nas próximas subseções retomamos a descrição do método Fusion-RE/I.

\subsubsection{Recuperação de Visões Funcionais}

Visando obter a abstração da funcionalidade do sistema, nesta primeira fase do método FusionRE/I, são realizadas duas tarefas: a obtenção de informações existentes sobre o sistema e a recuperação do modelo de análise do sistema, as quais são descritas a seguir.

\section{a. Obter Informações Existentes Sobre o Sistema}

Nesta tarefa busca-se toda a informação disponível sobre o sistema em estudo. Isso envolve reunir a documentação existente (manuais, listagens de código, etc.) sobre o sistema e também 
obter outras informações relevantes, como o domínio do sistema, linguagem de implementação, etc. Entrevistas com os usuários também podem ser úteis já que, muitas vezes, informações importantes podem não estar documentadas.

De fato, já existe um trabalho de mestrado sendo desenvolvido (Jubileu; Sanches, 1999) com o objetivo de sistematizar a coleta de informações, visando tornar essa tarefa mais eficiente.

Tendo reunida toda a documentação existente, esta deve ser analisada para identificação de informações relacionadas aos requisitos do sistema, ao projeto arquitetural, de dados e procedimental, ao ambiente onde o sistema é executado, a organização dos arquivos em disco, etc. (Costa, 1997).

\section{b. Recuperar Modelo de Análise do Sistema}

Tendo recuperado todas as informações existentes sobre o sistema, parte-se para a tarefa seguinte, de recuperação das informações da fase de análise. Todas as informações recuperadas nesse passo são obtidas por meio da investigação sobre a interface do sistema. O método FusionRE/I utiliza os modelos da fase de análise do método de desenvolvimento de software orientado a objetos Fusion para representar as informações recuperadas.

No entanto, por entendermos ser útil a representação dessas informações de forma independente de um método de desenvolvimento de software, optamos pela investigação da utilização da notação UML. Sendo assim, como um dos objetivos deste trabalho de mestrado, faremos um estudo que relacione a representação do modelo de análise Fusion à UML. Na Seção 2.4, é apresentado um estudo inicial sobre uma proposta de mapeamento dos elementos de modelagem Fusion para a UML.

A tarefa de recuperação do modelo de análise do sistema, segundo Costa (1997), compreende a elaboração dos três modelos da fase de análise do método Fusion: o Modelo de Ciclo de Vida, o Modelo de Operações e o Modelo de Objetos. Embora se trate de uma tarefa ligada à manipulação do sistema, por meio da sua interface, de forma bastante intensiva, sendo

dessa forma uma tarefa "concreta", é exigido um grande esforço de atenção e concentração por parte do engenheiro de software (ou mantenedor), ao investigar quase que exaustivamente todos os estados da interface do sistema. A seguir, são brevemente descritos os procedimentos para a elaboração dos modelos da fase da análise. 


\section{b.1. Elaborar o Modelo de Ciclo de Vida do Sistema}

A partir do uso do sistema, do estudo da documentação existente e das entrevistas com os usuários pode-se definir a seqüência de operações permitidas e os eventos de entrada e de saída que o sistema aceita.

As opções presentes no menu da interface do sistema formarão a expressão principal do Modelo de Ciclo de Vida. A partir das opções listadas na expressão principal, são construídas novas expressões, uma para cada opção, mostrando as sequiências de operações permitidas a partir daquele ponto. Para cada operação citada, é escrita uma nova expressão identificando a sequiência permitida de eventos de entrada (elementos da operação) e os respectivos eventos de saída, os quais aparecem precedidos pelo símbolo \# (Costa, 1997).

\section{b.2. Elaborar o Modelo de Operações do Sistema}

Para a elaboração do Modelo de Operações, no método Fusion-RE/I, parte-se do Modelo de Ciclo de Vida obtido anteriormente. Esse Modelo de Ciclo de Vida apresenta uma visão geral da funcionalidade das operações do sistema, as quais, para a elaboração do Modelo de Operações devem ser melhor estudadas, através do uso intensivo do sistema, de modo que possam ser especificadas detalhadamente (Costa, 1997).

Dessa forma, descreve-se a execução de cada operação identificada no Modelo de Ciclo de Vida. O método Fusion-RE/I considera não apenas as operações e eventos gerados através da interface, mas também operações e eventos não visíveis em tela, como criação e manipulação de arquivos pelas operações do sistema. Isso se dá através da observação do "diretório de trabalho" do sistema, após a execução de cada operação da interface, verificando a modificação ou a criação de novos arquivos.

Uma vez compreendida a operação, pode ser preenchido o formulário de descrição da mesma. Deste formulário constam os seguintes itens: nome, descrição, lê, modifica, envia, assume e resultado.

A descrição da operação pode ser obtida através do manual do usuário. As informações do item lê são obtidas a partir da observação da interface, identificando-se o valor referente a cada elemento acessado pela operação (eventos de entrada). Através da observação da interface e da execução da operação obtém-se as informações do item modifica, identificando-se o valor referente a cada elemento acessado e modificado pela operação. As informações do item envia 
são obtidas através da observação da interface, identificando os eventos de saída gerados pela operação. As informações do item assume especificam as pré-condições necessárias para a execução da operação e também são obtidas pela observação da interface. As informações do item resultado podem ser preenchidas identificando-se, através da execução da operação, o relacionamento entre o estado inicial do sistema (antes da operação) e o estado final do sistema (após o término da operação) (Costa, 1997).

\section{b.3. Elaborar o Modelo de Objetos do Sistema}

Para a elaboração desse modelo no Fusion-RE/I primeiramente definem-se os assuntos relacionados com a funcionalidade do sistema. Esses assuntos são denominados Temas (Costa, 1997).

Para que se possa definir os temas é necessária uma análise das informações recuperadas na primeira fase e também das abstrações observadas nos modelos de Ciclo de Vida e de Operações. Essa é uma das tarefas mais subjetivas do método Fusion-RE/I e é de fundamental importância para a aplicação do método (Costa, 1997).

Tendo definido os temas, é feito um agrupamento das operações de acordo com os temas a que se referem. Assim, ao final tem-se uma lista de temas e as operações dos temas. Temas podem ser constituídos de outros temas, quando os assuntos se relacionam em um nível de abstração mais alto.

Para cada um dos temas definidos, é construído um Modelo de Objetos. Para isso, as operações são novamente analisadas, agora buscando identificar componentes que constituem o Modelo de Objetos, ou seja, classes, relacionamentos, atributos, e possíveis agregações, especializações e generalizações.

Os componentes do Modelo de Objetos podem incluir componentes que não estão explícitos nas operações, mas que são identificados pela abstração e entendimento da funcionalidade de cada elemento e de cada operação (Costa, 1997).

A construção do Modelo de Objetos é uma tarefa bastante subjetiva, e embora não conste no método, provavelmente vá requerer um feedback após a recuperação das visões estruturais (visualização do código). Prevemos essa necessidade, uma vez que as principais referências sobre esse método de Engenharia Reversa não emitem uma diretriz única para a elaboração desse Modelo de Objetos. Em Costa (1997), onde o método Fusion-RE/I é descrito, não há uma 
definição clara de que o Modelo de Objetos possa ser construído através da observação da interface somente. Em Penteado (1996), onde é descrito o método Fusion-RE, do qual se origina o Fusion-RE/I, o Modelo de Objetos é recuperado através da investigação do código fonte, mas também não são claramente definidas as diretrizes para essa tarefa, ficando a cargo do engenheiro de software um processo quase que de "tentativa e erro" para identificar os possíveis objetos do sistema.

\subsubsection{Recuperação de Visões Estruturais}

Nesta fase trabalha-se com o código fonte do sistema, tendo como objetivo identificar os procedimentos que implementam as operações do sistema discriminadas na etapa anterior.

A seguir, são descritos os procedimentos de elaboração que devem ser realizados nesta fase.

\section{a. Elaborar Quadro de Procedimentos de Implementação}

Neste passo tem-se como objetivo identificar cada procedimento, sua funcionalidade e a seqüência de chamadas desse procedimento. Para tal, são utilizados dois quadros: um Quadro de Chamadas para cada arquivo de programa do sistema e um índice geral de procedimentos.

\section{a.1. Elaborar o Quadro de Chamadas}

O quadro de chamadas deve ser elaborado para cada arquivo de código fonte do sistema, apresentando os procedimentos contidos no arquivo, suas respectivas funcionalidades e os procedimentos utilizados (chamados) e utilizadores (chamados por) (Costa, 1997).

As informações de descrição (funcionalidade) dos procedimentos podem ser conseguidas a partir de comentários no código fonte. Os procedimentos chamados por outro procedimento são obtidos pela análise do próprio código, enquanto que os procedimentos utilizadores (Chamado por) vão sendo obtidos a medida que os quadros são elaborados.

Finalizando, os procedimentos de cada quadro são re-arranjados em ordem alfabética.

\section{a.2. Elaborar o Quadro Índice de Procedimentos}

O Índice de Procedimentos apresenta todos os procedimentos da implementação do sistema em ordem alfabética, com as respectivas localizações (arquivo e diretório). 
Para a elaboração desse quadro utiliza-se todos os quadros de chamadas obtidos anteriormente.

\section{b. Elaborar Quadro das Operações - Procedimentos de Implementação}

Nesse passo identifica-se os procedimentos que implementam as operações da interface e, de acordo com sua funcionalidade, os procedimentos são classificados como os que implementam os mecanismos da interface ou como implementando operações de um dos temas definidos anteriormente.

Nas primeiras colunas do quadro são colocadas as opções do menu e as operações de cada opção (descrição da interface). Na próxima coluna são colocados os procedimentos que implementam cada operação, de acordo com a hierarquia de chamadas descrita no Quadro de Chamadas.

O nível de profundidade que os procedimentos são detalhados nesse quadro depende do interesse em questão (Costa, 1997).

As próximas colunas do quadro são utilizadas para alocar os procedimentos à interface ou a um dos temas definidos. Assim, tem-se uma coluna para "interface" e uma para cada tema definido.

\subsection{Por que UML?}

O desenvolvimento da UML - Unified Modeling Language - teve início em 1994 com o objetivo de incorporar as melhores práticas da indústria de software em uma notação padrão para a especificação de sistemas orientados a objetos. Propositadamente, não é especificado um padrão de processo, baseado no fato de que cada organização e cada projeto adotam diferentes tipos de processos (Rational, 1997a). Desta forma, o processo pode ser ajustado de acordo com as necessidades do projeto e do desenvolvedor.

Os métodos de desenvolvimento de software estão evoluindo de forma que convergem em muitos pontos (Rational, 1997a). O objetivo da UML é remover as diferenças desnecessárias entre as notações e terminologias, permitindo que as similaridades entre os métodos se tornem 
mais claras. Essa padronização permitirá aos desenvolvedores uma melhor comunicação, independente do método utilizado e permitirá um melhor aproveitamento de ferramentas CASE.

Como é esperado que o próprio método Fusion, em sua nova versão, adote a notação UML, por ser um projeto apoiado por grandes empresas de software (Coleman et al., 1997), e por todos os motivos acima citados é que optamos por nos antecipar e representar as informações recuperadas através do Fusion-RE/I em UML. Desta forma, a familiarização e uma melhor compreensão da nova notação ocorrem não só através de estudos, mas de uma aplicação prática.

A seguir, são apresentados os principais aspectos da notação UML, de forma resumida, com o objetivo de fundamentar o uso da mesma para a investigação da correspondência aos modelos requeridos pelo Fusion-RE/I.

A notação UML está visualmente representada no documento UML Notation Guide (Rational, 1997b). Este documento apresenta uma explanação dos elementos notacionais e um breve resumo da semântica desses elementos.

A UML propõe nove diagramas e um conjunto de elementos que podem ser utilizados em quaisquer desses diagramas, chamados de elementos de notação genérica. Entre esses elementos encontram-se notas, packages, restrições, rótulos, strings, estereótipos, nomes, ou seja, elementos independentes da natureza do diagrama.

Os diagramas encontram-se agrupados em diagramas de estrutura estática, diagramas comportamentais (caso de uso, de seqüência, de colaboração, de estado e de atividade) e diagramas de implementação, e são brevemente descritos abaixo.

\section{a) Diagramas de Estrutura Estática}

Dois diagramas compõem os diagramas de estrutura estática: os diagramas de classes e os diagramas de objetos.

Um diagrama de classe é uma coleção de elementos estáticos, tais como classes, tipos e seus relacionamentos, conectados uns aos outros e aos seus conteúdos.

Um diagrama de objetos é uma instância de um diagrama de classes. Ele mostra o estado detalhado do sistema em um ponto no tempo. 


\section{b) Diagramas de Caso de Uso}

Um modelo de caso de uso descreve os requisitos funcionais de um sistema em termos de casos de uso. Um diagrama de caso de uso mostra as relações entre atores e casos de uso dentro do sistema.

Um caso de uso é um conjunto de seqüências de ações que um sistema realiza que produz um resultado de valor observável por um ator particular.

\section{c) Diagramas de Seqüência}

Um diagrama de seqüência mostra uma interação arranjada em uma seqüência de tempo. Em particular, ele mostra os objetos participando da interação pelas suas "linhas da vida" e as mensagens que eles trocam, arranjadas em uma seqüência de tempo. Esse diagrama não mostra a associação entre objetos.

Diagramas de colaboração e de seqüência expressam informações similares mas o fazem de formas diferentes. Os diagramas de seqüência mostram a seqüência explícita de mensagens e são melhores para especificações em tempo real e para cenários complexos. Diagramas de colaboração mostram os relacionamentos entre os objetos e são melhores para entender todos os efeitos sobre um dado objeto e para serem utilizados no projeto arquitetural.

\section{d) Diagramas de Colaboração}

Um diagrama de colaboração mostra uma interação organizada em torno dos objetos na interação e os links de uns para os outros. Um diagrama de colaboração mostra os relacionamentos entre os objetos, porém não mostra o tempo como uma dimensão separada.

Um diagrama de colaboração é um contexto, isto é, um grafo de objetos e ligações, com fluxos de mensagens conectados às ligações. O contexto do diagrama mostra os objetos relevantes para o desempenho de uma operação.

\section{e) Diagramas de Estado}

Um diagrama de estado representa a seqüência de estados que um objeto ou uma interação passa durante sua vida, em resposta a um estímulo recebido, junto com suas respostas e ações.

Todo diagrama de estado é conectado a uma classe ou a um método (implementação de operações). A sintaxe e semântica dos diagramas de estado estão descritas posteriormente. 


\section{f) Diagramas de Atividade}

Um diagrama de atividade é um caso especial de diagrama de estado no qual todos (ou pelo menos a maioria) os estados são estados de ação e no qual todas as transições (ou pelo menos a maioria) são disparadas pela finalização das ações nos estados origem.

Todo diagrama de atividade é conectado a uma classe, à implementação de uma operação ou a um caso de uso. O propósito desse diagrama é focalizar o fluxo direcionado pelo processamento interno.

\section{g) Diagramas de Implementação}

Esses diagramas mostram aspectos de implementação, incluindo estrutura do código fonte e a estrutura da implementação em tempo de execução. Existem dois tipos de diagramas de implementação: diagramas de componentes e diagramas de disponibilidade.

Os diagramas de componentes apresentam a estrutura do código em si, mostrando as dependências entre os componentes de software. Isso é apresentado através de um grafo de componentes conectado por relacionamentos de dependência.

Os diagramas de disponibilidade mostram a configuração de elementos processando em tempo de execução e os componentes de software, processos, e objetos que vivem sobre eles, ou seja, mostram a estrutura do sistema em tempo de execução.

Um diagrama de disponibilidade é representado por um grafo de nós conectados por associações de comunicação. Um nó é um tipo de objeto físico de execução que representa um recurso computacional, geralmente tendo no mínimo memória e capacidade de processamento.

\subsection{Representação dos Modelos do Método Fusion- RE/I em UML}

Tendo por base os estudos realizados sobre o método Fusion-RE/I, o método Fusion e a notação UML, nesta seção é apresentado o conjunto de elementos de modelagem e diagramas UML utilizados para que representem, adequadamente, os modelos construídos durante a aplicação do Fusion-RE/I. 


\subsubsection{Modelo de Análise do Método Fusion x UML}

Como o modelo de análise do Fusion é composto do Modelo de Objetos, do Modelo de Operações e do Modelo de Ciclo de Vida, tais modelos são brevemente discutidos a seguir, com o objetivo de apresentar as respectivas notações em UML.

\section{Modelo de Objetos}

A correspondência do Modelo de Objetos Fusion para a notação UML pôde ser feita diretamente, pois a UML modela os mesmos elementos existentes no Modelo de Objetos Fusion. Além disso, tanto o Modelo de Objetos Fusion como o Modelo de Objetos UML adotam a representação na forma de diagramas, e as diferenças encontram-se apenas na representação gráfica dos elementos de cada diagrama.

Pode-se observar que a UML, por sua vez, é mais abrangente que a notação proposta no Fusion, isto é, oferece mais recursos para a modelagem de objetos. Além dos elementos de modelagem definidos pelo Fusion, ela permite a inclusão da definição dos métodos pertencentes às classes como no Fusion, e também possibilita a diferenciação entre agregação fraca e agregação forte (composição), a dependência entre classes e a definição de interface entre as classes.

\section{Notação para Diagrama de Objetos em UML}

Na Figura 2.4 é exemplificada a notação usada pela UML para diagramas de classes e objetos. Os exemplos utilizados foram adaptados dos documentos da Rational (1997b).

Semanticamente, para a UML, um diagrama de classe é uma coleção de elementos estáticos, tais como classes, tipos, e seus relacionamentos, conectados uns aos outros e aos seus conteúdos como um grafo (Rational, 1997c).

Um diagrama de objetos é um grafo de instâncias. Um diagrama de objetos estático é uma instância de um diagrama de classe. Ele mostra o estado detalhado do sistema em um ponto no tempo (Rational, 1997b). 


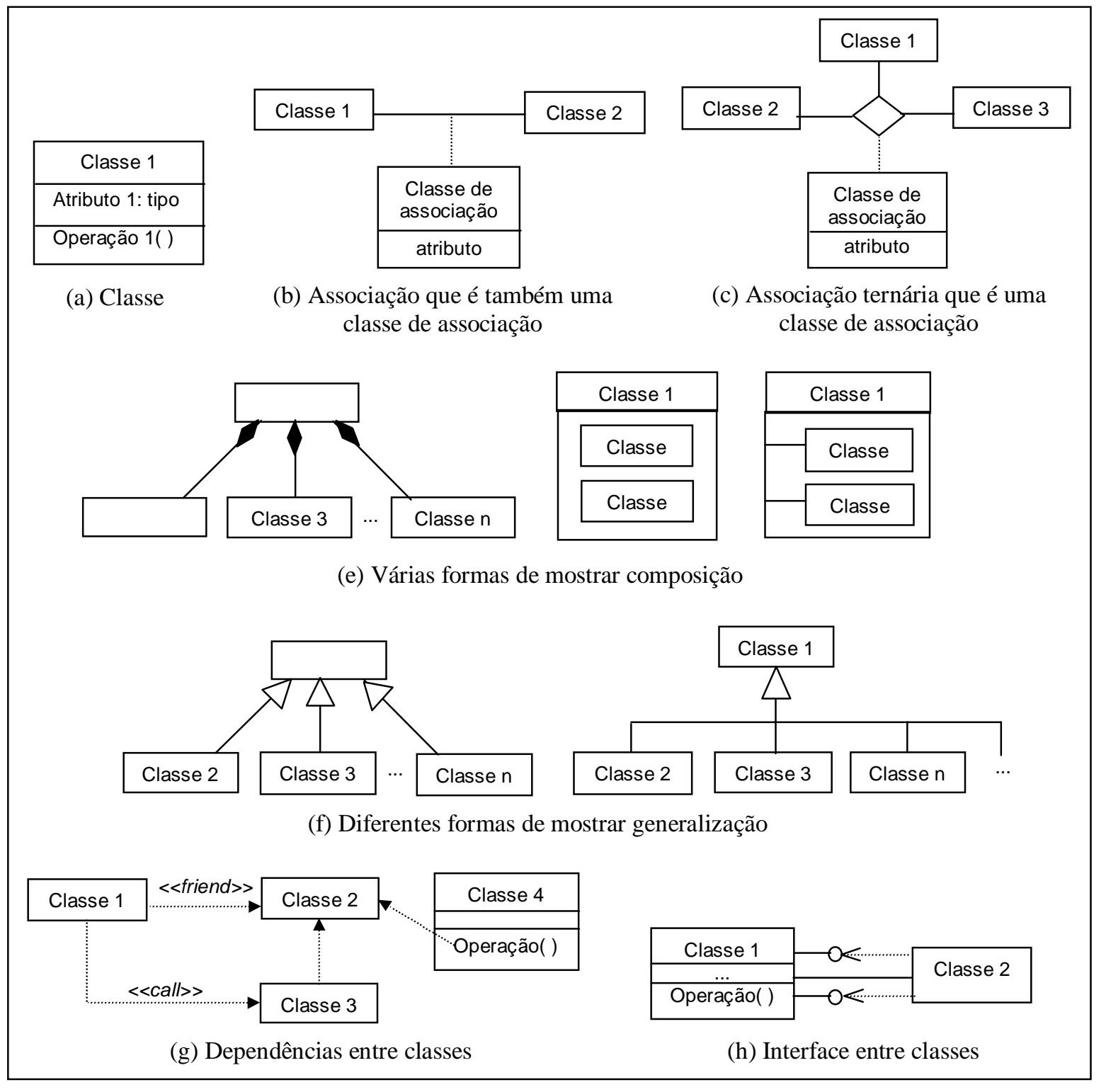

Figura 2.4 - Resumo da notação UML para diagrama de classes e objetos

Uma classe é um descritor para um conjunto de objetos com estrutura, comportamento e relacionamentos similares.

Conforme mostrado na Figura 2.4, uma classe é representada por um retângulo com três compartimentos separados horizontalmente por linhas. O primeiro compartimento contém o nome e outras propriedades da classe. O compartimento seguinte contém a lista de atributos e o último compartimento contém a lista de métodos (Rational, 1997b).

A notação para objetos é igual a notação usada para classes, uma vez que um objeto é uma instância de uma classe. Para diferenciar ambos, a UML usa um sublinhado. Desta forma, nomes de objetos aparecem sublinhados enquanto nome de classes não. 
Na Figura 2.5 é mostrado o Modelo de Objetos simplificado do sistema SASHE, recuperado durante o processo de engenharia reversa, utilizando-se a notação indicada pelo método FusionRE/I, a do método de desenvolvimento Fusion (Coleman et al., 1996). A Figura 2.6 apresenta o mesmo Modelo de Objetos, porém utilizando a notação UML para sua representação. Comparando-se esse exemplo é possível observar a correspondência entre as duas notações.

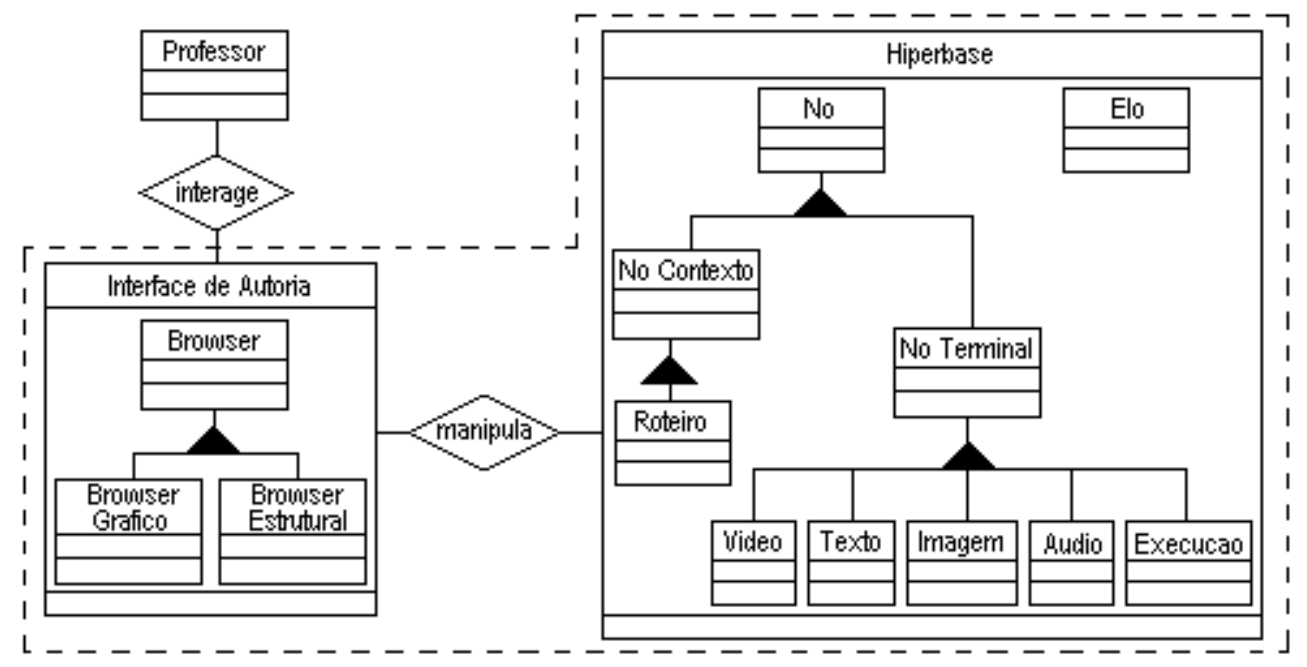

Figura 2.5 - Modelo de Objetos simplificado para o tema Autoria, em Fusion

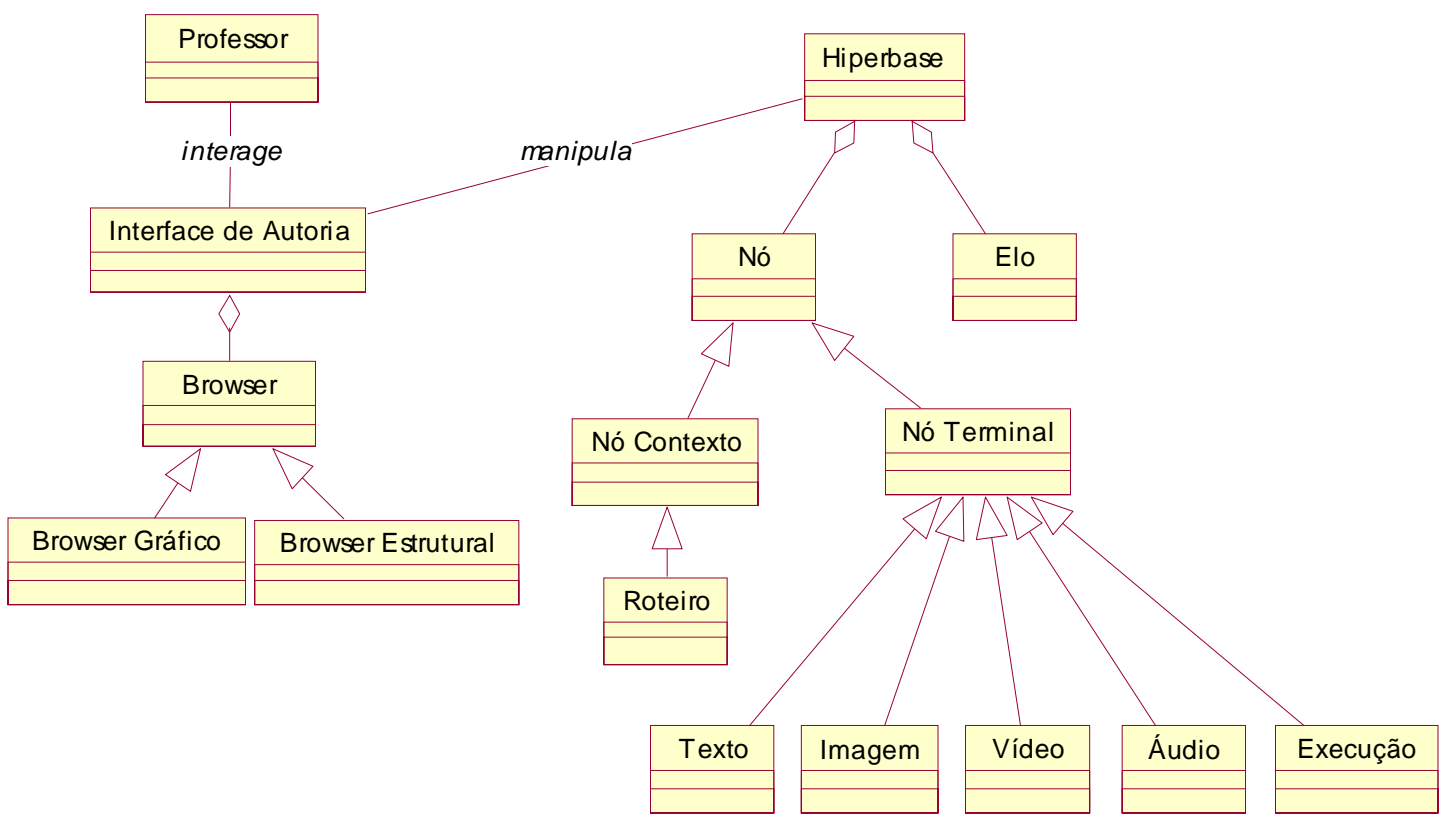

Figura 2.6 - Modelo de Objetos simplificado para o tema Autoria, em $U M L$ 


\section{Modelo de Interface}

A interface de um sistema é o conjunto de operações permitidas e o conjunto de eventos de saída desse sistema. O modelo de interface descreve o comportamento do sistema em termos de eventos e das mudanças de estado que eles causam (Coleman et al., 1996).

O modelo de interface do método Fusion usa dois modelos para a obtenção de diferentes aspectos do comportamento: Modelo de Ciclo de Vida e Modelo de Operações.

O Modelo de Ciclo de Vida caracteriza a seqüência permitida de operações do sistema declarativamente, em termos de mudanças de estado. O Modelo de Operações especifica os efeitos de cada operação do sistema de forma declarativa, em termos das mudanças de estado que eles causam e dos eventos de saída que envia (Coleman et al., 1996).

Por essas definições, o que nos pareceu mais adequado foi a representação desses modelos por meio de diagramas de estados ${ }^{4}$, que como já mencionado na Seção 2.2, caracterizam uma sequiência de estados possíveis para um determinado objeto, mapeando também suas ações e saídas.

Um diagrama de estados descreve de forma gráfica uma máquina de estados finitos. Por sua vez, uma máquina de estados finitos descreve o comportamento que especifica as seqüências de estados que um objeto ou uma interação assume durante sua vida em resposta a eventos, junto com suas respostas e ações (Rational, 1997b).

Parte dos modelos do método Fusion são descritos utilizando-se recursos gráficos (diagramas), e outra parte utiliza representações textuais, como expressões regulares e quadros declarativos. A UML não assume que toda a informação em um modelo deva ser expressa como um diagrama (Rational, 1997b). No entanto, toda a notação UML possui o suporte de diagramas, semanticamente definidos por meio de um metamodelo.

A representação tabular das informações é deixada para as ferramentas. A UML não faz esse tratamento porque toda a informação básica é adequadamente representada no metamodelo UML (Rational, 1997b).

Sendo objetivo deste trabalho representar as informações recuperadas de um sistema e recuperar essas informações por meio da aplicação do método de Engenharia Reversa Fusion-

\footnotetext{
${ }^{4}$ Diagramas de Estados ou Diagramas de Transição de Estados (DTE’s) são termos utilizados indistintamente nesta dissertação.
} 
RE/I, em UML, um estudo sobre a melhor adequação dos documentos requeridos pelo método foi realizado. Como não encontramos na notação UML diagramas diretamente correspondentes ao modelo de interface Fusion, optamos pela representação desse modelo através de diagramas de transição de estados, uma vez que os conceitos de tais diagramas parecem ir de encontro aos objetivos dos modelos de ciclo de vida e de operações, que compõem o modelo de interface.

De fato, o Modelo de Ciclo de Vida descreve o comportamento do sistema sob a perspectiva de como ele se comunica com o ambiente desde sua criação até o seu fim. Essa descrição se dá através de um conjunto de expressões regulares que definem as sequiências de operações permitidas. Essas expressões são decompostas até o nível de operações não decomponíveis (Coleman et al., 1996).

A grosso modo, podemos dizer que um Modelo de Ciclo de Vida pode ser visto como uma linguagem, já que é composto por sequiências de expressões regulares. Dessa forma, o Modelo de Ciclo de Vida pôde ser adequadamente representado por um diagrama de estados.

O Modelo de Operações define o comportamento das operações do sistema declarativamente, de forma textual. Isto é feito através de quadros que especificam as operações através dos seguintes itens:

- nome da operação;

- descrição informal da operação;

- valores a que a operação pode ter acesso (apenas leitura);

\ valores que a operação pode modificar;

- lista de eventos que pode ser enviada a agentes (entidades ativas que interagem com o sistema) pela operação;

- pré-condições; e

- pós-condições, relacionando o estado do sistema antes da operação e o estado posterior a efetivação da operação.

Uma vez que o Modelo de Ciclo de Vida pôde ser mapeado em diagrama de estados, já temos no próprio diagrama todas as operações realizadas pelo sistema que deveriam ser descritas no Modelo de Operações. Através dos recursos notacionais disponíveis ao diagrama de estados, as informações representadas no Modelo de Operações puderam ser incorporadas ao diagrama.

Vale ressaltar que os diagramas de transição de estados estão semântica e notacionalmente descritos nos documentos referentes a UML (Rational, 1997b), (Rational, 1997c), de forma que, 
por meio de seu uso de forma completa, o modelo de interface do método Fusion pode ser representado satisfatoriamente.

A maioria dos métodos de modelagem OO utilizam notação gráfica e formalismos baseados em estados para descrever o comportamento de sistemas. No entanto, na maioria dos casos, falta uma definição rigorosa da semântica da linguagem utilizada para a descrição comportamental, e sem essa semântica rigorosa, os métodos de modelagem não conseguem ser precisos o suficiente (Harel; Gery, 1997).

Sendo o diagrama de estados um elemento de modelagem poderoso sob o aspecto da modelagem de sequiências de eventos e de estados de um objeto, e sendo semanticamente bem definido, era esperado que a representação do aspecto comportamental do sistema através de tais diagramas revelasse aspectos sobre o sistema em análise, que não são tão claramente evidenciadas nos modelos propostos pelo método Fusion-RE/I. De fato, os diagramas de transição de estado possibilitaram uma melhor visualização da seqüência de operações representada no Modelo de Ciclo de Vida, permitindo que fossem feitas as devidas correções no modelo, para que mesmo ficasse consistente com a interface do SASHE.

A seguir é mostrado um resumo da notação UML para diagramas de transição de estado, juntamente com um exemplo de como as sentenças do Modelo de Ciclo de Vida foram representadas em DTE's (Figura 2.9).

\section{Notação para Diagrama de Estados em UML}

Um diagrama de estados representa a seqüência de estados pela qual um objeto ou uma interação passa durante sua vida, em resposta a um estímulo recebido, junto com suas respostas e as ações.

Embora os Statecharts sejam uma extensão dos diagramas de transição de estados, por possuírem características notacionais adicionais, a semântica e a notação, adotadas irrestritamente na notação UML para representar os diagramas de estados, são substancialmente as mesmas dos statecharts de Harel (1987).

Um diagrama de estado é um grafo bipartido de estados e transições. Todo o diagrama de estado é conectado (através do modelo) a uma classe ou a um método (uma implementação de operação), conforme definição encontrada em Rational (1997b). Esse conceito é implementado na ferramenta de apoio a modelagem em UML, a Rational Rose (Rational, 1999). 


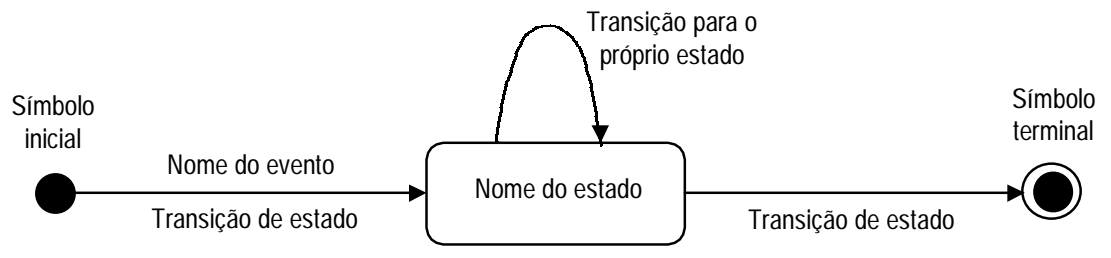

Figura 2.7 - Notação do Diagrama de Estado usado pela UML

Os diagramas de transição de estados são de grande importância no contexto deste trabalho, uma vez que tipicamente são destinados a descrever o comportamento de sistemas em geral. A Figura 2.7 mostra a notação básica utilizada pela UML para diagramas de estados (Rational, 1997b).

O Modelo de Ciclo de Vida e Modelo de Operações, diagramas da notação do método Fusion, foram representados através de um diagrama de estados da notação UML. A Figura 2.8 mostra as sentenças iniciais do Modelo de Ciclo de Vida do sistema SASHE, e que estão representadas no DTE apresentado na Figura 2.9. Todos os DTE's foram construídos com o auxílio da ferramenta Rational Rose (1999).

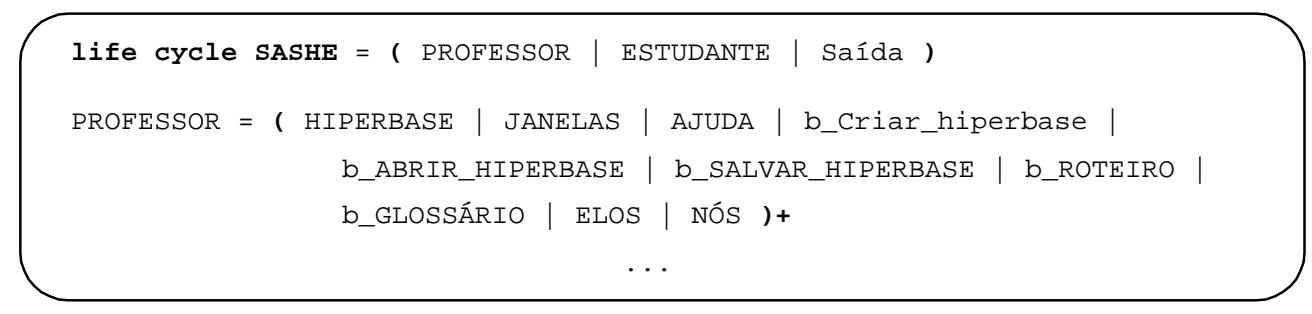

Figura 2.8 - Parte inicial do Modelo de Ciclo de Vida do SASHE

A primeira sentença presente na Figura 2.8 representa o menu inicial do SASHE, onde o usuário tem como opções o módulo de autoria (Professor), o módulo de navegação (Estudante), ou sair do sistema. A segunda sentença representa o menu principal do módulo Professor, descrevendo as opções disponíveis no momento em que o software executa o módulo de autoria. Nas sentenças, os nomes que iniciam com "b_" representam botões na interface, ao passo que o restante representa opções de menu. Além disso, para as opções que correspondem a ações "terminais" do sistema (ou seja, que não necessitam ser expandidas em sentença subseqüente, foi adotado escrevê-las com letras minúsculas). As interações escritas somente com letras maiúsculas correspondem a ações a serem expandidas. 


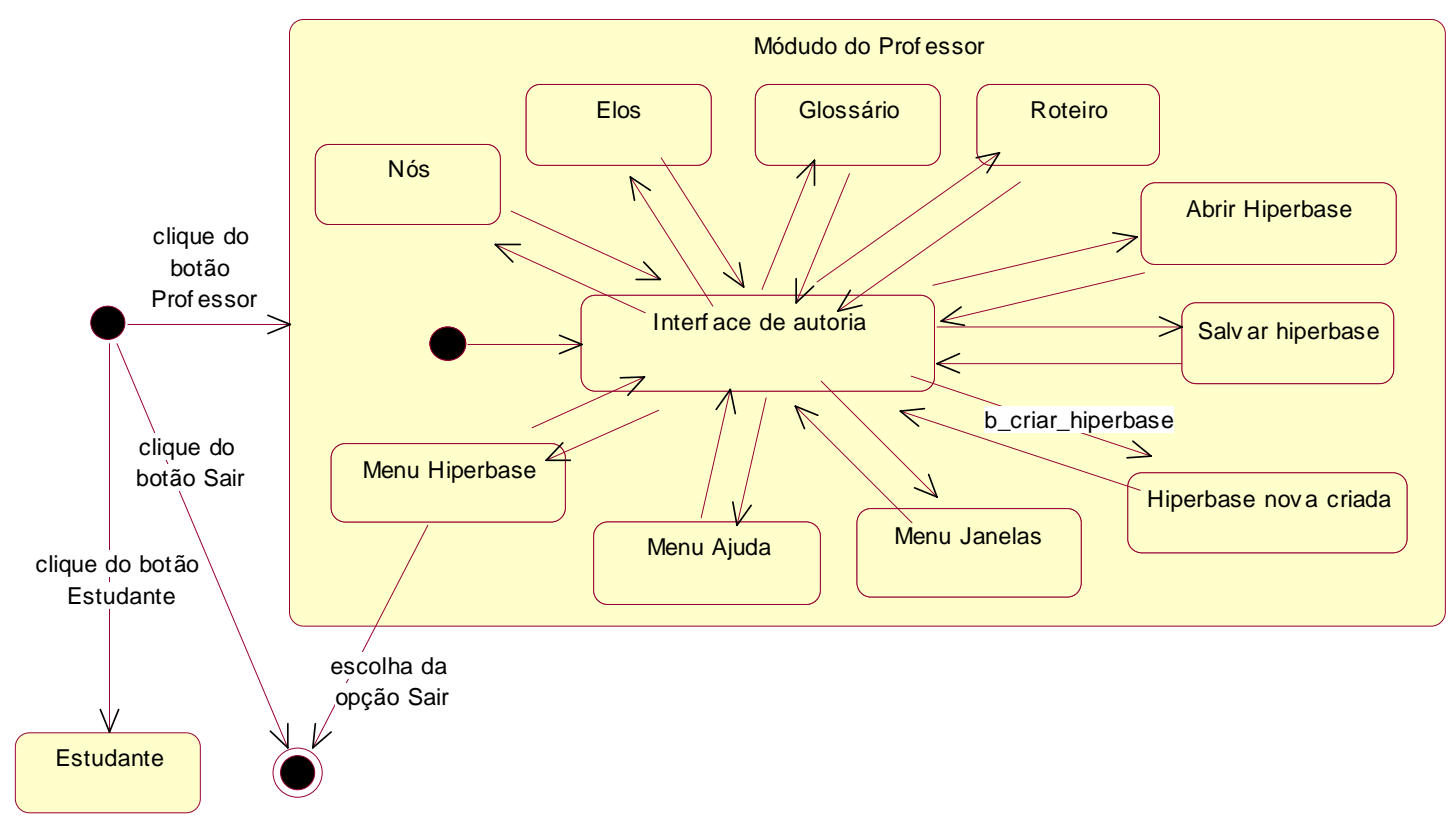

Figura 2.9 - Diagrama de estado representando as sentenças iniciais do ciclo de vida

Devido ao alto número de transições presentes no DTE mostrado na Figura 2.9, parte das transições não estão com os nomes dos eventos que as disparam, pois caso contrário a visualização do diagrama seria comprometida.

O Quadro 2.2 apresenta o formulário de descrição de uma das operações do sistema SASHE, representada no DTE da Figura 2.9 como a transição "b_criar_hiperbase”. Essa transição é disparada sempre que ocorre o evento do botão Criar Hiperbase ser clicado.

Quadro 2.2 - Descrição da operação "Criar Hiperbase"

\begin{tabular}{|c|c|}
\hline Operação: & b_Criar_hiperbase \\
\hline Descrição: & Cria uma nova hiperbase vazia \\
\hline Lê : & \\
\hline Modifica: & \\
\hline Envia: & \\
\hline Assume: & \\
\hline Resultado: & $\begin{array}{l}\text { Se existe uma hiperbase aberta, então é criada uma nova } \\
\text { área para edição de hiperbase e a hiperbase que estava } \\
\text { aberta é fechada } \\
\text { Alterações não salvas na hiperbase que estava aberta } \\
\text { estarão perdidas }\end{array}$ \\
\hline
\end{tabular}

Conforme comentado, a UML não especifica a representação de informação textual, deixando a critério das ferramentas de apoio à UML tal representação. As Figuras 2.10 e 2.11 apresentam os campos disponibilizados pela ferramenta Rational Rose para a especificação de 
cada transição entre os estados do DTE. Conforme é indicado nas figuras pelas setas, esses campos permitem que informações descritas no Modelo de Operações sejam incorporadas ao DTE como características das transições, sem que isso altere a semântica do diagrama. As informações que aparecem nas Figuras 2.10 e 2.11 como parte da transição b_criar_hiperbase foram retiradas do formulário de descrição da operação, mostrado no Quadro 2.2.

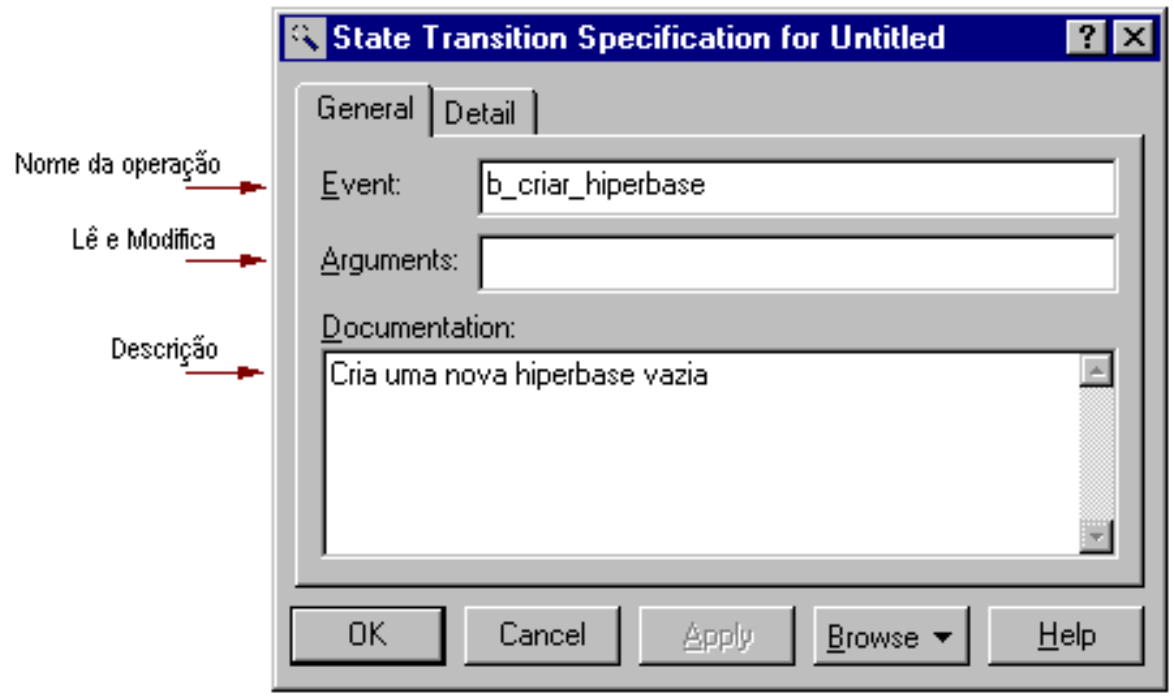

Figura 2.10 - Janela para especificação geral da transição de estado na Rational Rose

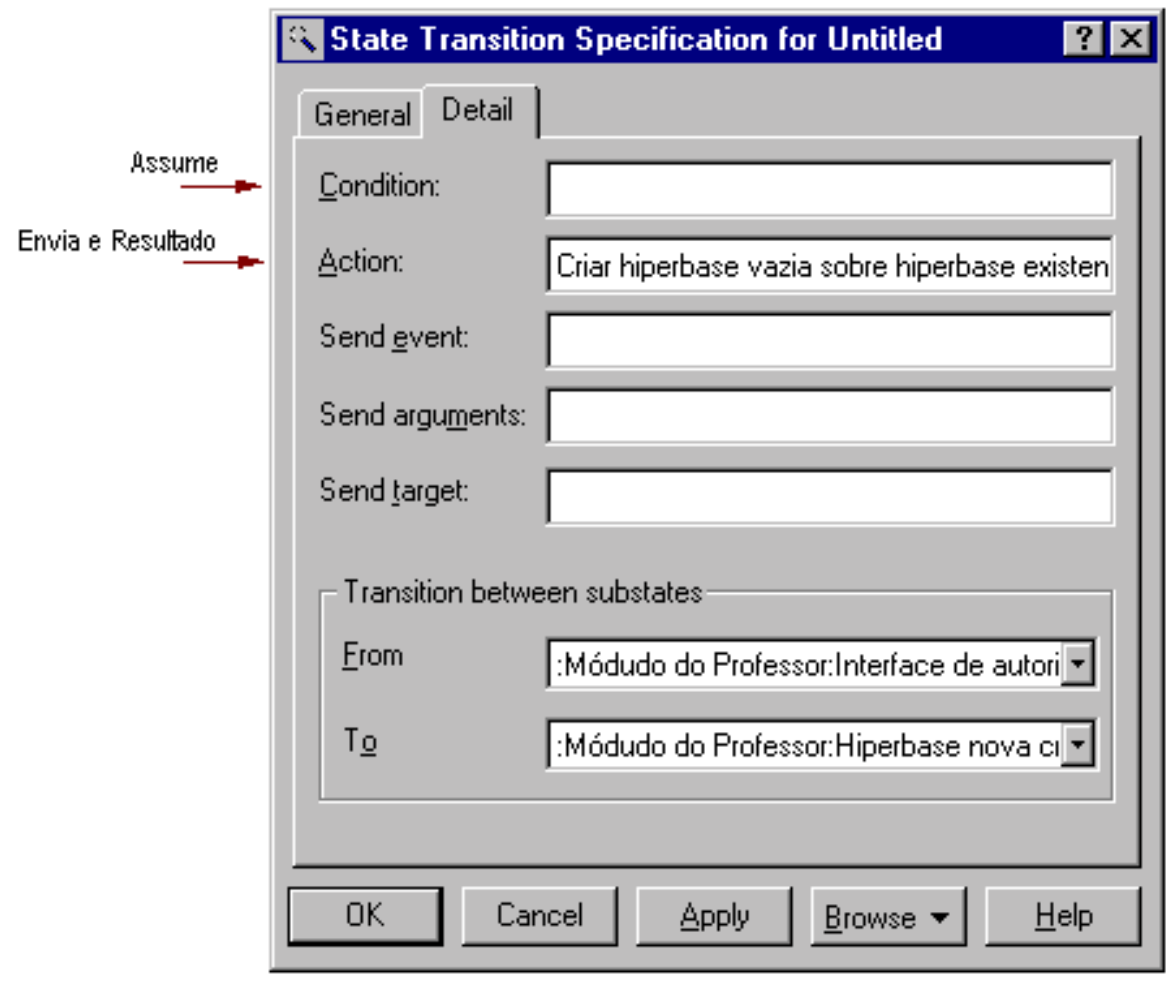

Figura 2.11 - Janela para especificação detalhada da transição de estado na Rational Rose 


\section{Mapeamento Fusion-RE/I x UML (Visão Funcional)}

Baseado nos estudos realizados sobre o método Fusion-RE/I e sobre a UML, foi elaborada uma proposta para a representação das informações da fase de análise recuperadas pela aplicação do Fusion-RE/I utilizando-se a notação UML. Essa proposta teve como objetivo encontrar as correspondências entre as duas notações, a utilizada pelo Fusion-RE/I e a UML, de forma que toda informação contida nos modelos de análise do método Fusion-RE/I pudessem ser representadas adequadamente em UML.

O Quadro 2.3 mostra de forma resumida quais elementos da UML foram utilizados para a representação dos modelos de análise do Fusion-RE/I.

Quadro 2.3 - Modelo de análise Fusion-RE/I x UML

\begin{tabular}{|c|c|}
\hline Fusion-RE/I & UML \\
\hline Modelo de Objetos Fusion & Modelo de Objetos UML \\
\cline { 1 - 1 } Modelo de Ciclo de Vida & Diagrama de Estados \\
\cline { 1 - 1 } Modelo de Operações & \\
\hline
\end{tabular}

\subsubsection{Visões Estruturais x UML}

Os documentos obtidos nessa etapa são compostos por três quadros: Quadro de Chamadas, Quadro Índice de Procedimentos e Quadro de Operações-Procedimentos de Implementação.

\section{Quadro de Chamadas}

Existe um Quadro de Chamadas para cada arquivo do sistema. Nesse quadro são descritos todos os procedimentos incluídos no arquivo, bem como quais são chamados e quais o chamam.

A partir de um estudo sobre quais tipos de notação UML suportariam tal quadro de chamadas, pudemos verificar duas: packages e diagramas de componentes.

Na UML, um package é um agrupamento de elementos de modelagem. Todos os tipos de elementos de modelagem e diagramas UML podem ser organizados em packages, inclusive outros packages (Rational, 1997b).

Um diagrama de componente é um dos diagramas de implementação disponíveis na UML. Esse diagrama mostra as dependências entre componentes de software, incluindo componentes 
de código fonte, componentes de código binário, e componentes executáveis. É representado como um grafo de componentes conectado por relacionamentos de dependência (Rational, 1997b).

O diagrama pode ser usado para mostrar interfaces e dependências de chamadas entre os componentes, usando setas pontilhadas dos componentes para interfaces de outros componentes. Os componentes podem conter objetos; isto indica que o objeto é parte do componente (Rational, 1997b). Existem estereótipos que qualificam o tipo de componente de software sendo representado. Um desses estereótipos distingue a representação de subprogramas.

Se cada procedimento de um Quadro de Chamadas for representado como um componente, podemos mostrar a seqüência de chamadas através das dependências entre os componentes. $\mathrm{O}$ conjunto de componentes (procedimentos) pertencentes a um mesmo arquivo podem ser agrupados em packages que teriam como nome, o nome do arquivo e seu diretório. Chamadas entre procedimentos de arquivos diferentes também podem ser representadas, pois dependências e importações entre packages são permitidas.

Dessa forma, a descrição informal dos procedimentos que faz parte do Quadro de Chamadas deverá continuar sendo descrita de forma textual, uma vez que a UML não fornece nenhuma estrutura para esse tipo de elemento.

\section{Notação para Diagrama de Componente em UML}

Um componente é uma parte reusável que fornece o "empacotamento" físico de elementos do modelo. A sua semântica representa uma mudança de nível de abstração: enquanto todos os outros elementos de modelagem (exceto componentes e nós) representam uma abstração lógica, componente representa uma abstração física, significando uma abstração da implementação física de instâncias de outros elementos de modelagem.

Uma instância de componente não pode implementar outra instância de componente ou de nó. Uma instância de componente pode implementar zero ou mais instâncias de elementos de modelagem, e toda instância de um elemento de modelagem pode ser implementada por zero ou mais instâncias de componentes.

Um tipo de componente representa um pedaço do código do software. Existem seis estereótipos padrão que se aplicam a componentes (Rational, 1997c). Eles são usados para tornar o diagrama mais preciso e claro, definindo o quê cada tipo de componente representa no mundo 
real (Eriksson; Magnus, 1998). Na Rational Rose (Rational, 1999) um componente que representa um subprograma pode ser apresentado como um retângulo, conforme mostrado na Figura 2.12.

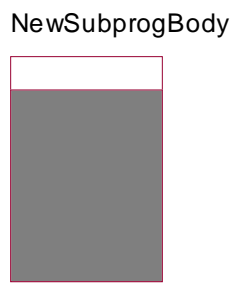

Figura 2.12 - Ícone utilizado pela Rational Rose para representar o corpo de um subprograma

Um componente é mostrado como um retângulo com uma pequena elipse e dois retângulos menores projetando-se em um de seus lados. Uma instância de componente tem um nome e um tipo. O nome do componente e seu tipo pode ser mostrado como uma string sublinhada, seja dentro do símbolo de componente, acima ou abaixo, com a sintaxe:

component-name : component-type

Um diagrama de componente engloba os componentes e seus relacionamentos. Um diagrama de componente é um grafo de componentes conectado por relacionamentos de dependência (Rational, 1997c), conforme mostrado na Figura 2.13. Componentes também podem ser conectados a componentes por um compartimento físico representando relacionamentos de composição.

Uma dependência indica uma relação semântica entre dois (ou mais) elementos do modelo. Ela relaciona os próprios elementos do modelo e não requer um conjunto de instâncias para ter significado. Ela indica uma situação em que uma mudança no elemento alvo pode requerer uma mudança no elemento fonte na dependência.

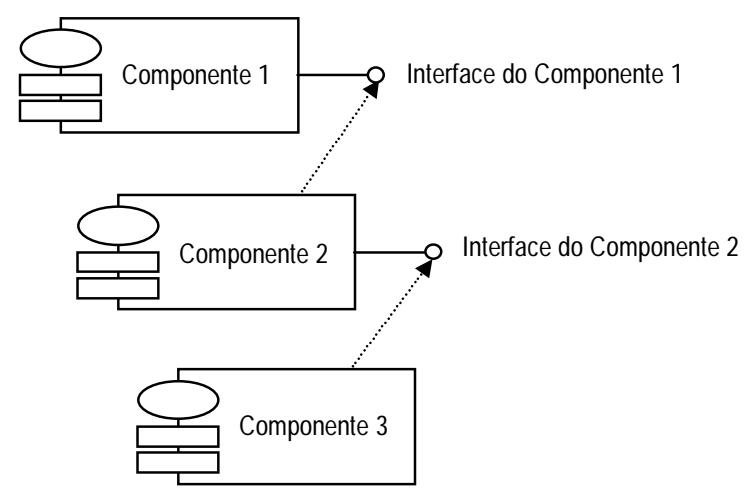

Figura 2.13 - Exemplo de diagrama de componente 
A relação de dependência é mostrada como uma seta pontilhada de um elemento para outro elemento do modelo, onde o primeiro elemento é o dependente (na Figura 2.13, Componente 3 depende do Componente 2, que depende do Componente 1). A seta pode ser rotulada opcionalmente com um estereótipo ou um nome. A UML provê estereótipos padrões que se aplicam a dependências, de forma a especificar o tipo de dependência que está sendo modelada.

A Figura 2.14 apresenta o diagrama de componentes construído para o Quadro de Chamadas do arquivo ancora.cpp. O Quadro de Chamadas é mostrado no Quadro 2.4. Os diagramas de componentes também foram construídos com o auxílio da ferramenta Rational Rose (Rational, 1999). Mesmo possibilitando a representação de subprogramas nos diagramas de componente, a ferramenta não disponibiliza espaço para descrição textual dos mesmos. Dessa forma, parte das informações contidas nos Quadros de Chamadas não são incorporadas ao diagrama.

A sintaxe utilizada na Figura 2.14 é a mesma apresentada anteriormente. As setas de dependência, no caso da figura, explicitam as chamadas entre os subprogramas. Algumas chamadas estão direcionadas para um arquivo e não para um procedimento. Isso foi feito para que o diagrama ficasse mais claro e sua leitura fosse facilitada.

Quadro 2.4 - Quadro de Chamadas recuperado do arquivo ancora.cpp

\begin{tabular}{|c|c|}
\hline $\begin{array}{l}\text { Sistema: SASHE } \\
\text { Arquivo: ancora.cpp }\end{array}$ & \\
\hline $\begin{array}{l}\text { Procedimento: } \\
\text { (12) ancora: :ancora(int Ind, int } \\
\text { ide): entidade (Ind) } \\
\text { Diretório/Arquivo: } \\
\text { hyperprop/ancora.cpp }\end{array}$ & 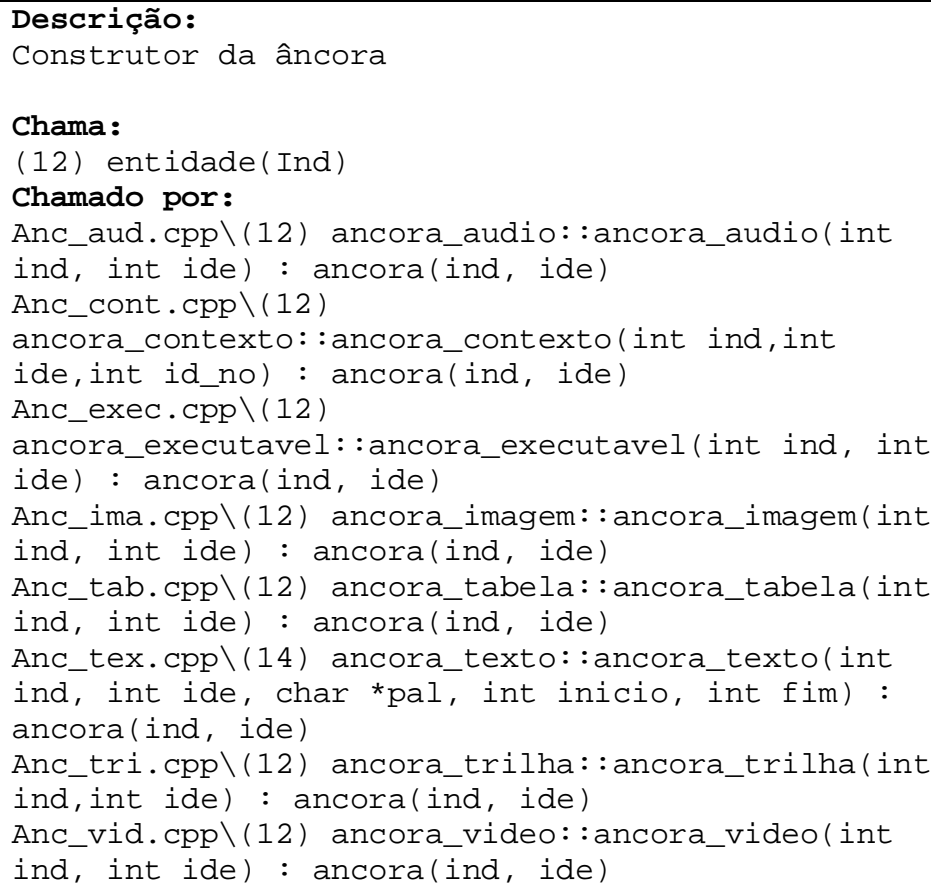 \\
\hline
\end{tabular}




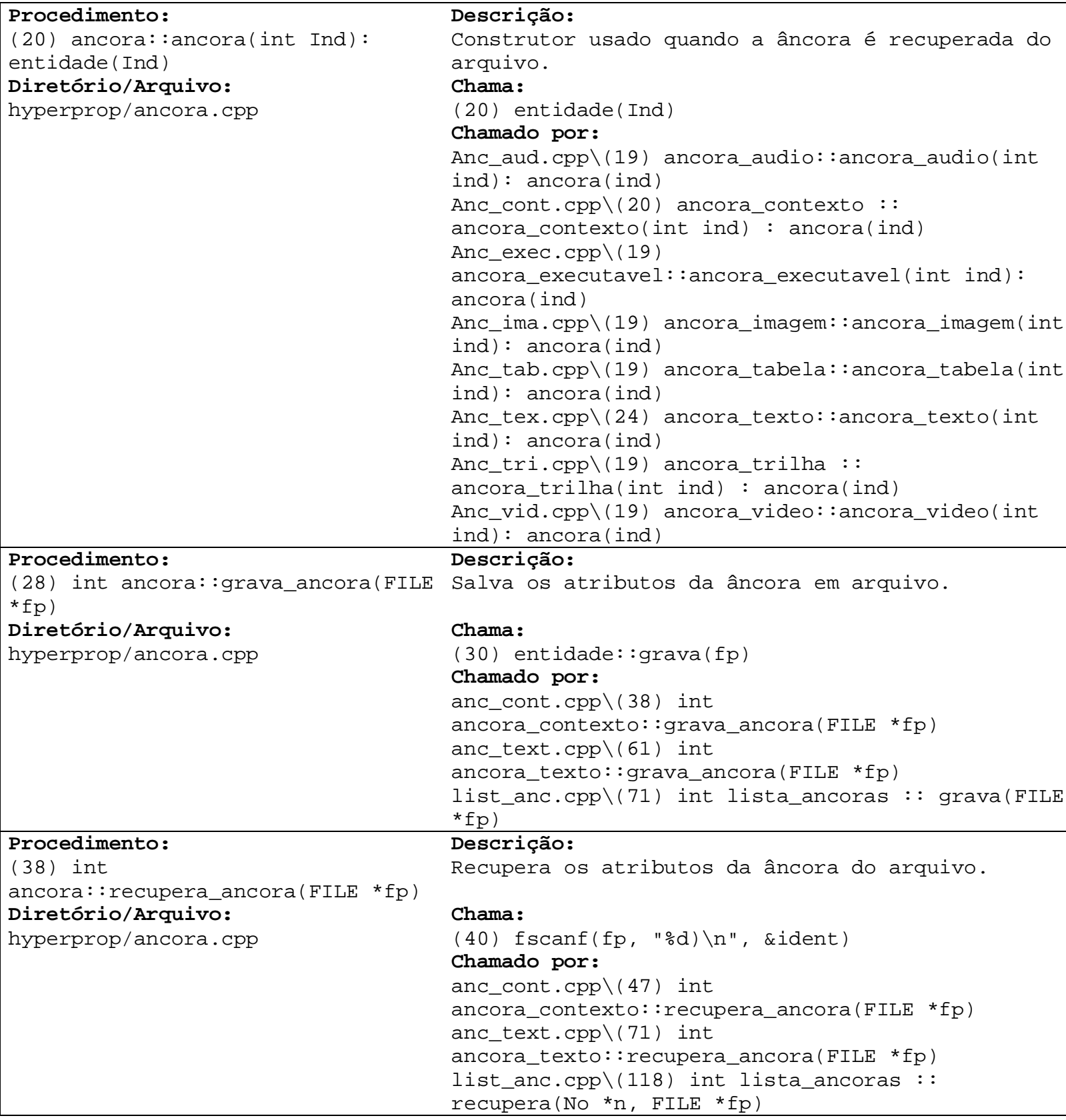

Descrição:

Construtor usado quando a âncora é recuperada do arquivo.

Chama:

(20) entidade (Ind)

Chamado por:

Anc_aud.cpp (19) ancora_audio: :ancora_audio(int

ind): ancora (ind)

Anc_cont.cpp $\backslash(20)$ ancora_contexto : :

ancora_contexto(int ind) : ancora(ind)

Anc_exec.cpp \(19)

ancora_executavel: :ancora_executavel (int ind) : ancora (ind)

Anc_ima.cpp \(19) ancora_imagem: :ancora_imagem(int ind) : ancora (ind)

Anc_tab.cpp \(19) ancora_tabela: :ancora_tabela (int

ind) : ancora (ind)

Anc_tex.cpp \(24) ancora_texto: :ancora_texto(int

ind): ancora (ind)

Anc_tri.cpp \(19) ancora_trilha : :

ancora_trilha(int ind) : ancora(ind)

Anc_vid.cpp \(19) ancora_video: :ancora_video(int ind): ancora (ind)

Descrição:

Salva os atributos da âncora em arquivo.

Chama:

(30) entidade: :grava (fp)

Chamado por:

anc_cont.cpp \(38) int

ancora_contexto: :grava_ancora (FILE *fp)

anc_text.cpp \(61) int

ancora_texto: :grava_ancora (FILE *fp)

list_anc.cpp \(71) int lista_ancoras : grava(FILE $\star f p)$

Descrição:

Recupera os atributos da âncora do arquivo.

\section{Chama:}

(40) $\operatorname{fscanf}(\mathrm{fp}, \quad " \circ \mathrm{d}) \backslash \mathrm{n} "$, \&ident)

Chamado por:

anc_cont.cpp \(47) int

ancora_contexto: :recupera_ancora (FILE *fp)

anc_text.cpp \(71) int

ancora_texto: :recupera_ancora (FILE *fp)

list_anc.cpp $\backslash(118)$ int lista_ancoras : : recupera (No *n, FILE *fp) 


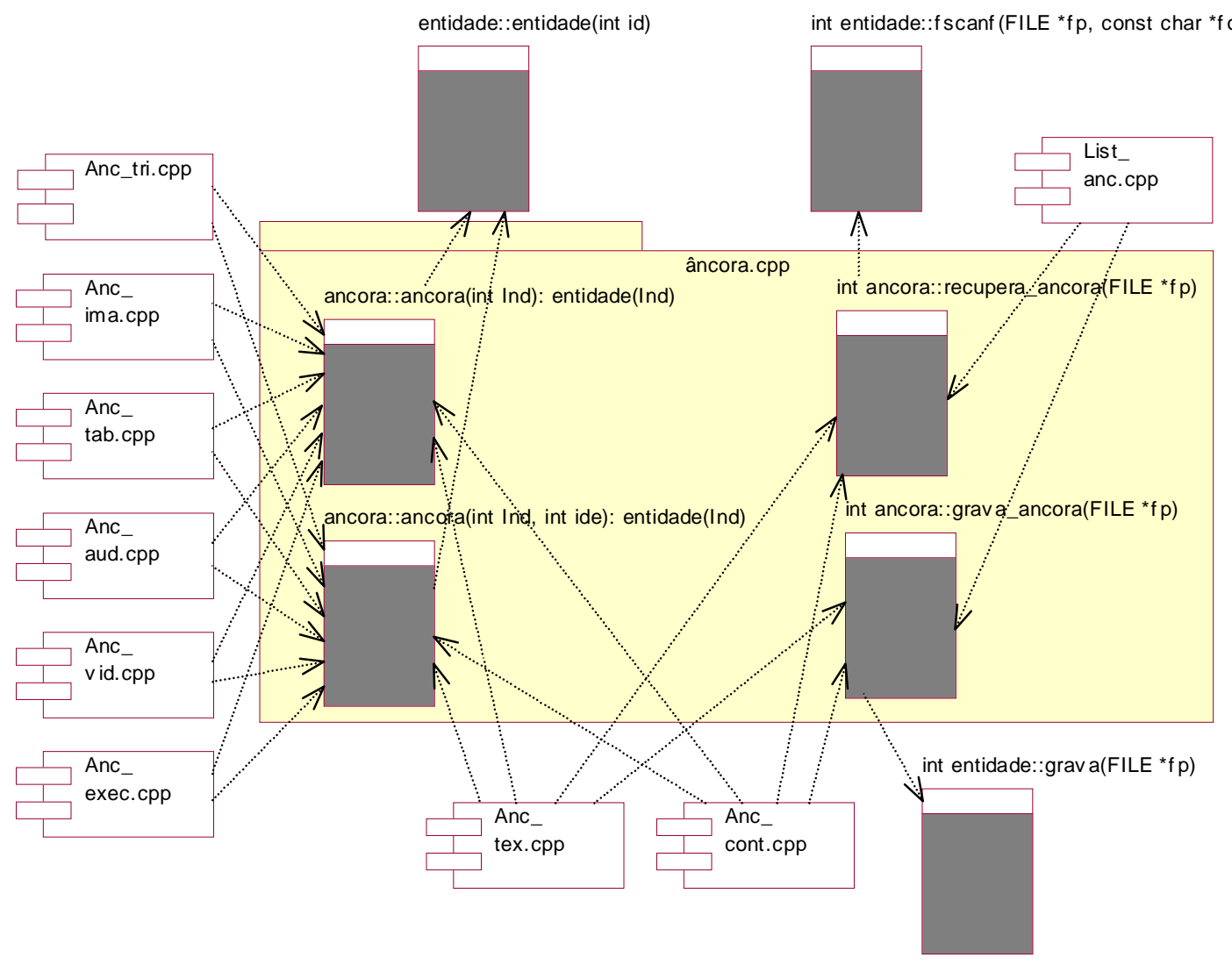

Figura 2.14 - Diagrama de componentes para o arquivo ancora.cpp

\section{Quadro de Índice}

O quadro de índice é proveniente do Quadro de Chamadas e trata-se de uma lista, em ordem alfabética, de todos os procedimentos de implementação do sistema, com suas respectivas localizações (arquivo e diretório).

Esse quadro tem como finalidade agilizar o trabalho de manipulação dos procedimentos. Por tratar-se apenas de uma lista textual, esse quadro não necessita de uma representação específica em UML.

\section{Quadro de Operações - Procedimentos de Implementação}

Esse quadro tem por objetivo identificar quais os procedimentos que implementam as operações da interface e classificá-los, de acordo com sua funcionalidade, à interface ou a um dos temas definidos. 
Por tratar-se de uma tabela, a UML não fornece uma representação direta. Não encontramos na notação UML um diagrama que relacionasse, diretamente, os procedimentos de implementação com as operações da interface com o usuário, como acontece no quadro de Operações - Procedimentos de Implementação.

Assim, optamos por deixar o mapeamento desse quadro em aberto.

\section{Mapeamento Fusion-RE/I x UML (Visão Estrutural)}

Os quadros gerados durante a fase de recuperação de visões estruturais do Fusion-RE/I não utilizam modelos de um método de desenvolvimento de software, como acontece na fase de recuperação do modelo de análise, na qual são utilizados os modelos do método Fusion. Desta forma, as informações recuperadas são expressas de forma tabular.

Como a UML não trata representações tabulares, foi proposto um diagrama UML para a representação de um dos quadros gerados através da aplicação do Fusion-RE/I, de forma que haja correspondência entre o quadro e o diagrama. Os outros quadros deverão permanecer na forma tabular.

O Quadro 2.5 mostra de forma resumida quais elementos da UML podem ser utilizados para a representação das visões estruturais do Fusion-RE/I.

Quadro 2.5 - Visões Estruturais Fusion-RE/I x UML

\begin{tabular}{|c|c|}
\hline Fusion-RE/I & UML \\
\hline Quadro de Chamadas & Diagrama de Componentes \\
\hline Quadro de Índice & - \\
\hline $\begin{array}{c}\text { Quadro de Operações - Procedimentos } \\
\text { de Implementação }\end{array}$ & - \\
\hline
\end{tabular}

\subsection{Considerações Finais}

Neste capítulo foram abordados os principais conceitos relacionados à Engenharia Reversa de Software, bem como o método de engenharia reversa utilizado neste trabalho, o Fusion-RE/I. Sendo que o Fusion-RE/I utiliza modelos do método de desenvolvimento de sistemas Fusion, esse foi introduzido, seguido das respectivas fases de recuperação de informação do FusionRE/I: recuperação de visões funcionais do sistema e recuperação de visões estruturais do 
sistema. O Quadro 2.6 apresenta um resumo das etapas previstas pelo método Fusion-RE/I, mostrando a ordem de execução das tarefas.

Quadro 2.6 - Ordem das tarefas prescritas pelo Fusion-RE/I

\begin{tabular}{|l|}
\hline Etapa 1. Recuperação de Visões Funcionais \\
\hline a. Obtenção de informações existentes sobre o sistema \\
b. Recuperação do modelo de análise \\
b1. Elaboração do Modelo de Ciclo de Vida \\
b2. Elaboração do Modelo de Operações \\
b3. Elaboração do Modelo de Objetos \\
\hline Etapa 2. Recuperação de Visões Estruturais \\
\hline a. Elaboração do Quadro de procedimentos de implementação \\
a1. Elaboração do Quadro de Chamadas \\
a2. Elaboração do Quadro Índice de procedimentos \\
b. Elaboração do Quadro de Operações-Procedimentos de Implementação \\
\hline
\end{tabular}

Também nesse capítulo foi discutido o porquê da opção pela utilização da notação UML para a representação dos modelos recuperados através da aplicação do método Fusion-RE/I e foi apresentada uma proposta para o mapeamento da representação utilizada pelo Fusion-RE/I para a notação UML, já que foi objetivo deste trabalho que as informações recuperadas pela aplicação do método Fusion-RE/I estivessem de acordo com a notação UML. Tal mapeamento foi realizado, e foram apresentados exemplos dos resultados.

Orientando-se para utilizar a notação UML, o processo de engenharia reversa segundo o método Fusion-RE/I foi então realizado. Entretanto, devido a restrição do SASHE de não permitir a criação de âncoras e links entre documentos gráficos, os modelos textuais do Fusion-RE/I foram construídos de forma a tornar completa a recuperação de informações almejada.

Compõem a proposta deste trabalho a construção de uma hiperbase, com um conjunto de links representativos no domínio da Engenharia Reversa, que auxilie no decorrer do processo de recuperação de informações, permitindo que os documentos gerados durante a aplicação de um método de engenharia reversa estejam disponíveis na forma de hiperdocumento. Dessa forma, no próximo capítulo é discutido o suporte dado pela tecnologia de hipermídia à organização de documentos dentro de vários domínios de aplicação, mais especificamente a Engenharia de Software e a Engenharia Reversa. 


\section{Capítulo 3}

\section{O Suporte de Sistemas Hipermídia}

Nielsen (1995) define hipermídia como sendo "a tecnologia que habilita intrinsecamente a leitura não-seqüencial, em contraste com a forma de leitura sequiencial disponível nos livros-textos”. Então, um hiperdocumento consiste de pedaços de informação (denominados nós) interconectados (pelos chamados links) e o conteúdo de um nó pode ser de vários tipos tais como texto, gráfico, imagem, som, código executável, etc.

Essa forma de estruturação fornece uma grande flexibilidade para que se faça o relacionamento entre documentos que não possuem uma estrutura de relacionamentos bem definida (Meira; Cabral, 1994).

Os sistemas hipermídia têm sido aplicados em vários domínios, como pode ser constatado nos trabalhos de Castro (1997), Nunes et al. (1997b), Nunes e Fortes (1997), cujo domínio de aplicação é o ensino, e outros como: Meira e Cabral (1994), e Bigelow e Riley (1987), onde o domínio é a engenharia de software; Rizk e Sutcliffe (1997), e Bullock e Goble (1997), onde o domínio é informações turísticas e culturais. O uso dos sistemas hipermídia em domínios diversificados têm ocorrido devido não só a sua flexibilidade para relacionar diferentes tipos de documentos, mas também por permitir um maior controle por parte do usuário sobre as informações que são recuperadas.

Para engenharia de software a tecnologia hipermídia pode ser de grande auxílio, uma vez que existe um relacionamento entre os documentos gerados durante o ciclo de vida de um software, embora esse relacionamento não tenha uma forma bem definida (Meira; Cabral, 1994). 
A estruturação dos documentos do ciclo de vida do software na forma de hiperdocumento pode ser explorada não só no auxílio à navegação, mas também como forma de associar mais informações aos relacionamentos, tornando-os mais explícitos. Isso permite uma melhor avaliação das dependências entre os documentos que descrevem o ciclo de vida do software, de forma que a visualização dos efeitos que as mudanças em um documento causariam sobre outro pode ser feita com maior precisão.

$\mathrm{Na}$ Engenharia Reversa, a estruturação adequada das informações recuperadas de um sistema na forma de um hiperdocumento possibilitaria estabelecer não só um melhor relacionamento entre os documentos, mas traria uma maior garantia de fidelidade do conteúdo da documentação com relação ao produto de software que está sendo documentado (Tilley; Smith, 1997). Além disso, espera-se que uma melhor consistência entre as partes do hiperdocumento e os componentes de software seja obtida com mais facilidade por meio dos links definidos.

Dessa forma, o alvo deste trabalho foi especificar uma estrutura de hiperbase que fosse adequada à engenharia reversa. Para tanto, foi realizada a engenharia reversa no sistema hipermídia SASHE, cujo domínio de aplicação é o ensino. Esse exercício proporcionou um levantamento efetivo dos requisitos para a especificação do conjunto de estruturas relevantes ao domínio de documentação do processo de engenharia reversa de software.

Para que tivéssemos um ponto de partida bem definido para a construção da hiperbase, contendo os documentos recuperados, uma modelagem conceitual do domínio de engenharia reversa foi necessária. Para a realização de tal modelagem, foi utilizado o método OOHDM Object Oriented Hypermidia Design Methodology (Schwabe; Rossi, 1995), (Rossi, 1996), (Schwabe et al., 1996). O OOHDM é um método voltado para o desenvolvimento de aplicações hipermídia que descreve as tarefas a serem executadas desde a análise de domínio da aplicação até a sua implementação (Schwabe et al., 1996). Ele é um descendente direto do HDM (Garzotto et al., 1993), incorporando uma série de novos conceitos vindos sobretudo da orientação a objetos.

Uma vez que o método de Engenharia Reversa utilizado, o Fusion-RE/I, também é orientado a objetos, a utilização do OOHDM nos pareceu mais natural, já que o Fusion-RE/I serviu como base para essa modelagem. A fim de estabelecer o método de modelagem hipermídia a ser utilizado para modelar o domínio do processo de engenharia reversa, em Feltrim e Fortes 
(1998a) foi feito um estudo de algumas abordagens presentes na literatura que pudessem satisfazer os nossos objetivos.

Baseada na modelagem conceitual resultante e levando em conta os conceitos do MCA (Casanova et al., 1991), foi construída uma hiperbase contendo os documentos recuperados do sistema SASHE, no próprio sistema. Com a hiperbase pronta, a modelagem pôde ser validada, uma vez que o processo realizado foi uma instância do modelo proposto.

Essa tarefa de inserir os documentos do sistema SASHE no próprio SASHE foi o exercício que revelou requisitos necessários para que o esse sistema se tornasse adequado ao domínio de engenharia reversa. De fato, foi constatado que para que o SASHE comportasse a documentação de engenharia reversa e permitisse uma navegação eficiente através desses documentos, alguns pontos precisam ser ajustados. Assim, elaboramos uma proposta de adequação, contendo as modificações necessárias para que o sistema se torne adequado ao domínio de engenharia reversa.

O SASHE, sistema alvo da engenharia reversa realizada, é apresentado na Seção 3.1. Na Seção 3.2 é descrito o método utilizado, OOHDM, seguido pelos resultados da modelagem resultante, que é mostrada na Seção 3.3. Na Seção 3.4 é mostrada a hiperbase construída para o sistema SASHE, e na Seção 3.5 é apresentada uma proposta de adequação do sistema SASHE para o domínio de engenharia reversa de software. Finalmente, na Seção 3.6 são apresentadas as considerações finais sobre este capítulo.

\subsection{O Sistema SASHE}

Desenvolvido totalmente no Departamento de Computação do ICMC-USP/S.Carlos, o ambiente SASHE teve como suporte, um projeto maior do ProTeM/HyperProp (Soares et al., 1995), o qual tinha como um de seus objetivos explorar as potencialidades do Modelo de Contextos Aninhados (MCA) (Casanova et al., 1991) como modelo conceitual de dados de hipermídia.

A Figura 3.1 apresenta a arquitetura geral dos módulos funcionais de SASHE, mostrando seus usuários de forma esquemática, segundo Nunes et al. (1997b). Pode-se observar que existem módulos funcionais específicos para cada um dos tipos de usuários previstos no ambiente (Autoria e Navegação). No entanto, essa arquitetura modular não havia sido detalhada 
por meio de documentação de projeto, em qualquer dos documentos pertinentes ao ambiente SASHE.

Dessa forma, com o desenvolvimento da engenharia reversa sobre o SASHE, pôde ser recuperada toda a documentação fiel ao sistema implementado.

O sistema hipermídia SASHE - Sistema de Autoria e Suporte Hipermídia para Ensino tem como característica permitir que um autor de hiperdocumentos possa qualificar e organizar os elementos constituintes (nós) do documento, de modo que o sistema resultante contenha funções adicionais à navegação tradicional. Tais funções incluem recursos para a localização contextual do leitor, bem como estratégias instrucionais dependentes dos valores dos atributos dos nós (Nunes et al., 1997b).

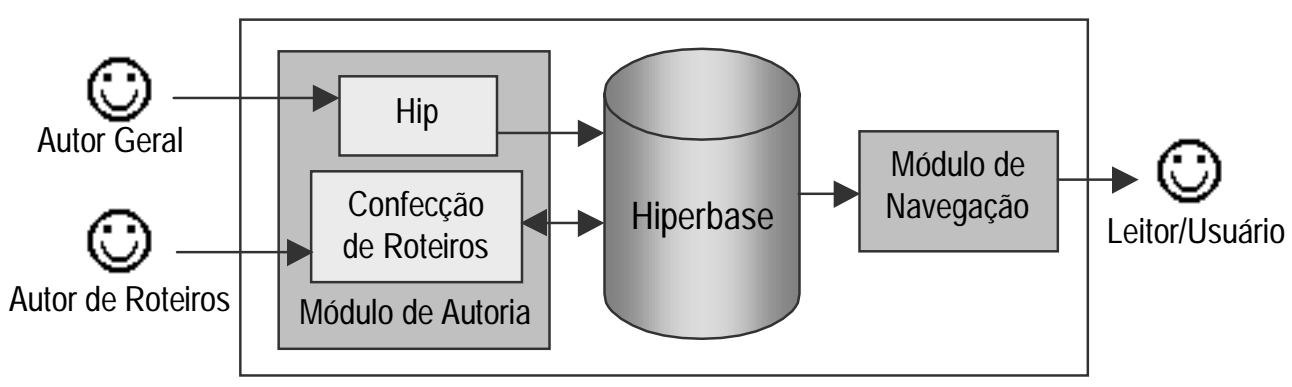

Figura 3.1 - Arquitetura geral dos módulos funcionais de SASHE.

O ambiente SASHE prevê dois tipos de usuários: o professor, atuando como autor, e o estudante, atuando como leitor. Os usuários são chamados professor e estudante devido ao domínio da aplicação atual do sistema ser o ensino. Por autor entende-se o construtor da hiperbase bem como o construtor de roteiros sobre uma hiperbase já existente.

Embora o MCA se fundamente nos conceitos de nós terminais e várias classes de nós de contexto, o SASHE utiliza apenas nós terminais, nós de contexto do tipo trilha, contexto de usuário e hiperbase pública. Dentro da aplicação, os nós de contexto são classificados de acordo com o assunto que englobam, ao passo que os nós terminais são classificados quanto a sua função didática, dificuldade e palavras-chave que qualificam o conteúdo.

A função didática indica um dos seguintes tipos possíveis de documento no domínio de aplicação ensino: introdução, exercício, motivação, definição, bibliografia, glossário, exemplo, resumo e ajuda. Caso desejado, esses valores podem ser revistos ou estendidos, sem causar problemas no funcionamento geral do sistema. 
A dificuldade indica o nível de dificuldade do nó terminal, que pode ser classificado como fácil, regular ou difícil.

No caso de nós de contexto, apenas o atributo nome deve ser preenchido, sendo que este passa a ter a função de assunto, indicando qual assunto é tratado pelos nós contidos nesse contexto. Por definição, o sistema considera que todos os nós contidos em um determinado contexto pertencem ao assunto correspondente. Dessa forma, para a construção da hiperbase, deve-se levar em conta essa característica e atribuir os assuntos mais específicos aos contextos mais internos. Dessa forma, o hiperdocumento apresentará uma hierarquia de assuntos, facilitando o entendimento da estrutura do mesmo (Nunes et al., 1997b).

A partir de um hiperdocumento já existente, o autor pode criar roteiros de navegação, visando atingir um determinado grupo de usuários. Dessa forma, o autor de roteiros decide quais nós estarão no roteiro, definindo também o grau de liberdade associado a cada nó, de forma a especificar quanto o leitor poderá se "afastar" do roteiro, sem que isso comprometa a relevância do material. A criação de roteiros é feita no mesmo módulo de autoria em que o hiperdocumento foi criado.

Como ferramenta para auxiliar tanto na criação da hiperbase como na criação de roteiros, o SASHE disponibiliza um browser gráfico, que permite ao usuário visualizar a estrutura do hiperdocumento ou parte dela como um grafo. Para ativá-lo basta clicar sobre o botão browser gráfico, e os nós pertencentes ao contexto atual serão exibidos. Através do título da janela é possível se saber qual contexto está sendo visualizado. Para a visualização de contextos mais aninhados, caso existam, basta pressionar o botão direito do mouse sobre o nó escolhido.

No módulo de leitura o usuário encontra vários recursos de navegação adicionais (Figura 3.2), que permitem a navegação levando em conta as informações dos atributos e da contextualização dos nós. O usuário pode navegar normalmente, avançando ou retrocedendo no roteiro que está seguindo, ou navegar de acordo com o grau de dificuldade encontrado. Isso se dá através das funções Está fácil e Está difícil. Dessa forma, o atributo dificuldade é levado em conta quando é feito uso desse recurso, apresentando ao usuário um nó com grau de dificuldade maior ou menor, dependendo da função escolhida. A busca por nós "mais fáceis" ou "mais difíceis" se dá sempre dentro do contexto em que se encontra o usuário. Caso não se encontre dentro do contexto atual um nó que seja adequado ao grau de dificuldade requerido, passa a ser feita a busca por um nó com uma função didática anterior à atual, no caso de 
se procurar por um nó "mais fácil” ou, com uma função didática posterior, no caso de se procurar por um nó "mais difícil".

As estratégias de busca por função didática associada ao grau de dificuldade é um diferencial importante, o qual reflete um suporte melhor para orientação do usuário/leitor.

O usuário também pode avançar ou retroceder dentro do caminho percorrido por ele, independente se esse caminho é coincidente com o roteiro ou não, através da função Histórico. A função Onde estou? situa, graficamente, a posição do nó atual em relação ao roteiro programado.

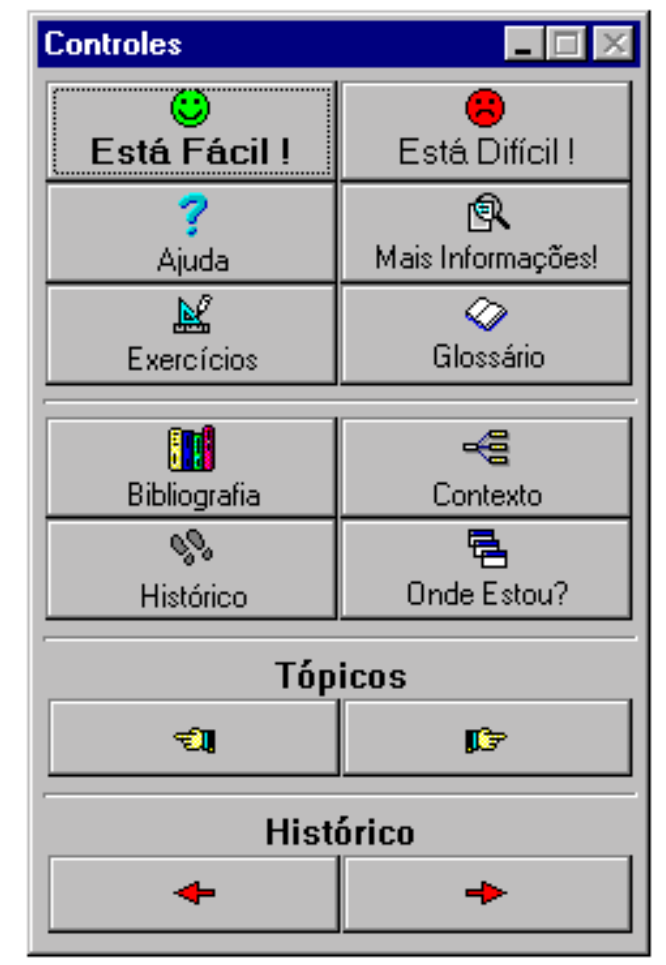

Figura 3.2 - Controles de navegação disponíveis no sistema SASHE

A função Mais informações dispara uma busca por uma lista, em todo hiperdocumento, de nós que possuem palavras-chave em comum com o nó atual, sendo que qualquer um dos nós selecionados poderão ser visualizados pelo leitor. Informações úteis também podem ser conseguidas através das funções Bibliografia, Exercícios e Glossário. A funcionalidade das funções Bibliografia e Exercícios é recuperar nós com os respectivos valores de função didática. A função Glossário permite o acesso ao glossário disponível. 
A partir dessas características operacionais descrevendo a interface do SASHE, obtidas dos “documentos de requisitos” Nunes et al. (1996, 1997b), foi possível dar início à aplicação do Fusion-RE/I ao SASHE, por meio do cumprimento da primeira fase do método.

Na seção seguinte (3.1.1) é brevemente comentado o MCA, o modelo conceitual de dados de hipermídia sobre o qual o sistema SASHE é baseado.

\subsubsection{Modelo de Contextos Aninhados}

No modelo MCA (Casanova et al., 1991), os documentos são definidos com base nos conceitos de nós e elos. Nós são fragmentos de informação e elos interconectam os nós que mantêm alguma relação entre si. Nesse modelo, os nós podem ser classificados como nós terminais ou nós de composição.

Segundo Nunes et al. (1996), um nó terminal caracteriza-se por conter dados cuja estrutura interna é dependente da aplicação. Sendo assim, essa classe de nó pode conter objetos com informações textuais, gráficas, de áudio, vídeo, etc.

Um nó de composição é um agrupamento de nós que pode incluir outros nós de composição. Podemos distinguir duas classes de nós de composição: nós de contexto e nós do tipo trilha.

Um nó de contexto agrupa um conjunto de elos, trilhas, nós terminais e de contexto, recursivamente. Esse tipo de nó permite o aninhamento em qualquer profundidade, permitindo organizar hierarquicamente, ou não, conjuntos de nós. Os nós de contexto se especializam nas classes de nós de anotação, contexto de versões, bases privadas, hiperbases públicas e contexto de usuário.

São denominados trilhas nós de composição que contêm uma lista ordenada de nós. Nós trilha podem incluir, recursivamente, outros nós trilha. A idéia é representar caminhos que devem ser, ou que foram, percorridos pelo usuário.

Como o MCA foi o fundamento lógico dos mecanismos que devem estar disponibilizados no SASHE, as investigações referentes às estruturas lógicas dos dados e procedimentos implementados no SASHE, se orientam a partir das definições propostas no MCA. Tais conceitos, de certa forma, auxiliaram também a primeira etapa do método Fusion-RE/I. 


\subsection{0 método OOHDM}

O OOHDM considera o processo de desenvolvimento de uma aplicação hipermídia como um processo de quatro atividades, desempenhadas combinando-se estilos iterativos e incrementais de desenvolvimento; em cada etapa um modelo é construído ou enriquecido (Rossi, 1996).

\begin{tabular}{|c|c|c|c|}
\hline Fases & Produtos & Mecanismos & Interesses do Projeto \\
\hline & $\begin{array}{l}\text { Classes, subsistemas, } \\
\text { relacionamentos, } \\
\text { perspectivas de atributos }\end{array}$ & $\begin{array}{l}\text { Classificação, composição, } \\
\text { generalização e } \\
\text { especialização }\end{array}$ & $\begin{array}{l}\text { Modelagem da semântica } \\
\text { do domínio de aplicação }\end{array}$ \\
\hline & $\begin{array}{l}\text { Nós, elos, estruturas de } \\
\text { acesso, contextos de } \\
\text { navegação, } \\
\text { transformações } \\
\text { navegacionais }\end{array}$ & $\begin{array}{l}\text { Mapeamento entre objetos } \\
\text { conceituais e de navegação. } \\
\text { Padrões de navegação para } \\
\text { a descrição da estrutura geral } \\
\text { da aplicação. }\end{array}$ & $\begin{array}{l}\text { Leva em conta o perfil do } \\
\text { usuário e a tarefa; ênfase } \\
\text { em aspetos cognitivos e } \\
\text { Arquiteturais. }\end{array}$ \\
\hline & $\begin{array}{c}\text { Objetos de interface } \\
\text { abstrata, reações a eventos } \\
\text { externos, transformações } \\
\text { de interface }\end{array}$ & $\begin{array}{l}\text { Mapeamento entre objetos de } \\
\text { navegação e objetos de } \\
\text { interface. }\end{array}$ & $\begin{array}{l}\text { Modelagem de objetos } \\
\text { perceptíveis, implementa } \\
\text { metáforas escolhidas. } \\
\text { Descrição de interface para } \\
\text { objetos navegacionais }\end{array}$ \\
\hline & Aplicação em execução & $\begin{array}{l}\text { Aqueles fornecidos pelo } \\
\text { ambiente alvo }\end{array}$ & Desempenho, completitude \\
\hline
\end{tabular}

Figura 3.3 - Esboço da Metodologia OOHDM (Rossi, 1996)

Na Figura 3.3 é mostrado um esboço do OOHDM, destacando cada uma das quatro fases que compõem o método, juntamente com os produtos gerados em cada fase, os mecanismos de abstração utilizados na fase correspondente, e qual o foco empregado em cada uma das fases do método.

A modelagem conceitual dos dados é feita utilizando-se os princípios da modelagem orientada a objetos, onde o principal objetivo é construir um modelo do domínio da aplicação. O resultado é um modelo conceitual composto por subsistemas, classes e relacionamentos.

Na modelagem da navegação é feita a descrição da estrutura navegacional da aplicação, em termos de contextos navegacionais, levando em conta os tipos de usuários da aplicação e suas tarefas. Os nós representam "visões" sobre as classes conceituais definidas durante a análise do domínio e os links são derivados dos relacionamentos conceituais. Diferentes modelos navegacionais podem ser feitos para o mesmo modelo conceitual, expressando diferentes visões 
do mesmo domínio. Tendo os nós e os links definidos, o movimento dentro do espaço navegacional pode ser modelado, independente do modelo conceitual.

No projeto da interface abstrata é construído um modelo especificando quais objetos de interface serão vistos pelo leitor, e particularmente, a forma de apresentação dos diferentes objetos navegacionais, as transformações causadas pela ativação desses objetos, quais objetos ativarão a navegação, a maneira como os objetos multimídia serão sincronizados e quais transformações ocorrerão na interface. Podem ser feitos diferentes projetos de interface abstrata para o mesmo projeto navegacional, de acordo com as preferências dos leitores.

Na etapa de implementação é feito o mapeamento dos objetos de interface para objetos de implementação.

Em Feltrim e Fortes (1998a) é apresentado um estudo mais aprofundado do método OOHDM, com o intuito de realizar a modelagem do domínio do processo de engenharia reversa.

\subsection{Modelagem hipermídia do domínio de Engenharia Reversa}

Nas subseções seguintes são mostrados os modelos gerados através da aplicação do método OOHDM para o domínio de engenharia reversa de software. Cada um dos modelos é descrito, esclarecendo suas semânticas. Para este trabalho, apenas a primeira etapa do método OOHDM foi suficiente para que os objetivos fossem alcançados. Dessa forma, foram construídos um modelo conceitual, um modelo de classes navegáveis e um modelo de contexto de navegação.

Em Feltrim e Fortes (1998b), essa modelagem é apresentada como parte dos requisitos funcionais identificados no processo de Engenharia Reversa de Software que possam ser suportados por um Sistema Hipermídia.

\subsubsection{Esquema Conceitual}

$\mathrm{Na}$ fase de modelagem conceitual é construído um esquema conceitual do domínio em questão. O foco está em modelar os objetos que constituem o domínio e os relacionamentos entre eles, 
sendo que nessa atividade observa-se uma maior preocupação com a estrutura dos objetos do que com seu comportamento. Para o desenvolvimento do modelo é empregada a abordagem orientada a objetos, segundo a notação do método OMT (Rumbaugh et al., 1991), com a adição de alguns elementos novos, como o conceito de subsistemas e de perspectiva de atributos.

Dessa forma, dizemos que um modelo conceitual é definido através de classes, subsistemas e relações, organizados de acordo com a semântica do domínio.

O modelo de classes do processo de engenharia reversa (PER) foi derivado do estudo desse processo sob a perspectiva do método de engenharia reversa Fusion-RE/I, segundo demonstrado na Figura 3.4. Os elementos presentes no modelo podem ser agrupados em duas hierarquias principais: uma hierarquia de tarefas de engenharia reversa e uma hierarquia de produtos gerados.

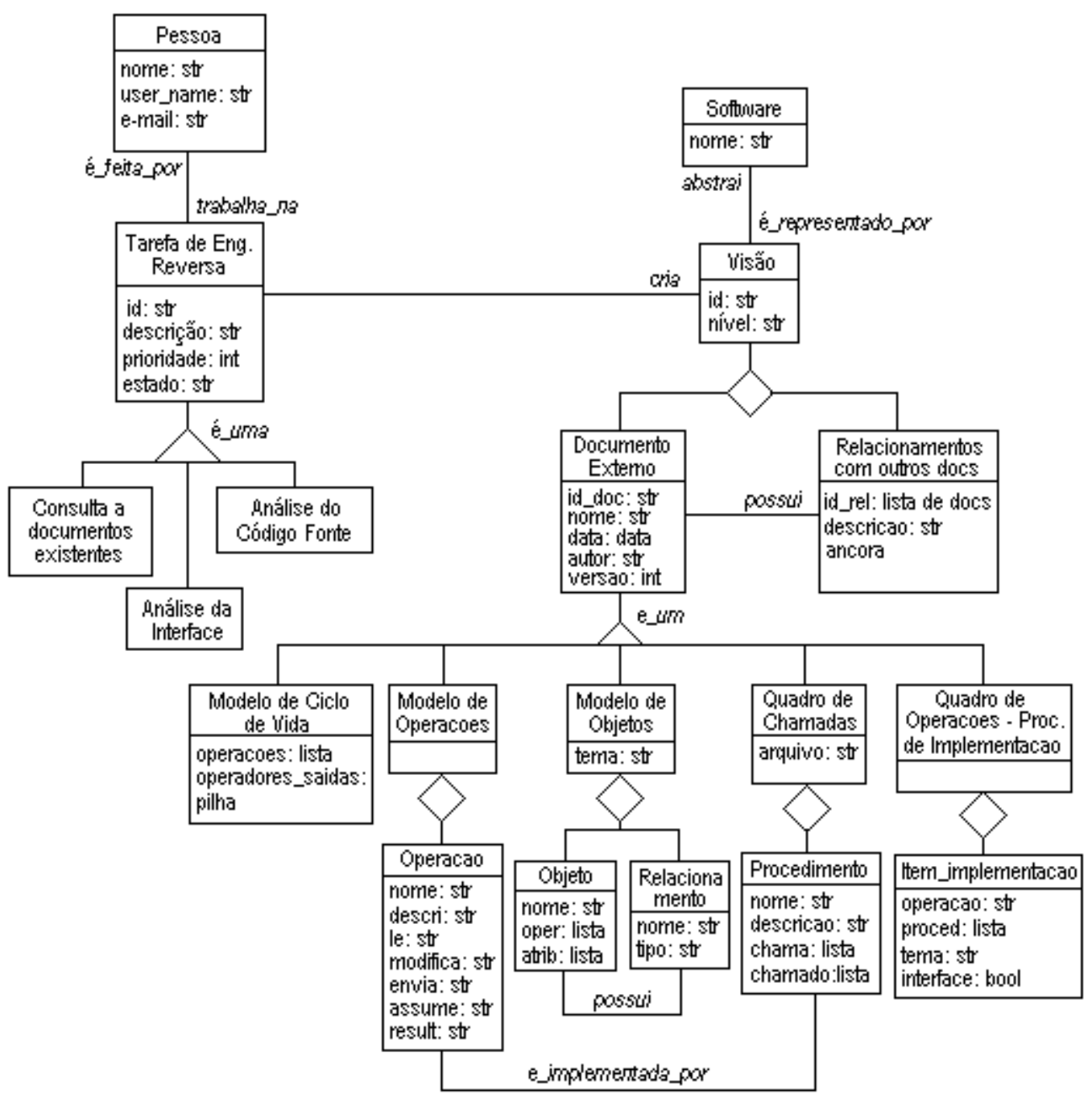

Figura 3.4 - Modelo Conceitual do PER para o Fusion-RE/I 
As classes Pessoa e Tarefa de Engenharia Reversa (TER) definem a parte do modelo correspondente ao gerenciamento de projeto. Como TER corresponde a atividade de recuperação de informações relevantes à geração de uma visão do sistema, foi definido o relacionamento umpara-um entre TER e Visão. Pessoa está relacionada com TER apesar dessa tarefa poder ser vista como mais de uma atividade. Na modelagem, entretanto, foi considerado TER como uma tarefa que pode ser desenvolvida por uma única pessoa e não existe a necessidade de se controlar a execução da TER por mais de uma pessoa, daí o relacionamento muitos-para-um entre TER e Pessoa. São as TER que conectam a parte de projeto e os produtos gerados. Uma TER pode ser uma: Consulta a Documento Existente, Análise da Interface, ou Análise do Código Fonte. Essas tarefas são descritas pelo método Fusion-RE/I, sendo que, segundo o método, apresentam uma ordenação definida para a realização de cada uma delas. No decorrer do processo, no entanto, essa ordem pode mudar de acordo com as necessidades do engenheiro reverso, e certas tarefas podem ser novamente realizadas.

Uma Visão define uma interpretação do sistema sob Engenharia Reversa. Essa interpretação corresponde a um nível de abstração, sendo que pode ser estrutural, funcional ou de domínio. O Fusion-RE/I propõe recuperação de visões tanto ao nível estrutural como funcional. Assim, a representação de um sistema é composta por um conjunto de visões, e isso é expresso pelo relacionamento um-para-muitos entre Software e Visão.

Uma Visão é um agregado de documentos e dos relacionamentos existentes entre esses documentos. Um documento é um Documento Externo que descreve informações recuperadas por uma TER. Relacionamento com outros Docs descreve uma ligação entre um documento e seus documentos relacionados.

Documento Externo é um dos modelos ou quadros propostos como resultado do FusionRE/I. No esquema conceitual (modelo de classes), todos os documentos são implicitamente relacionados através de seus atributos. As operações contidas no Modelo de Ciclo de Vida são as mesmas que compõem o Modelo de Operações. Da mesma forma, cada operação descrita em Operação é constituinte do Modelo de Operações e é parte de um Objeto. Modelo de Objetos é um agregado de objetos relacionados sendo que o atributo Tema indica o tema que inspirou o Modelo de Objetos em questão. O Quadro de Operações-Procedimentos de Implementação é um agregado de Item, onde cada Item compõe uma entrada do quadro. As operações citadas nesse modelo também são as mesmas descritas nos modelos mencionados anteriormente. Da mesma 
forma, os procedimentos presentes em cada Item também são descritos em Procedimento. A agregação de Procedimento compõe os Quadros de Chamadas, cujo atributo arquivo indica o arquivo onde se encontra o código que implementa Procedimento. O relacionamento explícito entre Operação e Procedimento se faz necessário uma vez que, apesar de existir o relacionamento (uma operação é implementada por um procedimento), não existem atributos relacionados. O relacionamento um-para-muitos se explica por uma operação ser implementada por um ou mais procedimentos.

\subsubsection{Esquema de Classes Navegacionais}

A modelagem navegacional gera dois produtos principais: um esquema de classes navegacionais e um esquema contextual ou de contextos de navegação (Seção 3.3.3). Neles são descritos as classes de nós, as classes de ligações, as estruturas de acesso e os contextos de navegação que compõem a aplicação (Cerqueira, 1997).

Como pode ser visualizado na Figura 3.5, o esquema de classes navegacionais é derivado do esquema conceitual descrito anteriormente, e é composto pelas classes que serão efetivamente navegadas, ou seja, serão visualizadas pelo usuário do aplicativo, e as ligações entre elas, isto é, as conexões que fazem sentido na visão navegacional sendo modelada.

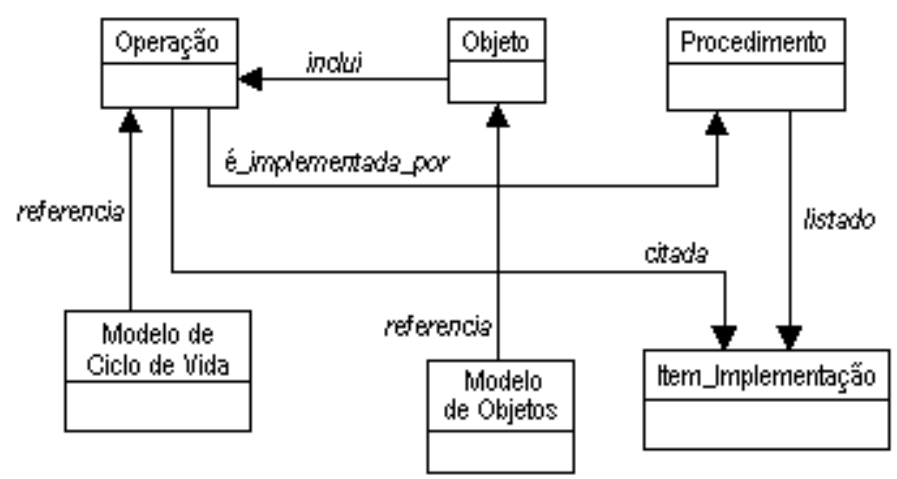

Figura 3.5 - Modelo de Classes Navegacionais

Dentro do processo descrito anteriormente no esquema conceitual, as classes navegáveis serão os produtos gerados pelas TER (modelos e quadros). Com exceção do Modelo de Ciclo de Vida e do Modelo de Objetos, todos os outros produtos são uma agregação de outros objetos. Dessa forma, as classes que compõem a agregação é que serão navegados, e não a classe agregada. 
Assim, as classes componentes do esquema navegacional são Operação, Objeto, Procedimento, Item, Modelo de Objetos e Modelo de Ciclo de Vida. Nesse esquema tornam-se explícitos os relacionamentos que no esquema conceitual estão implícitos por meio dos atributos contidos nas classes. Esses relacionamentos são expressos pelas setas rotuladas. O direcionamento das setas foi decidido considerando os objetos Operação, Objeto, Procedimento, Modelo de Ciclo de Vida e Modelo de Objetos como possíveis entradas para o início da navegação. A partir disso os outros objetos foram relacionados de forma que todos pudessem ser alcançados e os relacionamentos fossem coerentes.

\subsubsection{Esquema Contextual}

Os contextos navegacionais são geralmente induzidos pelas classes navegacionais e expressam a estrutura navegacional geral da aplicação, enquanto as classe navegacionais especificam os objetos que serão vistos pelo usuário (Rossi, 1996).

Os contextos são um conjunto de instâncias relacionadas, como, por exemplo, todos procedimentos em um determinado arquivo, todos os procedimentos com uma determinada data, etc. No esquema contextual as classes navegáveis são mostradas juntamente com os contextos em que podem aparecer na aplicação. Os contextos são representados por caixas pontilhadas que aparecem dentro da classe a qual o contexto pertence. Para simplificação do diagrama, os contextos podem ser agrupados em quadros pontilhados maiores quando conveniente. As setas indicam navegação ou mudança de contexto. Quando uma seta chega a um agrupamento de contexto, isto indica que qualquer um dos contextos pertencentes ao agrupamento estará disponível para a navegação, sendo que os contextos da classe que não estiverem no agrupamento não serão visíveis. Os índices também aparecem com caixas pontilhadas entre as setas de navegação.

No esquema contextual apresentado na Figura 3.6, o índice à esquerda é o principal, a partir do qual podem ser acessados diversos índices intermediários. Cada classe pode então ser navegada nos contextos mostrados na figura. Um exemplo de navegação em diferentes contextos pode ser visualizado na classe Procedimento. Uma vez que os procedimentos são acessados através do índice de procedimentos, cada instância da classe Procedimento pode ser navegada tanto no contexto por data como no contexto por arquivo. No entanto, quando a classe 
Procedimento é acessada através da classe Operação, a classe Procedimento passa a poder ser navegada no contexto por operação, uma vez que uma operação pode ser implementada por mais de um procedimento. A partir desse contexto, a classe Procedimento pode ser navegada também nos contextos por data e por arquivo. Dessa forma, o contexto por operação só é visível quando a classe é acessada através da classe Operação, e não aparece quando a classe é acessada através do índice.

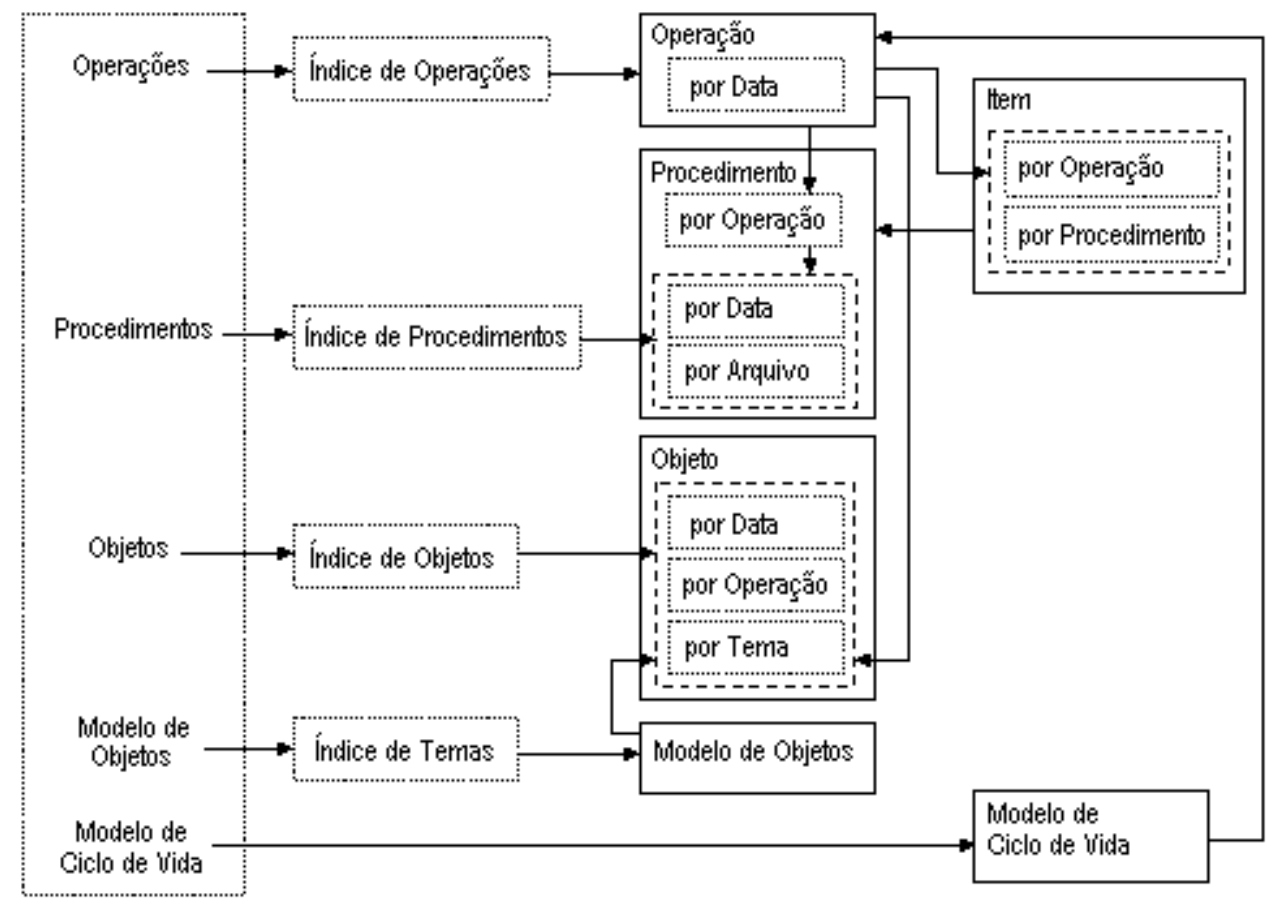

Figura 3.6 - Modelo Contextual

A navegação mostrada nesse esquema é a mesma do esquema de classes navegáveis, porém em maior nível de detalhamento. Neste diagrama são visualizados os contextos em que cada classe pode ser navegada. Na seção seguinte, é mostrada a hiperbase construída para o sistema SASHE, baseada na modelagem apresentada nesta seção.

\subsection{A hiperbase construída no SASHE}

No momento da construção da hiperbase, sentiu-se a necessidade de re-arranjar o modelo navegacional construído em OOHDM, de forma que fosse considerada a característica de contextos aninhados (MCA) implementada no SASHE. 
O esquema apresentado na Figura 3.7 foi criado considerando-se apenas a idéia de contextos aninhados, organizando a documentação do SASHE em contextos coerentes, que orientasse a navegação. Na figura, os retângulos representam contextos, as elipses representam documentos textuais e a elipse irregular representa documentos gráficos. As setas indicam possíveis links entre os documentos, dando uma idéia do contexto a que cada link pertence. Quando a ligação implementada por um link ultrapassa os limites de um contexto (seta pontilhada), esse link deve ser criado no maior contexto que o contém (no caso da Figura 3.7, o contexto Documentos de Engenharia Reversa).

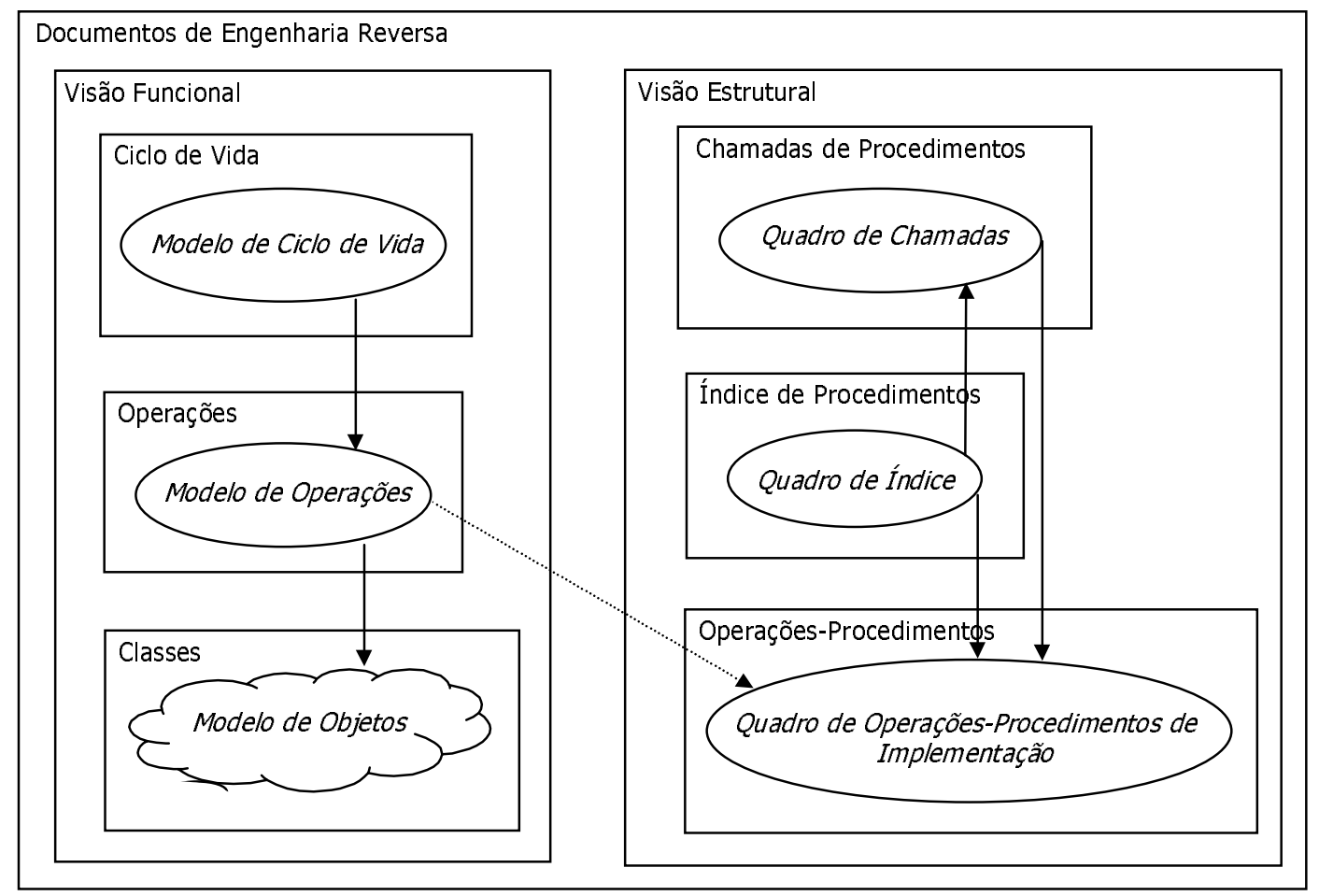

Figura 3.7 - Projeto dos contextos aninhados da hiperbase para documentar a engenharia reversa segundo o Fusion-RE/I

Tendo organizado os contextos que seriam criados na hiperbase com os documentos de engenharia reversa, o esquema contextual do OOHDM foi adaptado para que ficasse consistente com os contextos criados. A Figura 3.8 apresenta um novo esquema contextual, baseado no esquema contextual da modelagem OOHDM (Figura 3.6) e no esquema de contextos da Figura 3.7. Nessa figura, os índices de acesso são apresentados como retângulos pontilhados, como no OOHDM, porém os documentos ainda são mostrados como elipses para diferenciar nós documentos de nós de contextos (retângulos). O retângulo "Nó Inicial" equivale ao índice de acesso principal, fornecendo links para os outros índices. 


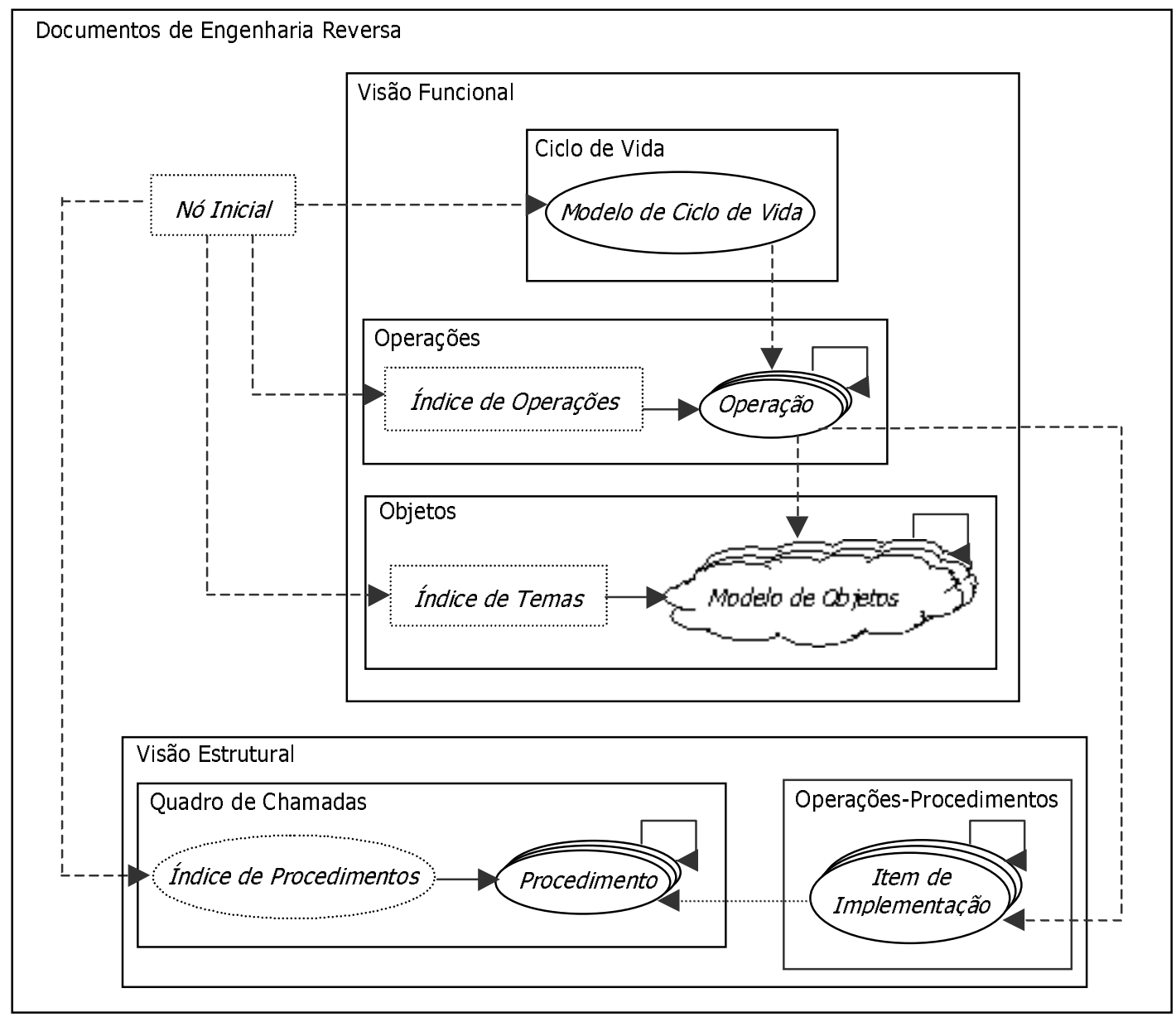

Figura 3.8 - Esquema contextual adaptado aos nós de contextos criados

A Figura 3.9 mostra a interface do módulo navegacional do estudante no SASHE, juntamente com a janela que apresenta o índice de acesso principal da hiperbase com os documentos do SASHE, e a janela com o índice de acesso às descrições das operações. Nessa figura não são mostrados os controles de navegação atualmente disponíveis no SASHE, uma vez que esses comandos não são adequados fora do domínio de ensino. Sendo assim, na hiperbase com os documentos de engenharia reversa toda a navegação é feita através das âncoras criadas e dos links estabelecidos.

A versão 1.0 do SASHE possui algumas restrições de edição que precisaram ser contornadas para que a hiperbase fosse construída de acordo com o que havia sido modelado. Como o SASHE não estabelece links dentro do mesmo nó, os modelos que eram apresentados de forma tabular tiveram que ser "desmembrados" em vários documentos individuais, possibilitando a criação de links que direcionassem uma parte específica do modelo, já que cada parte do modelo passou a ser apresentada em um nó. Esse desmembramento foi feito com o Modelo de 
Operações, com o Quadro de Chamadas, e com o Quadro de Operações-Procedimentos de Implementação.

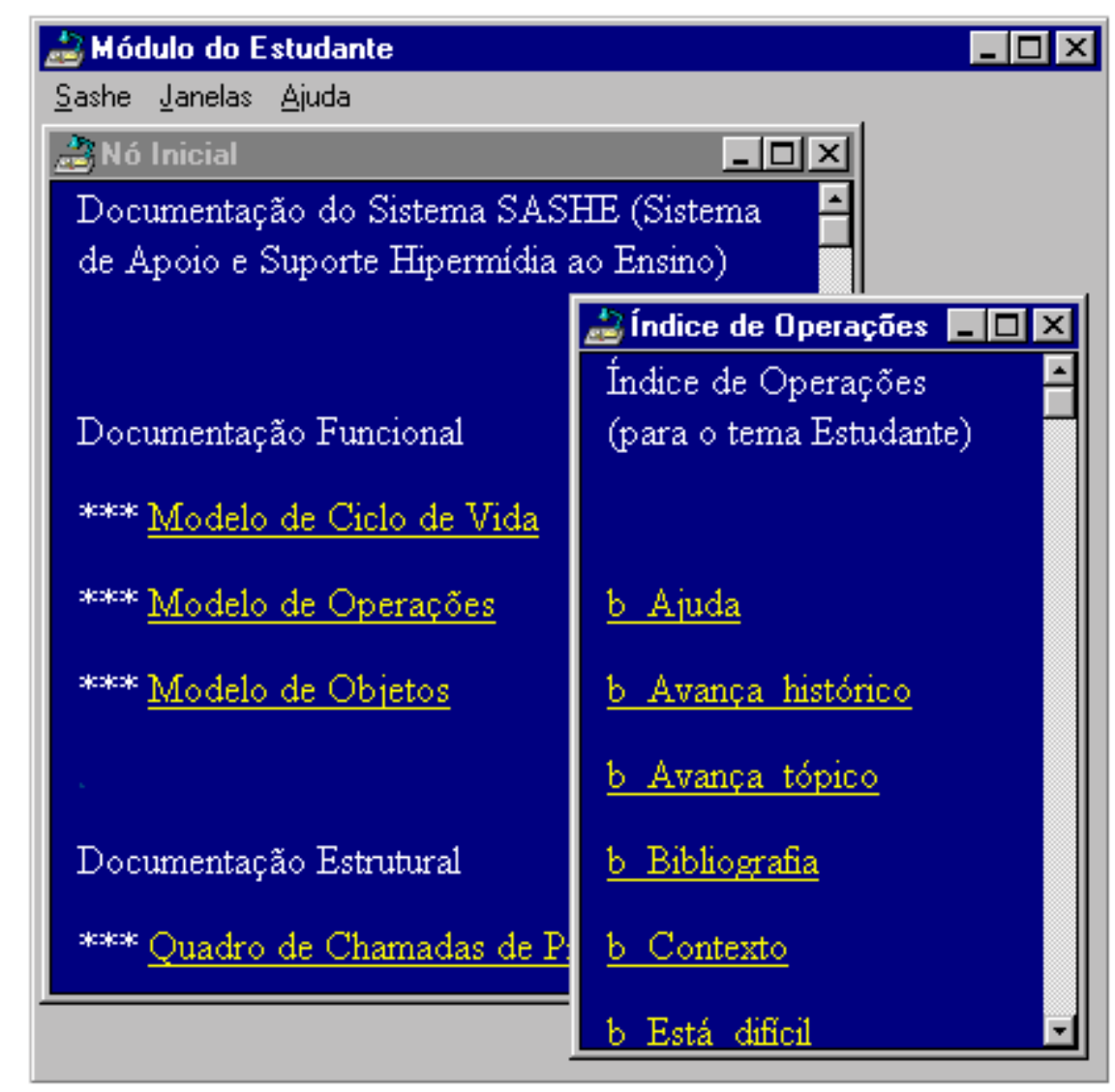

Figura 3.9 - Parte do índice principal da hiperbase juntamente com o índice de operações

Também devido ao fato do sistema não suportar a edição de tabelas, os documentos tabulares foram descritos como um texto seqüencial, conforme mostra a Figura 3.10. Nessa figura é apresentada uma das entradas da tabela que compõem o Modelo OperaçõesProcedimentos de Implementação.

Quadro 3.1 - Parte do Modelo Operações-Procedimentos de Implementação

\begin{tabular}{|c|c|c|}
\hline \multicolumn{2}{|c|}{ Opções da Interface do tema NAVEGAÇÃo } \\
\hline Opções & Operações & Procedimentos \\
\hline Controles & b_Avança_histórico & $\begin{array}{l}\text { To_fo_Controles.o_bu_ProximoClick(Sender: TObject); } \\
\text { To_fo_Principal.Apresentar_No(p_NomeDoNo: Ptochar; } \\
\text { ApresentarNosTerminais: integer); }\end{array}$ \\
\hline
\end{tabular}




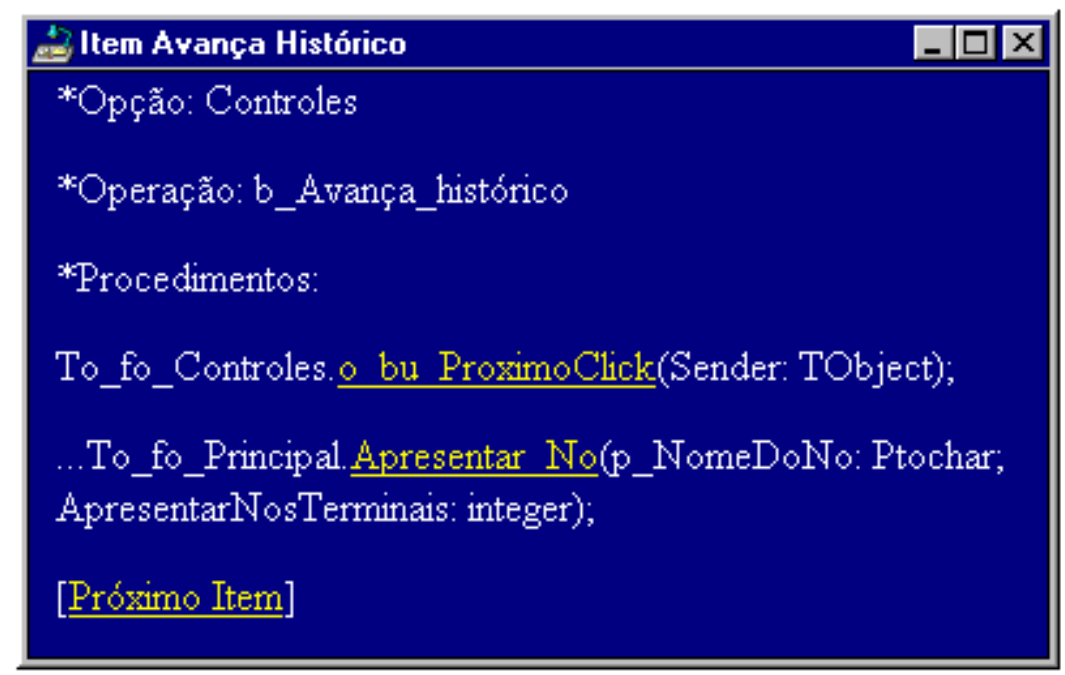

Figura 3.10 - Item de implementação Avança Histórico

Esse modelo (Operações-Procedimentos de Implementação) foi desmembrado em itens de implementação, sendo que cada item corresponde a uma linha da tabela que compõe o modelo. As informações apresentadas nos itens de implementação são exatamente as mesmas contidas na forma tabular do modelo, conforme pode ser observado através do Quadro 3.1, que descreve a entrada do modelo de Operações-Procedimentos de Implementação representada no item de implementação apresentado na Figura 3.10. Esse item de implementação corresponde a operação “Avança Histórico", contida na opção de interface "Controles".

Para conseguir uma navegação eficiente, foi necessário também a inserção de novos elementos nos textos dos documentos, a fim de que as âncoras necessárias ao estabelecimento dos links pudessem ser criadas.

A Figura 3.11 mostra uma janela (nó) contendo a descrição de uma das operações componente do modelo de operações. Note-se que nesse nó foi necessário inserir três elementos não pertencentes ao modelo (descrição da operação) a fim de que fossem criadas as âncoras necessárias à navegação modelada no esquema contextual. Como o próprio nome sugere, a âncora Próxima operação faz o link para um outro nó contendo a descrição de outra operação. A âncora Objeto faz o link para um nó contendo o modelo de objetos no qual a classe que implementa a operação do nó atual faz parte. A âncora Implementação faz o link para um nó contendo o item de implementação que descreve os procedimentos de implementação da operação exibida no nó atual. 
Ativar janela n

*Operação: Ativar_Janela_n (Janela_1 ou Janela_n)

*Descrição:

Ativa uma das janelas listadas no menu Janelas. Esta operação consiste

em rolar o cursor e escolher uma das janelas disponíveis no menu

*Lê:

*Modifica:

*Envia:

*Assume:

*Resultado:

A janela n estará ativa

[Próxima Operação $\mid$ Objeto $\mid \underline{\text { Implementação] }}$

Figura 3.11 - Janela apresentando a descrição da operação "Ativar Janela n”

A necessidade de se criar essas âncoras em todos nós acarreta um esforço que poderia ser poupado através de controles de navegação adequados para esse tipo de documento. A seguir é discutida uma forma de se resolver essa e outras questões relacionadas a adequação do SASHE para o armazenamento e navegação de documentos de engenharia reversa.

\subsection{Proposta de adequação do SASHE para Engenharia Reversa}

Conforme comentado na seção anterior, existem alguns pontos que necessitam de modificação para que o SASHE torne-se um sistema apto à construção e navegação de hiperbases contendo documentos de engenharia reversa. Além da mudança da nomenclatura utilizada pela interface, algumas funções de navegação teriam de ser modificadas, pois atualmente, os controles de navegação disponíveis no SASHE são direcionados ao domínio de documentos didáticos.

Dessa forma, com base na experiência adquirida durante o processo de engenharia reversa e na inserção dos documentos resultantes desse processo no SASHE, foi elaborada uma proposta de modificação da nomenclatura utilizada na qualificação dos nós terminais e também de mudança dos controles de navegação atuais. 


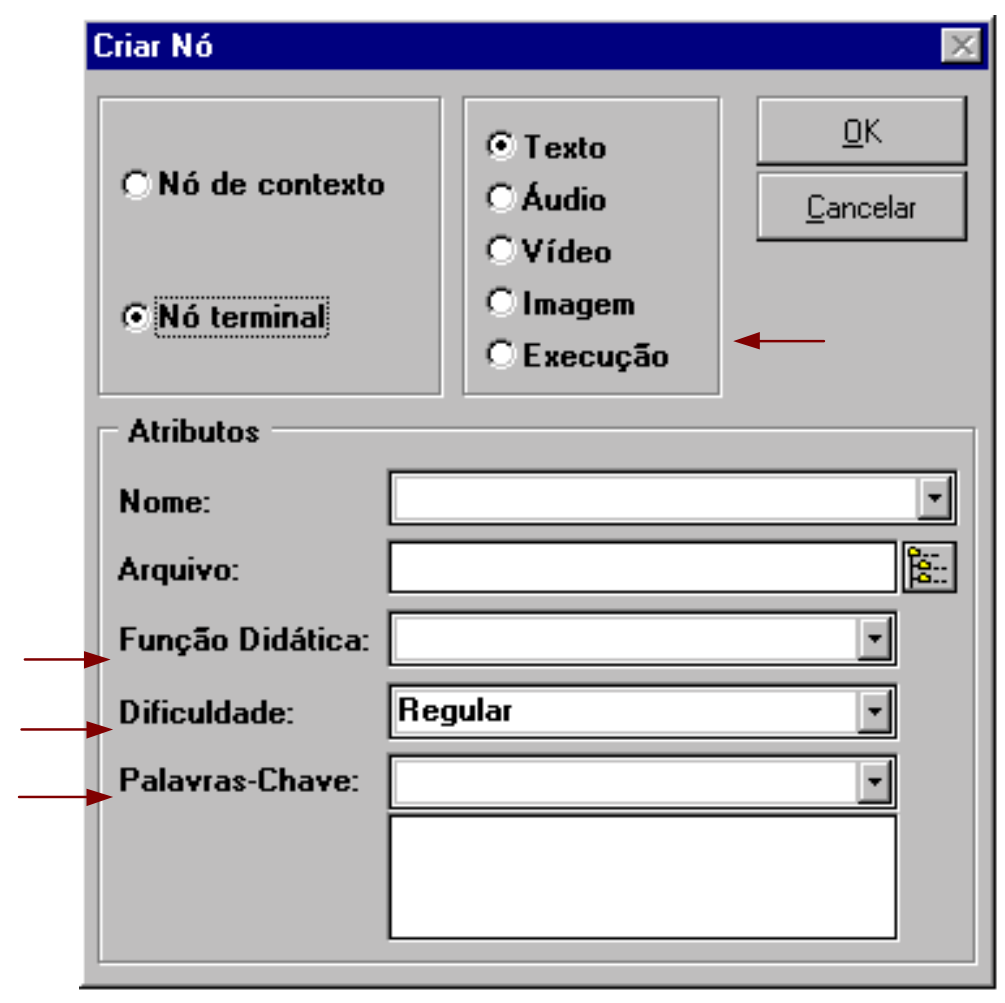

Figura 3.12 - Janela do SASHE para a criação de um nó terminal

Atualmente, quando um nó terminal é criado no SASHE, ele pode ser classificado como um texto, uma imagem, um vídeo, um áudio ou um nó execução, conforme pode ser observado na Figura 3.12. Além do tipo do nó, outros atributos são definidos, como sua função didática, seu grau de dificuldade e uma lista de palavras-chave com as quais o assunto do nó se relaciona. Tanto essa classificação quanto os atributos especificados perdem o sentido quando o domínio de documentação deixa de ser o de ensino. No entanto, é interessante que a idéia de qualificação de nós terminais permaneça, pois são esses atributos que possibilitam a existência de outros controles de navegação além dos tradicionais (Nunes et al., 1997b). As setas, na Figura 3.12, indicam os campos que necessitam modificação.

Sendo assim, na Figura 3.13 é apresentado um exemplo de como poderia ser a janela de criação de nós, de modo a estabelecer atributos adequados à documentação de engenharia reversa. Os tipos de nó foram reduzidos a dois: nó texto e nó gráfico. Basicamente, um documento de software pode ser textual ou gráfico. De forma geral, outros tipos de nó poderiam ser definidos, porém essa proposta foi baseada na capacidade atual de edição do sistema SASHE. 


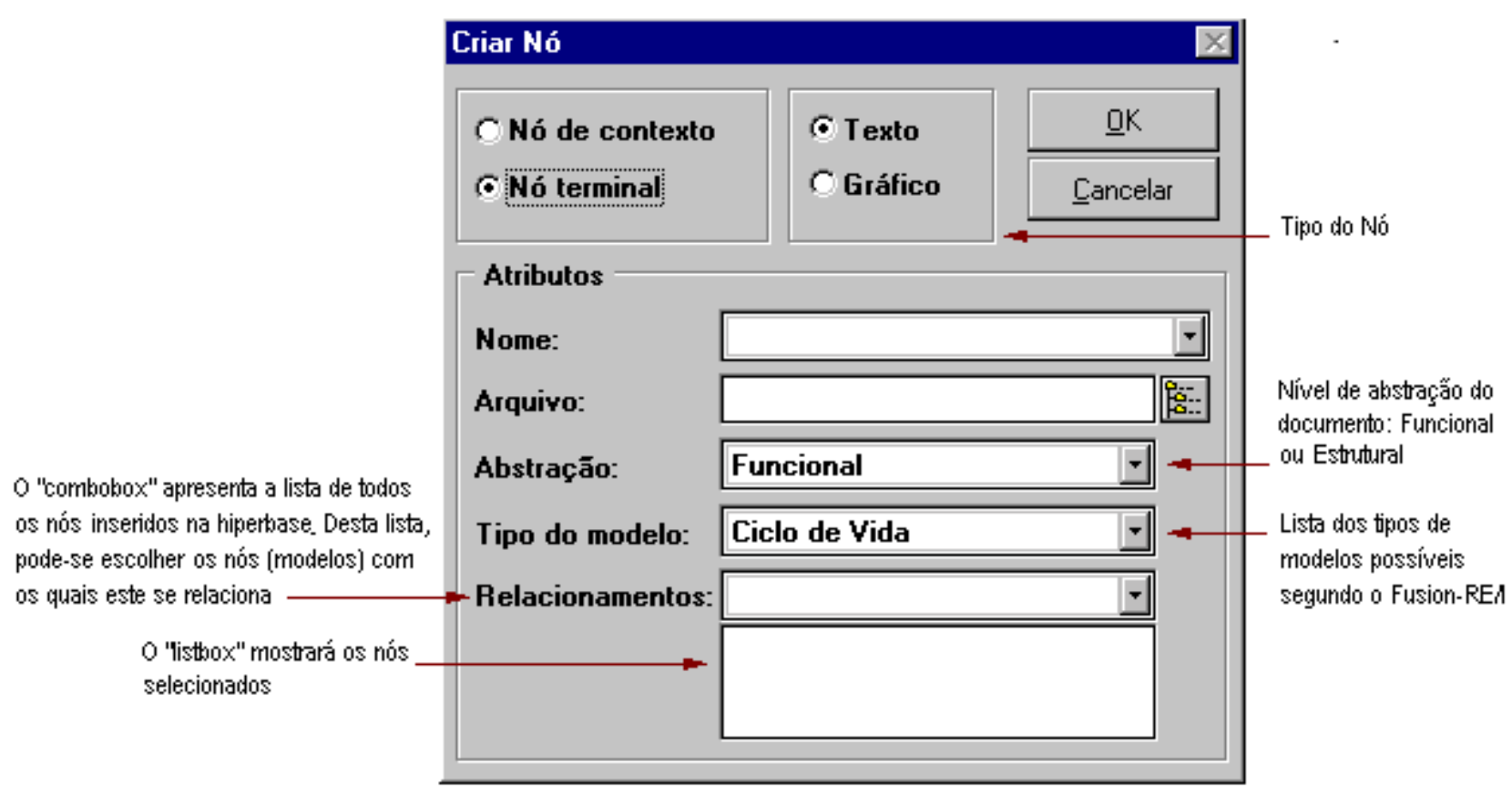

Figura 3.13 - Possível modificação de interface para a janela de criação de nó

O atributo Abstração define o nível de abstração do modelo pertencente ao nó sendo criado. Esse atributo permitirá a navegação entre documentos com o mesmo nível de abstração, que pode ser Funcional ou Estrutural.

O atributo Tipo do Modelo classifica o nó como um modelo ou parte de um modelo definido pelo Fusion-RE/I. Dessa forma, um nó pode ser um Modelo de Ciclo de Vida, uma Operação (parte do Modelo de Operações), um Modelo de Objetos, um Item de Chamada (parte do Quadro de Chamadas), um Índice, ou um Item de Implementação (parte do Quadro de OperaçõesProcedimentos de Implementação). Esses tipos de modelo são apresentados no combobox desse atributo, de forma que no momento da criação ou edição do nó basta escolher um dos tipos disponíveis. A definição dos nós com um atributo de tipo de modelo permitirá a navegação entre os mesmos tipos de modelos (por exemplo, entre operações) sem que seja necessário criar no nó uma âncora que faça o link para um próximo item.

O atributo Relacionamentos consiste de uma lista de nós relacionados ao nó sendo criado. Conforme mostrado na Figura 3.13, o combobox desse atributo apresentará o nome de todos os nós da hiperbase, para que sejam escolhidos os nós que se deseja relacionar com o nó sendo criado ou editado. No listbox logo abaixo do combobox são apresentados os nomes do nós selecionados. Esse atributo permitirá a navegação entre nós de tipos diferentes, porém relacionados, sem seja preciso se criar um âncora para se estabelecer o link desejado. 
Tendo definidos esses atributos para os nós, elaboramos uma proposta de novos controles de navegação, mostrados na Figura 3.14. Embora a maior parte da navegação seja feita através das âncoras explicitamente definidas no conteúdo dos nós, esses controles viriam facilitar a navegação e reduzir o esforço de criação de âncoras e definição de links.

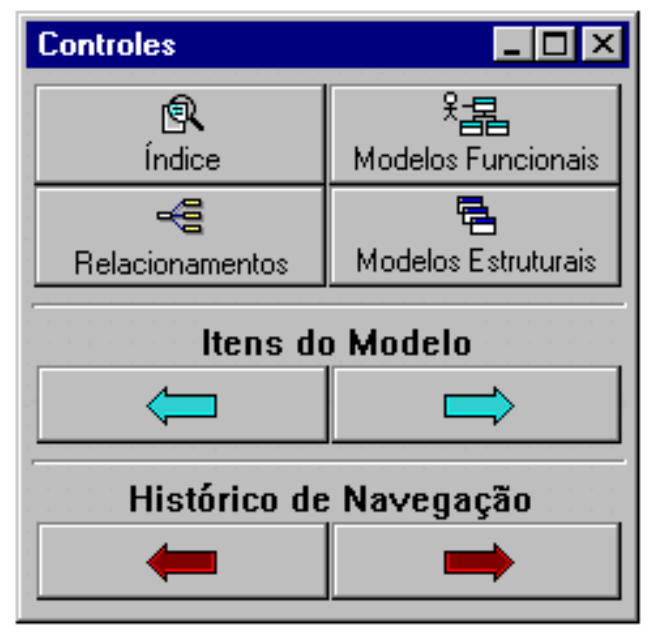

Figura 3.14 - Possível modificação dos controles de navegação

Os botões Histórico de Navegação permitiriam retroceder e avançar na lista de nós já navegados na seção atual do SASHE. Esses controles funcionariam da mesma maneira como estão no SASHE atual.

Os botões Itens do Modelo permitiriam a navegação entre nós pertencentes ao mesmo tipo de modelo dentro do contexto atual. Observando o conceito de contextos aninhados (Figura 3.8), é razoável que os itens de um mesmo modelo sejam organizados em contextos, assim como é feito atualmente com nós de um mesmo assunto. Dessa forma, elimina-se a necessidade da criação de âncoras para navegação seqüencial dentro do mesmo contexto.

Os botões Modelos Funcionais e Modelos Estruturais mostrariam uma lista com os nós da hiperbase de acordo com o atributo Abstração. Esse "índice" de modelos permitiria a navegação dentro de um único nível de abstração, sem que o usuário final da hiperbase precise ter conhecimento de quais documentos são considerados funcionais e quais são considerados estruturais.

O botão Índice ativaria, dentro do contexto atual, o nó que tiver o atributo Tipo de Modelo sendo Índice. Caso não exista um nó índice no contexto atual de navegação, será ativado o índice principal, ou seja, do maior contexto que englobe o contexto atual. 
Finalmente, o botão Relacionamentos acionaria uma janela contendo uma lista dos nós que possuem relacionamento com o nó atual. Esse controle de navegação possibilita que sejam estabelecidos links entre modelos diferentes, sem a inserção de novas âncoras para o estabelecimento do link. Por exemplo, a partir de um nó Operação, poder-se-ia navegar para o Item de Implementação que lista os procedimentos que implementam a operação do nó atual.

Um conceito importante para o SASHE é o de roteiros de navegação, pois no domínio de ensino, o roteiro permite que o professor limite o contexto de navegação do estudante com o objetivo de guia-lo pela hiperbase quando este a estiver navegando. No domínio de engenharia reversa, o conceito de roteiro deixa de ser necessário, pois os próprios controles de navegação propostos (Figura 3.14) já fornecem recursos que guiam o usuário pela hiperbase.

Embora seja definida uma sequiência de etapas a serem seguidas durante desenvolvimento do processo de engenharia reversa (por exemplo, os passos propostos pelo Fusion-RE/I), após ter a documentação resultante inserida na hiperbase, não existe uma seqüência especificada para o acesso aos documentos. Dessa forma, não há como delimitar o contexto de navegação da documentação, sendo que o usuário deve ter a possibilidade de navegar em todos os contextos, guiado pela necessidade de informação que estiver buscando.

Os atributos e controles de navegação propostos nesta seção foram baseados na experiência adquirida durante a interação com SASHE para sua "auto-documentação". Essa proposta foi elaborada a partir de problemas encontrados na utilização do SASHE para a manipulação de documentos que não fossem didáticos. Dessa maneira, a proposta apresentada se restringiu aos aspectos funcionais do sistema, deixando os aspectos de implementação do sistema como trabalho futuro.

O grande volume de documentação envolvida num processo de engenharia reversa foi um dos motivadores para a utilização de um sistema hipermídia neste trabalho. A realização do estudo de caso com o sistema SASHE comprovou a necessidade de um meio de acesso às informações recuperadas que fosse mais ágil e eficiente. Num sistema hipermídia, além dos links estabelecidos facilitarem a manipulação dos documentos, também explicitam seus relacionamentos, orientando tanto o usuário final como o engenheiro construtor ou mantenedor da hiperbase. 


\subsection{Considerações Finais}

Neste capítulo foram apresentadas as considerações sobre como os sistemas hipermídia têm apoiado atividades que englobam a manipulação de grandes volumes de informação que não possuem uma estrutura seqüencial para essas informações, entre elas a engenharia de software.

Também foi introduzido na Seção 3.1 o sistema hipermídia SASHE, que foi o sistema alvo para o processo de engenharia reversa e também foi o sistema utilizado para o armazenamento das informações recuperadas.

Na Seção 3.2 foi mostrado um estudo feito sobre o método de modelagem de aplicações hipermídia OOHDM, e na Seção 3.3 foi apresentada a modelagem conceitual realizada para o domínio de engenharia reversa, segundo o método Fusion-RE/I, utilizando-se o método OOHDM.

A hiperbase construída no sistema SASHE com os documentos resultantes do processo de engenharia reversa foi apresentada na Seção 3.4 e na sequiência, na Seção 3.5 foram propostas modificações ao SASHE, para que o sistema passe a ser adequado ao domínio de engenharia reversa.

No próximo capítulo é mostrado um resumo dos documentos recuperados durante o processo de engenharia reversa aplicado ao SASHE, assim como algumas métricas registradas durante o processo. Também são comentados os problemas encontrados no desenvolvimento da engenharia reversa. 


\section{Capítulo 4}

\section{Engenharia Reversa aplicada ao sistema SASHE}

Este capítulo apresenta os produtos obtidos como resultado do processo de engenharia reversa aplicado ao sistema SASHE. Conforme descrito na Seção 3.1, o sistema SASHE é um sistema para autoria e navegação de documentos hipermídia, cujo domínio de aplicação é o ensino. Baseado no Modelo de Contextos Aninhados (MCA) (Casanova et al., 1991), o SASHE tem como característica permitir que um autor de hiperdocumentos possa qualificar e organizar os elementos constituintes (nós) do documento, de modo que o sistema resultante contenha funções adicionais à navegação tradicional. Tais funções incluem recursos para a localização contextual do leitor, bem como estratégias instrucionais dependentes dos valores dos atributos dos nós (Nunes et al., 1997b).

Funcionalmente, puderam ser identificados uma hiperbase, um módulo de autoria e um módulo de navegação. Toda a funcionalidade do sistema foi documentada através dos modelos propostos pelo método Fusion-RE/I para a etapa de recuperação funcional: o Modelo de Ciclo de Vida, o Modelo de Operações e o Modelo de Objetos (em UML). Esses modelos foram recuperados exclusivamente através da interação com a interface, sem nenhuma visão do códigofonte.

Em nível de implementação, o sistema é composto pela hiperbase, um gerenciador da hiperbase, uma biblioteca de classes e uma interface. Na análise do código fonte do sistema 
SASHE foram manipuladas cerca de dez mil linhas de código $\mathrm{C}++$, que implementam o gerenciador da hiperbase e as estruturas para o suporte do MCA, e cerca de quatro mil linhas de código Delphi, implementando a interface do sistema. A interface entre o gerenciador da hiperbase e a interface usuário/computador se dá através de uma DLL, a qual exporta as funções de manipulação da hiperbase para a interface.

No total, foram analisados oitenta e quatro (84) arquivos de código C++ e vinte e um (21) arquivos de código Delphi.

$\mathrm{Na}$ próxima seção são apresentados exemplos tirados do conjunto de documentos recuperados através da aplicação do método Fusion-RE/I ao sistema hipermídia SASHE. A documentação completa encontra-se em Feltrim e Fortes (1999). Na Seção 4.2 são mostradas algumas métricas do processo desenvolvido e na Seção 4.3 são então citados os problemas enfrentados durante a realização da engenharia reversa.

\subsection{Resumo dos resultados da Engenharia Reversa}

Devido ao grande volume de documentação gerada como produto do processo de engenharia reversa, nesta seção são apresentadas apenas partes dos documentos, com o intuito de propiciar uma visão geral dos resultados obtidos. Nas subseções 4.1.1, 4.1.2 e 4.1.3 são mostrados documentos componentes da visão funcional, recuperados na primeira etapa do método. No restante das subseções são apresentados documentos recuperados na segunda etapa do método, que compõem a visão estrutural do software.

\subsubsection{Modelo de Ciclo de Vida}

A partir do uso intensivo do sistema, do estudo da documentação existente e das entrevistas com os usuários pôde-se definir a sequiência de operações permitidas e os eventos de entrada e de saída que o sistema aceita.

O Modelo de Ciclo de Vida é composto por expressões regulares que definem a sequiência de eventos a que o sistema pode interagir durante todo o período que está em execução. Ele 
descreve o comportamento completo de como o sistema se comunica com o ambiente, desde sua inicialização até o seu término (Masiero, 1995), (Penteado, 1996).

O Modelo de Ciclo de Vida construído para o SASHE contém cerca de cinqüenta e cinco (55) sentenças compondo as seqüências de operações permitidas no sistema, incluindo ambos os módulos ${ }^{5}$ que compõem o software: o módulo do Professor e o módulo do Estudante.

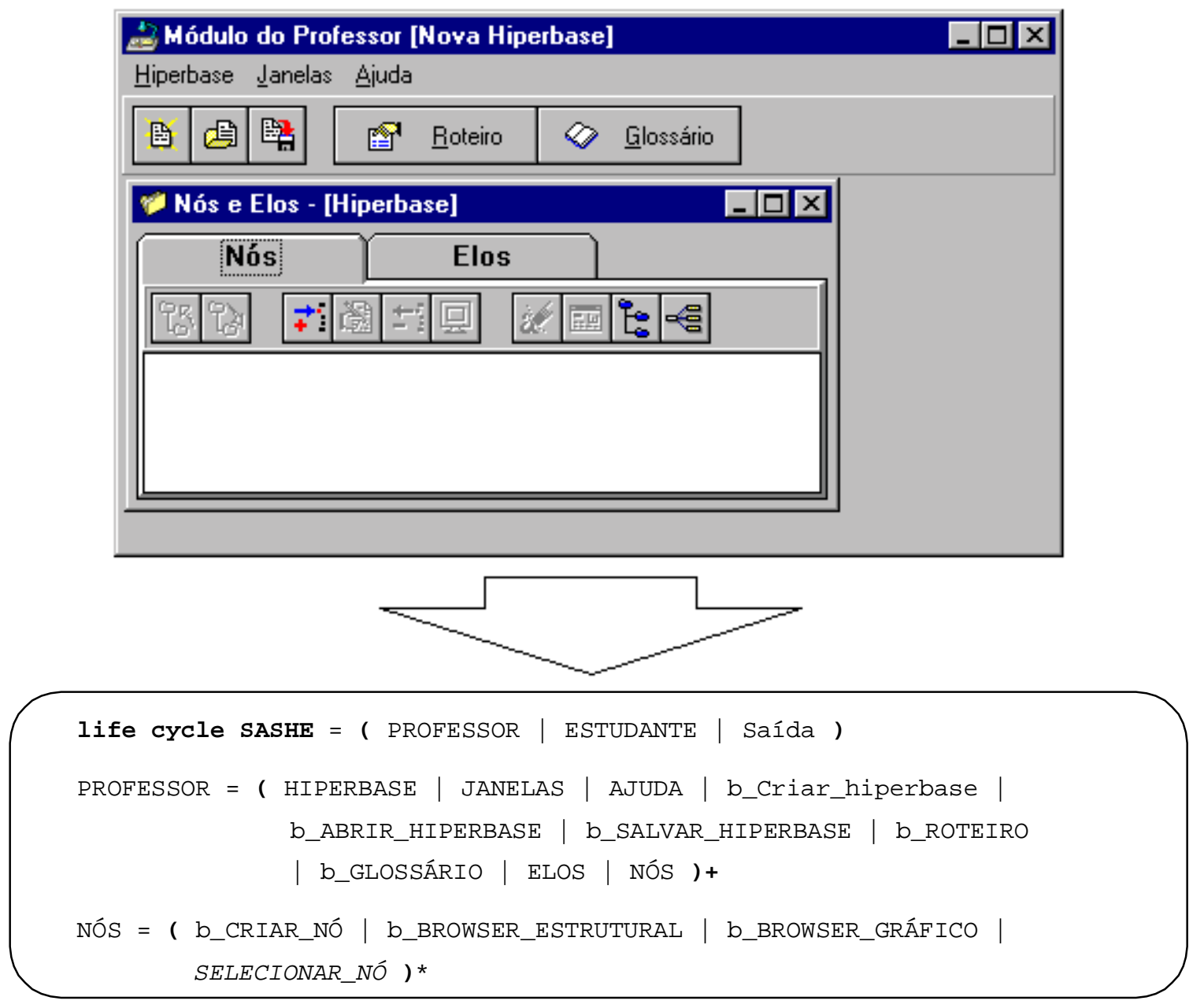

Figura 4.1 - Parte inicial do Modelo de Ciclo de Vida do SASHE

A primeira sentença que aparece no ciclo de vida, exemplificada no texto apresentado na parte inferior da Figura 4.1, descreve a tela de entrada do SASHE, onde existem apenas três opções: Professor (Módulo de Autoria), Estudante (Módulo de Navegação) e Saída.

A segunda e terceira sentenças descrevem a interface do módulo de autoria, conforme mostrado na Figura 4.1. Nesta figura é apresentada a tela principal desse módulo, e as sentenças definem a seqüência de comandos possíveis a partir desse ponto de interação do software. 


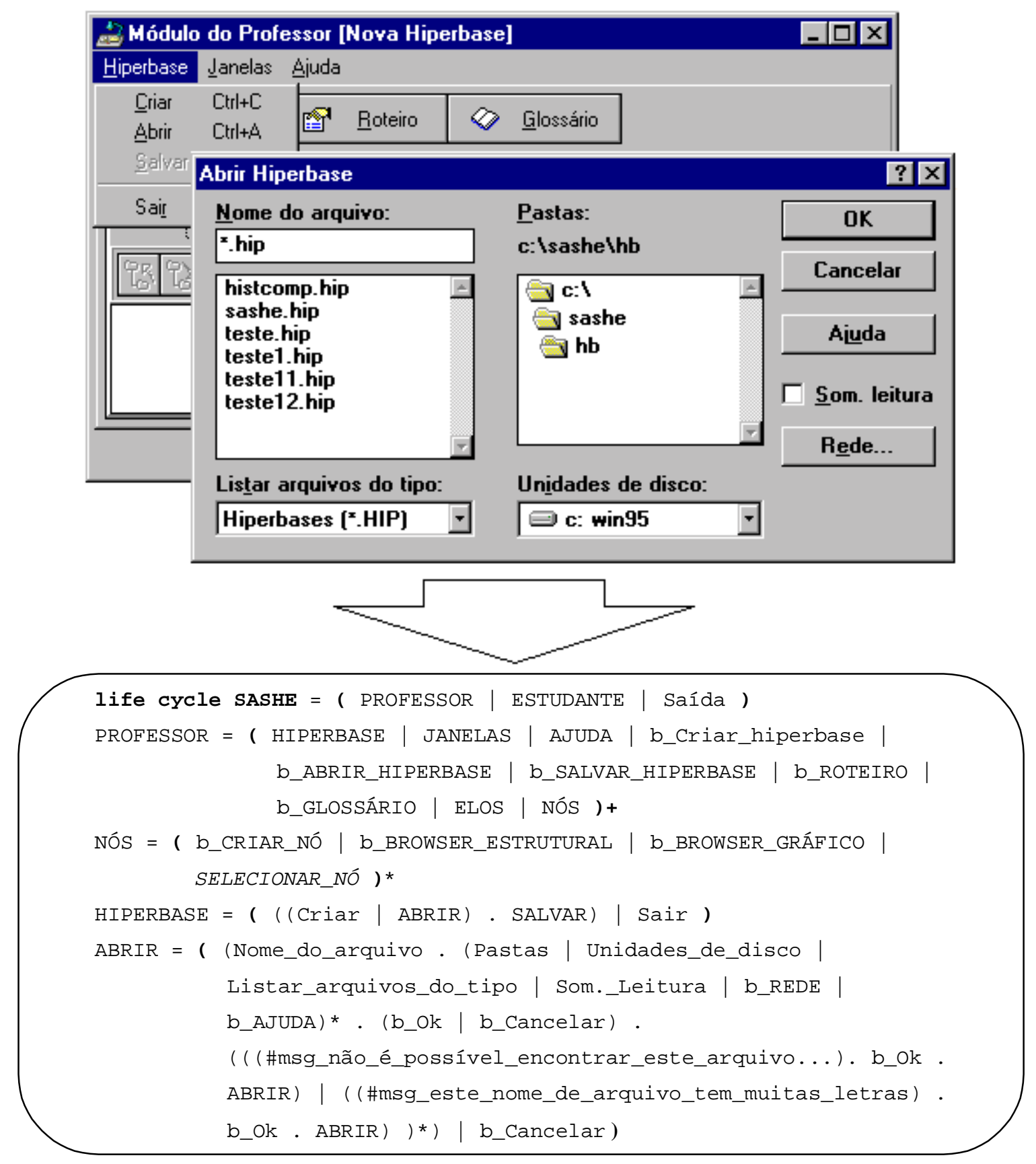

Figura 4.2 - Refinamento da opção "Hiperbase" e da operação "Abrir"

Para facilitar a compreensão do modelo, foi adotada uma convenção para a escrita do ciclo de vida neste trabalho. Os nomes que aparecem em itálico não são constantes da interface do sistema, ou seja, não aparecem de fato na interface. Esses nomes, ou são ações do usuário, como selecionar elementos que aparecem na hiperbase, ou são recursos de abstração para facilitar a escrita e o entendimento do ciclo de vida. Os nomes que são precedidos de "b_" aparecem na

\footnotetext{
${ }^{5}$ O SASHE utiliza a terminologia "módulo" para diferenciar os modos de interação do sistema: um para o Professor e um para o Estudante.
} 
interface como botões, ao passo que os outros são opções de menu. Quando um nome (uma opção da interface) aparece em letras maiúsculas, é porque existe uma sentença que descreve com mais detalhes essa opção. Os nomes em letras minúsculas são símbolos terminais, que podem ser uma operação ou uma entrada.

A Figura 4.2 mostra um refinamento em dois níveis, pois além da sentença refinando a opção de menu Hiperbase, é apresentado o refinamento da operação "Abrir", pertencente ao menu "Hiperbase". A Figura 4.2 apresenta também a tela para a abertura de uma hiperbase. Note-se que todas as entradas requeridas na interface estão descritas nas sentenças de ciclo de vida. Na sentença que descreve especificamente a operação "Abrir", existe uma chamada a própria operação, caracterizando uma recursão. Isso se deve ao fato da janela para a abertura de hiperbase continuar ativa caso um erro de abertura do arquivo ocorra. Dessa forma, o usuário só volta à janela anterior quando a operação for bem sucedida ou quando for cancelada através do botão "Cancelar".

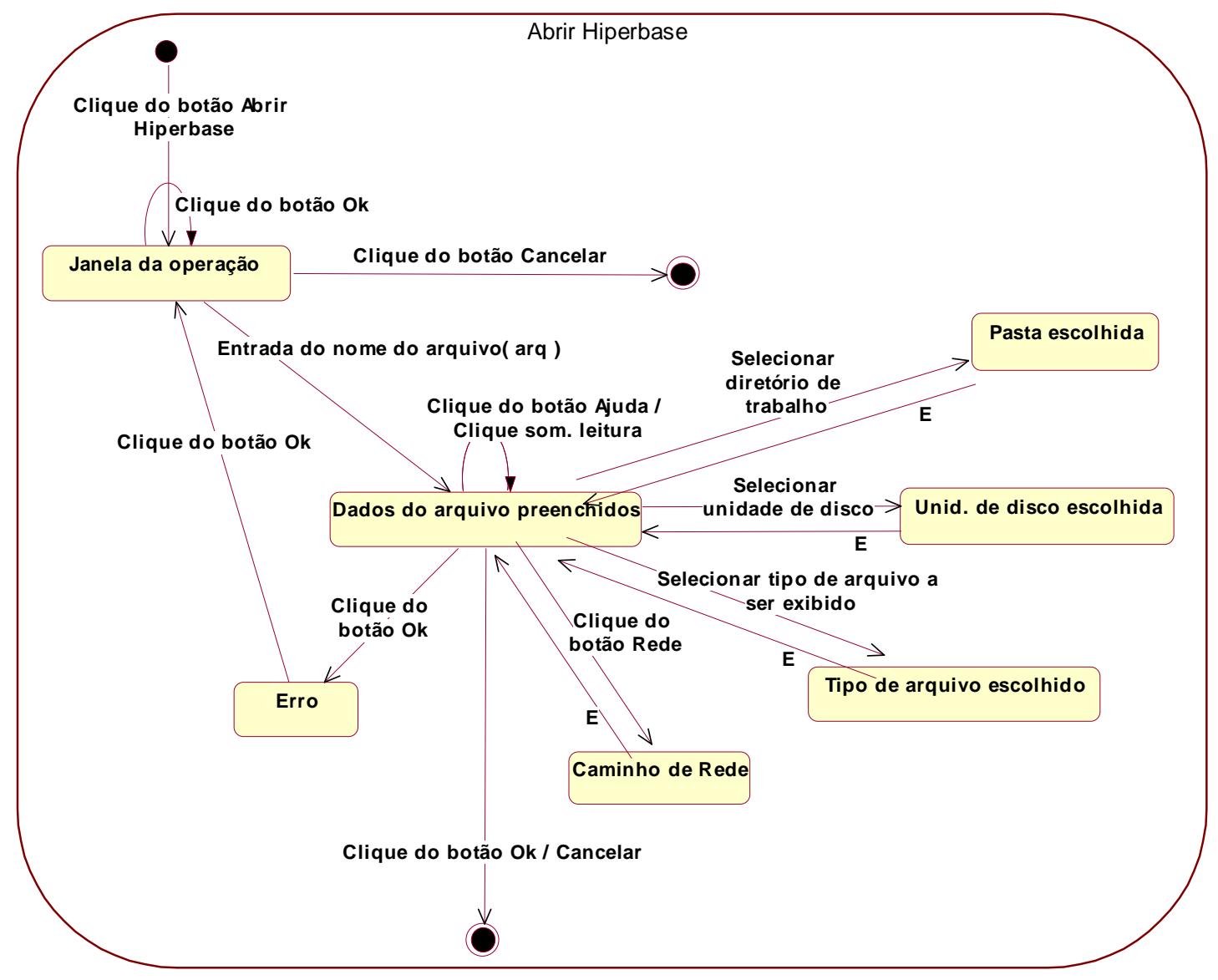

Figura 4.3 - Diagrama de transição de estado para a operação “Abrir Hiperbase” 
O mesmo procedimento de refinamento foi aplicado a todas as opções apresentadas na interface do software, até que todas as seqüências de operações possíveis estivessem descritas no modelo.

Para facilitar a verificação da corretitude do Modelo de Ciclo de Vida, foram construídos Diagramas de Transição de Estado (DTE), representando cada uma das sentenças presentes no modelo. Os DTE's foram construídos com o auxílio da ferramenta Rational Rose (Rational, 1999), segundo a notação UML. Esses diagramas propiciaram uma melhor visualização das seqüências de operações descritas nas sentenças do ciclo de vida, facilitando assim sua verificação. A Figura 4.3 mostra o DTE construído para a operação “Abrir Hiperbase”.

\subsubsection{Modelo de Operações}

O Modelo de Operações é decorrente do Modelo de Ciclo de Vida. Esse modelo tem como objetivo especificar o comportamento de uma operação de forma declarativa em termos das mudanças de estado do sistema e eventual geração de eventos de saída (Masiero, 1995). Conforme abordado no Capítulo 2, cada operação identificada no Modelo de Ciclo de Vida é descrita individualmente através de um formulário textual, descrito na Figura 2.4.

Dessa forma, o Modelo de Operações é expresso por uma série de esquemas, sendo que existirá, no mínimo, um esquema para cada operação do sistema (Coleman et al., 1996). Foram identificadas no ciclo de vida construído para o sistema SASHE sessenta e duas (62) operações, sendo que cada uma delas foi estudada exaustivamente para que pudesse ser descrita de acordo com os requisitos do esquema proposto pelo método. Todos os esquemas juntos compõem o Modelo de Operações.

As informações representadas nesse modelo foram quase totalmente recuperadas a partir da interação com o software, pois na documentação disponível na ocasião, havia muito pouca menção ao comportamento das operações em si. As informações conseguidas nas entrevistas com os usuários do sistema foram de grande ajuda, complementando os resultados de descrição obtidos e até mesmo orientando a interação com o software. 
$\mathrm{Na}$ elaboração desse modelo foram analisadas também as ações do sistema que não são visíveis na interface, por serem ações internas do sistema, como criação e modificação de arquivos, resultantes das operações realizadas pelo usuário.

O Quadro 4.1 apresenta a descrição (um dos esquemas) feita para a operação "Abrir" do menu "Hiperbase".

Quadro 4.1 - Esquema descrevendo a operação "Abrir" do menu "Hiperbase"

\begin{tabular}{|l|l|}
\hline Operação: & Abrir \\
\hline Descrição: & Abre uma hiperbase já existente \\
\hline Lê: & $\begin{array}{l}\text { Nome do arquivo; diretório; drive; somente leitura; botão ok; } \\
\text { botão cancelar }\end{array}$ \\
\hline Modifica: & $\begin{array}{l}\text { Agente externo: }\{\text { msg não é possível encontrar este arquivo\}; } \\
\text { Agente externo: }\{\text { msg este nome de arquivo tem muitas letras }\}\end{array}$ \\
\hline Envia: & $\begin{array}{l}\text { Se botão cancela, operação é cancelada } \\
\text { Se arquivo existente, a hiperbase é aberta } \\
\text { Assume: } \\
\text { Resultado nada, e continua na operação Abrir hiperbase } \\
\text { Se nome de arquivo tem mais de } 8 \text { letras, mensagem de nome com } \\
\text { muitas letras é enviada, e continua na operação Abrir hiperbase }\end{array}$ \\
\hline
\end{tabular}

\subsubsection{Modelo de Objetos}

Para a elaboração do Modelo de Objetos no Fusion-RE/I primeiramente definem-se os assuntos relacionados com a funcionalidade do sistema. Esses assuntos são denominados Temas (Costa, 1997). Tendo definido os Temas, é feito um agrupamento das operações de acordo com os Temas a que se referem. Assim, ao final tem-se uma lista de Temas e as operações dos Temas. Finalmente, para cada um dos Temas definidos, é construído um Modelo de Objetos.

Para que se pudesse definir os Temas foi necessária uma análise das informações recuperadas na primeira etapa (Obtenção de Informações Existentes Sobre o Sistema) e também das abstrações vindas dos modelos de ciclo de vida e de operações. Essa é uma das tarefas mais subjetivas do método Fusion-RE/I e é de fundamental importância para a aplicação do método (Costa, 1997). De fato, constatamos a subjetividade da definição dos Temas, o que nos levou a várias tentativas de possíveis Temas, antes de decidirmos quais seriam os Temas definitivos do sistema. 


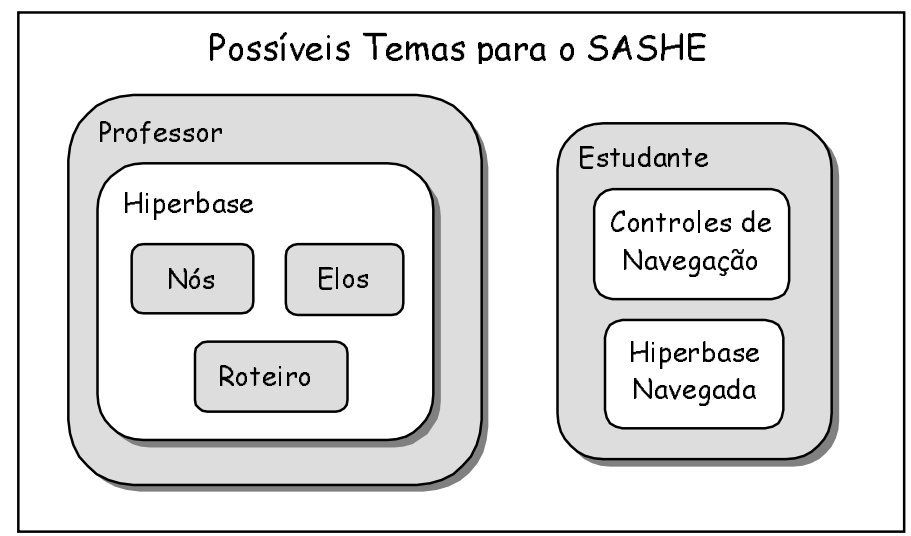

Figura 4.4 - Primeira tentativa de definição de Temas para o SASHE

Após uma primeira tentativa de fazer o agrupamento das operações identificadas nos Temas propostos (Figura 4.4), percebeu-se que os Temas definidos ainda não eram adequados, pois algumas operações não se encaixavam em nenhum dos Temas, e alguns Temas não continham nenhuma operação. Além disso, os Temas definidos não evoluíam para os modelos de objetos. Sendo assim, analisando cuidadosamente as operações e seus relacionamentos propusemos dois Temas para o sistema: Autoria e Navegação, o que nos pareceu adequado (Figura 4.5). Foi feito então a agrupamento de todas as operações identificadas no Modelo de Operações em um dos dois Temas.

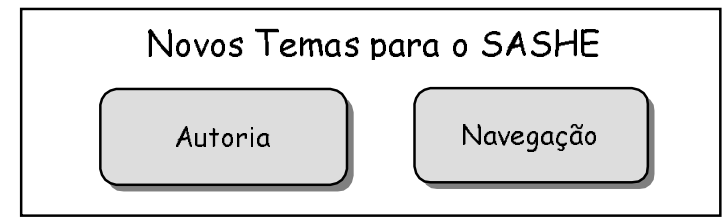

Figura 4.5 - Temas propostos para o SASHE

Após esse agrupamento, as operações foram novamente analisadas, buscando identificar componentes que constituíssem o Modelo de Objetos, ou seja, classes, relacionamentos, atributos, e possíveis agregações, especializações e generalizações. Dessa forma foram construídos dois modelos de objetos, um para o tema Autoria (Figura 4.6) e um para o tema Navegação (Figura 4.7).

Para a edição dos modelos de objetos foi utilizada a ferramenta Rational Rose (Rational, 1999). Sendo que essa ferramenta suporta a modelagem em UML, os modelos de objetos já foram construídos utilizando essa notação. Dessa forma, embora o Fusion-RE/I se baseie na notação do método Fusion, os modelos das Figuras 4.6 e 4.7 são apresentados em UML. 
É importante ressaltar que esses modelos foram propostos baseados apenas na visão funcional do software, conseguida através da interação exaustiva com o software. Embora não conste no método Fusion-RE/I, esperávamos que após a recuperação das informações estruturais do software esses modelos de objetos sofressem algumas alterações, para que se tornassem consistentes com a estrutura do software, porém esperava-se que essas alterações fossem pequenas. De fato, os modelos de objetos sofreram modificações razoáveis em relação ao Modelo de Objetos recuperado a partir do código do sistema.

A Figura 4.8 apresenta esse modelo recuperado do código fonte, retratando o Modelo de Objetos Real, isto é, o verdadeiramente implementado no sistema. Nessa modelagem não foram considerados aspectos de interface, direcionando o foco para o sistema Hip/Windows (Nunes et al., 1996) e o módulo de navegação do SASHE, isto é, não foram incluídas no modelo classes que implementam janelas, barras de rolagem, etc. No modelo apresentado na Figura 4.8 também não estão representadas dez (10) classes, utilizadas para a manipulação de som, imagem e vídeo, e que não estão no modelo por não influenciarem a estrutura geral do sistema. As classes que aparecem limitadas por uma linha pontilhada, fazem parte da implementação do browser gráfico.

Com o término da recuperação do Modelo de Ciclo de Vida, do Modelo de Operações e dos modelos de objetos, encerra-se a primeira etapa do método Fusion-RE/I, que recupera visões funcionais do software unicamente através da interação com a interface do sistema. Na próxima etapa são recuperadas informações estruturais através da análise do código-fonte do software. Os documentos resultantes dessa nova etapa são apresentados nas próximas subseções. 


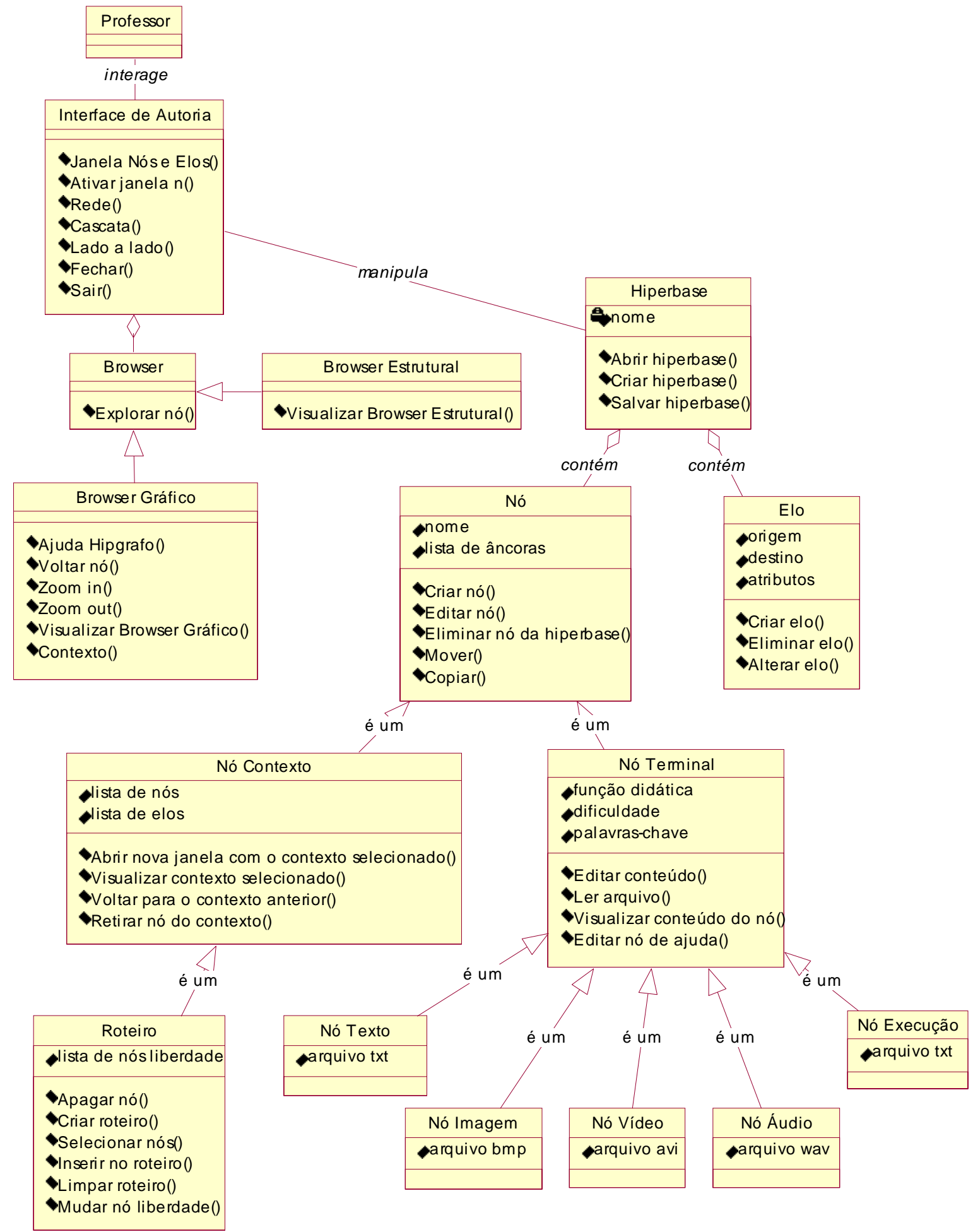

Figura 4.6 - Modelo de Objetos para o tema Autoria 


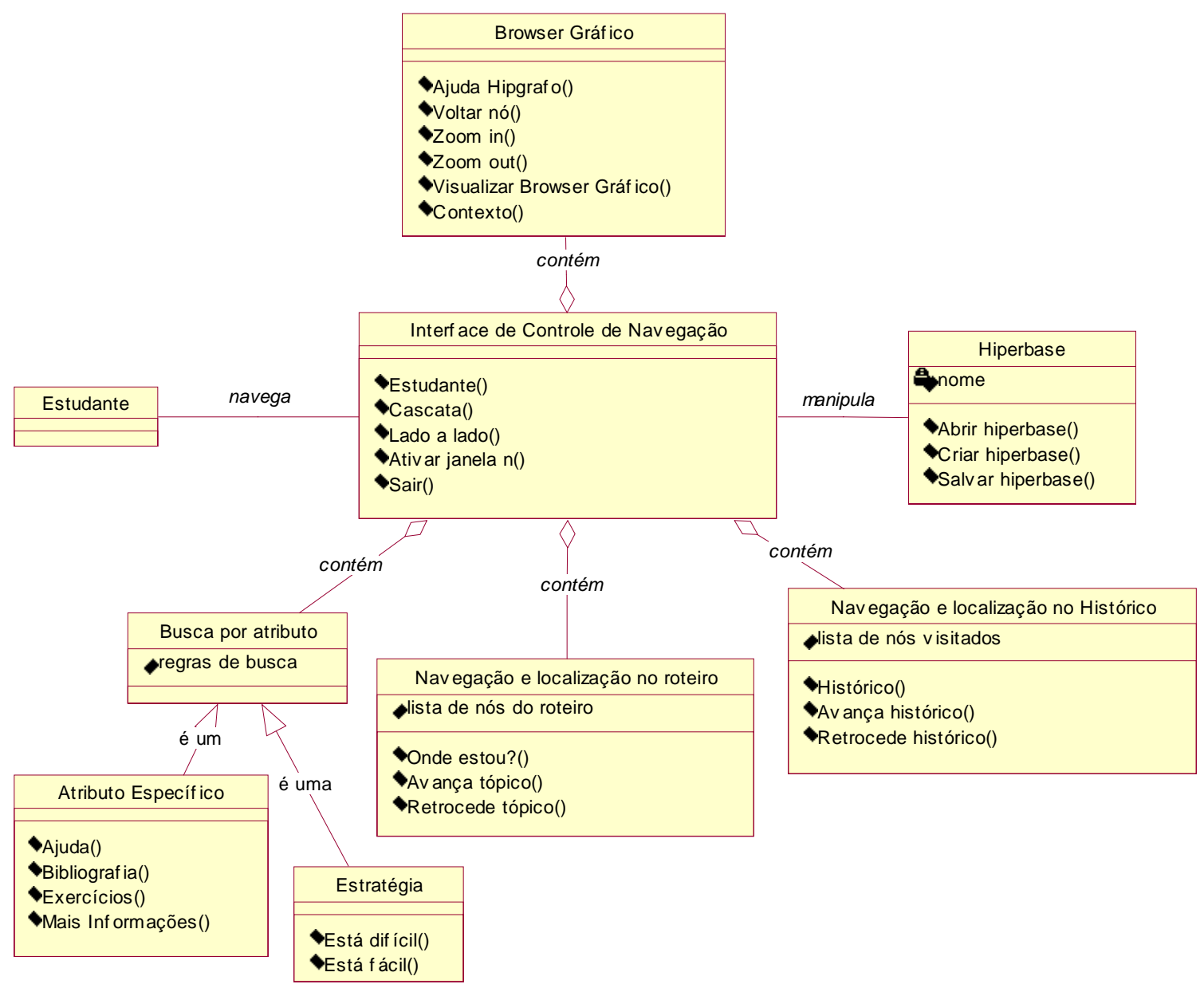

Figura 4.7 - Modelo de Objetos para o tema Navegação 


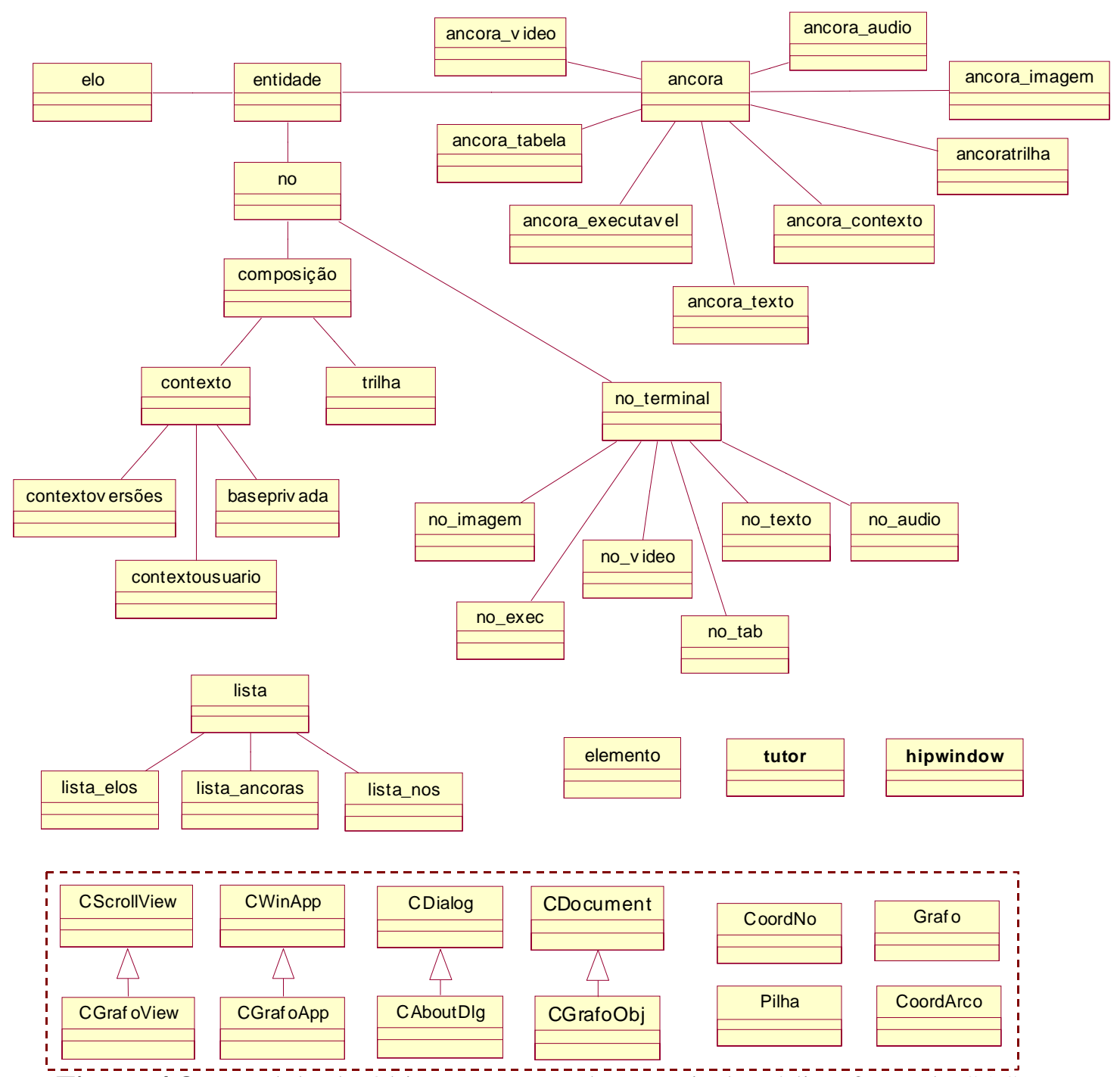

Figura 4.8 - Modelo de Objetos recuperado a partir do código fonte do SASHE

\subsubsection{Quadro de Chamadas}

Esse quadro foi elaborado para cada arquivo de código fonte do sistema, apresentando os procedimentos contidos no arquivo, suas respectivas funcionalidades e os procedimentos utilizados (chamados) e utilizadores (chamados por).

Parte das informações de descrição (funcionalidade) dos procedimentos foram conseguidas a partir de comentários no código fonte. Os procedimentos chamados por cada procedimento foram obtidos pela análise do próprio código, enquanto que os procedimentos utilizadores (chamados por) foram obtidos através dos próprios Quadros de Chamadas elaborados e da análise do código fonte. 
A construção desse quadro de forma manual requer um esforço muito grande. Dessa maneira, foi utilizada uma ferramenta de apoio à engenharia reversa para código $\mathrm{C}++$, a Understand for C/C++ (STI, 1999). Através de um sistema de busca eficiente proporcionado pela ferramenta, foi possível rastrear de forma mais ágil as chamadas a procedimentos. Essa ferramenta também auxilia na recuperação do Modelo de Objetos implementado, traçando um grafo de herança para cada classe do sistema.

Nesta etapa, foi necessária a recuperação do Modelo de Objetos implementado, através da análise do código fonte (Figura 4.8), para a composição do Quadro de Chamadas. Essa necessidade se deu por uma série de fatores decorrentes do paradigma de implementação do sistema, como herança, ponteiros dinâmicos, entre outros. Esses fatores são detalhados na Seção 4.3, onde são descritas as principais dificuldades encontradas para a realização da engenharia reversa do SASHE.

Foram construídos setenta e nove (79) quadros para os arquivos C++ e vinte e um (21) quadros para os arquivos Delphi, num total de 100 Quadros de Chamadas. Existem cinco (5) arquivos C++ que não possuem Quadros de Chamadas, pois são arquivos de definição de constantes e importação de bibliotecas, não contendo nenhum procedimento. Também na instalação da versão 1.0 do SASHE são encontrados treze (13) arquivos Delphi para os quais não foram elaborados Quadros de Chamadas. Esses treze arquivos não são de fato utilizados na interface do SASHE, porém não foram retirados do projeto do sistema. Na nova versão 2.0 esse problema já foi corrigido.

O Quadro 4.2 mostra um dos Quadros de Chamadas elaborados para os arquivos do sistema SASHE, referente ao arquivo elo.cpp. Existe um quadro como este para cada arquivo de código fonte do sistema (Feltrim; Fortes, 1999). Os números que aparecem no quadro entre parênteses correspondem ao número da linha em que aquele código se apresenta. Os nomes de arquivos que aparecem no início da linha de cada procedimento da seção "Chamado por" correspondem aos arquivos em que cada chamada é feita. 


\section{Quadro 4.2 - Quadro de Chamadas recuperado do arquivo elo.cpp}

Sistema: SASHE

Arquivo: Hyperprop \elo.cpp

Procedimento:

(15) elo: :elo(int id) :

entidade (id)

Diretório/Arquivo: elo.cpp

\section{Procedimento:}

(23) elo: :elo(int id, No *orig,

char *ani_orig, int ind_or, No

*dest, char *ani_dest, int

ind_dest, int simul, int mostr) : entidade (id)

Diretório/Arquivo: elo.cpp

\section{Procedimento:}

(41) int elo: grava_elo(FILE *fp)

Diretório/Arquivo: elo.cpp

\section{Procedimento:}

(56) int elo: :recupera_elo(FILE *fp)

Diretório/Arquivo: elo.cpp

\section{Descrição:}

Construtor utilizado apenas quando o elo é

carregado do arquivo

Chama:

(15) entidade (id)

Chamado por:

List_elo.cpp \(61) int lista_elos: :recupera(No *pno, FILE *fp)

\section{Descrição:}

Construtor utilizado pela interface

\section{Chama:}

(23) entidade (id)

\section{Chamado por:}

Trilha.cpp \(62) int trilha: :insere_no(No *pno, contexto *pno_liberdade)

Trilha.cpp \ (97) int trilha::insere_no(No *pno) Trilha.cpp \ (131) int trilha: :insere_no(No *pno, contexto *pno_liberdade, int posicao)

Trilha.cpp \(164) int trilha: :insere_no(No *pno, int posicao)

Hipger.cppl (1517) extern "C" int FAR PASCAL _export cria_elo(char *nome_contexto, int id_elo, char *origem, int anc_origem, char *destino, int anc_destino, int simultaneo, int mostra_conteudo)

\section{Descrição:}

Grava o identificador do elo, nome do nó origem, identificador da âncora origem, nome do nó destino e o identificador da âncora destino Chama:

(43) obtem_identificador()

(44) obtem_origem()

( 44 ) obtem_aninhamento_origem ()

(45) obtem_destino()

(45) obtem_aninhamento_destino()

Chamado por:

List_elo.cpp \(51) int lista_elos::grava(FILE *fp)

\section{Descrição:}

O identicador do elo foi recuperada pela lista de elos. Recupera do arquivo o nome do nó origem, identificador da âncora origem, nome do nó destino e o identificador da âncora destino.

\section{Chama:}

(60) fscanf(fp, "\t\torigem(\%s, \" ", pnome)

(61) hb.Retorna (pnome)

(63) fscanf(fp, "\%s\",", aninhamento_origem)

(64) fscanf(fp, "\%d) \n", \&ancora_no_origem)

(65) fscanf(fp, "\t\tDestino (\%s, $\backslash " "$, pnome)

(66) hb.Retorna (pnome)

(68) fscanf (fp, "\%s\",", aninhamento_destino)

(69) fscanf (fp, "\%d) \n", \&ancora_no_destino)

(70) fscanf(fp, "\t\tAtributos (\%d,", \&simultaneo)

(71) fscanf (fp, "\%d) $\backslash \mathrm{n} "$,

\&mostra_conteudo_contexto)

Chamado por:

List_elo.cpp \(61) int lista_elos: :recupera (No *pno, FILE *fp) 


\subsubsection{Quadro Índice de Procedimentos}

Esse quadro apresenta todos os procedimentos da implementação do sistema em ordem alfabética, com as respectivas localizações (arquivo e diretório).

Para a elaboração desse quadro foram utilizados todos os Quadros de Chamadas obtidos anteriormente. Esse quadro também pode ser gerado automaticamente por uma ferramenta de apoio a engenharia reversa, como a já citada (STI, 1999). No caso deste trabalho especificamente, esse quadro foi especialmente útil, pois serviu como índice de acesso aos procedimentos na construção da hiperbase.

Parte do Quadro Índice de Procedimentos obtido para os arquivos C++ é apresentada no Quadro 4.3.

Quadro 4.3 - Parte do Quadro Índice para os procedimentos C++

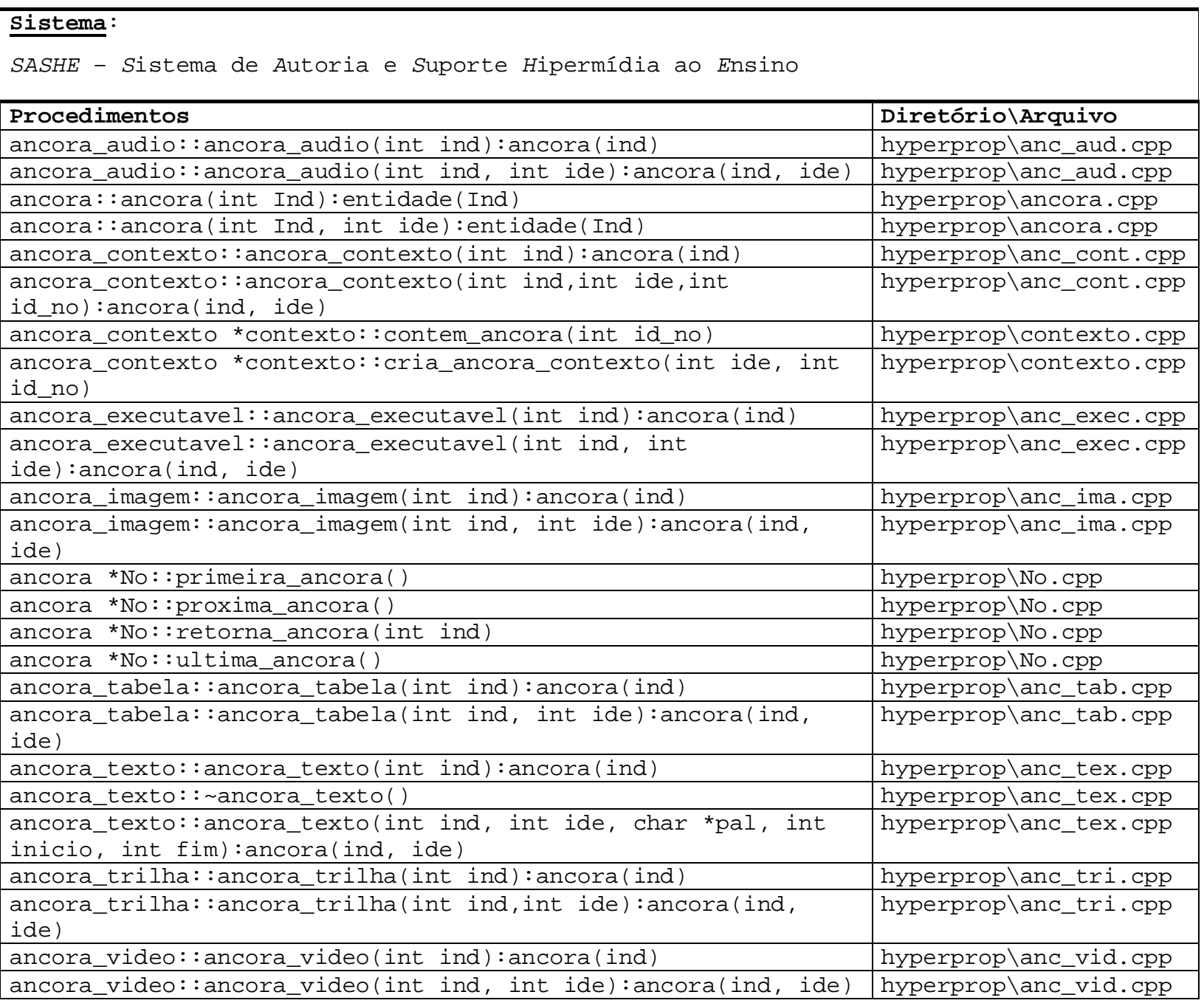


Para facilitar o manuseio do documento, e também devido ao fato do software ser implementado em duas linguagens de programação, optamos por dividir o índice de procedimentos em dois quadros: um para os arquivos $\mathrm{C}++$ e outro para os arquivos Delphi.

\subsubsection{Quadro de Operações-Procedimentos de Implementação}

Nesse quadro estão identificados os procedimentos que implementam cada uma das operações disponíveis na interface do SASHE. Nas primeiras colunas do quadro são colocadas as opções do menu e as operações de cada opção (descrição da interface). Na próxima coluna são colocados os procedimentos que implementam cada operação, de acordo com a hierarquia de chamadas descrita no Quadro de Chamadas.

De acordo com a definição apresentada em Costa (1997), cada um dos procedimentos deve ser classificado, de acordo com funcionalidade, como implementação da interface ou relacionado a um dos Temas definidos anteriormente. Isso é feito através de colunas, sendo uma para a interface e uma para cada tema definido.

Também em Costa (1997), é citado que o nível de detalhamento das chamadas de procedimentos, descritos nesse quadro, depende do objetivo do processo de engenharia reversa em realização.

No caso deste trabalho, a documentação recuperada será utilizada na re-engenharia do sistema para mudança do domínio de aplicação. Como o foco principal dessa re-engenharia se concentra na interface do sistema, o Quadro de Operações-Procedimentos de Implementação está detalhado até o nível das chamadas das operações exportadas pela DLL. Outro fato é que, devido à natureza do software (módulos distintos) e dos Temas definidos, os quadros puderam ser separados por Temas (um quadro para o tema Autoria e um quadro para o tema Navegação), proporcionando também uma melhor visualização.

Sendo que os quadros estão separados por Temas, e estão detalhados apenas os procedimentos de implementação da interface, com exceção das chamadas a DLL, as referidas colunas de classificação foram excluídas. O Quadro 4.4 apresenta parte do Quadro de Operações-Procedimentos de Implementação recuperado, mostrando operações do tema Autoria. 
Quadro 4.4 - Parte do Quadro de Operações-Procedimentos de Implementação

\begin{tabular}{|c|c|c|}
\hline \multicolumn{3}{|r|}{ Opções da Interface para o tema AUTORIA } \\
\hline Opções & Operações & Procedimentos \\
\hline Hiperbase & $\begin{array}{l}\text { Criar } \\
\text { Abrir } \\
\text { Salvar } \\
\text { Sair }\end{array}$ & $\begin{array}{l}\text { To_fo_Principal.o_bu_CriarHiperbaseClick(Sender: TObject); } \\
\text { To_fo_Principal.Ler_DLL; } \\
\text { extern "C" int FAR PASCAL_export cria_base_privada(char *nome); } \\
\text { To_fo_Principal.o_bu_AbrirHiperbaseClick(Sender: Tobject); } \\
\text { To_fo_Principal.Ler_DLL; } \\
\text { extern "C" int FAR PASCAL_export recuperar(char *nome); } \\
\text { To_fo_Principal.o_bu_GravarHiperbaseClick(Sender: TObject); } \\
\text { extern "C" int FAR PASCAL_export salvar(char *nome); } \\
\text { To_fo_Principal.o_mn_SairClick(Sender: Tobject); } \\
\text { To_fo_Principal.FormCloseQuery(Sender: TObject; var Canclose: } \\
\text { Boolean); }\end{array}$ \\
\hline Janelas & Lado_a_lado & ( \\
\hline
\end{tabular}

\subsection{Métricas do processo de Engenharia Reversa realizado}

Durante o andamento da engenharia reversa foram registradas algumas medidas sobre o processo em desenvolvimento e sobre os produtos gerados, com o intuito de dar uma noção do esforço requerido e de revelar informações implícitas à documentação.

O Quadro 4.5 apresenta um resumo de toda a documentação recuperada em totais de elementos por documento, dimensionando cada um dos documentos recuperados. Também é mostrada a medida do esforço de tempo dedicado à recuperação.

Quadro 4.5 - Resumo dos produtos obtidos, em totais

\begin{tabular}{|c|c|c|}
\hline Modelos & \multicolumn{2}{|c|}{ Totais } \\
\hline Modelo de Ciclo de Vida & \multicolumn{2}{|c|}{55 sentenças } \\
\hline Modelo de Operações & \multicolumn{2}{|c|}{62 operações } \\
\hline Modelo de Objetos & \multicolumn{2}{|c|}{2 modelos (24 classes no total) } \\
\hline \multicolumn{3}{|c|}{ Esforço de tempo para recuperação funcional: $\cong 2$ meses } \\
\hline Quadros & \multicolumn{2}{|c|}{ Totais } \\
\hline Quadro de Chamadas de Procedimentos & $\begin{array}{l}84 \text { arquivos } / 722 \\
\text { procedimentos } \mathrm{C}++\end{array}$ & $\begin{array}{c}21 \text { arquivos/ } 165 \\
\text { procedimentos Delphi }\end{array}$ \\
\hline Quadro de Índice de Procedimentos & \multicolumn{2}{|c|}{887 entradas } \\
\hline $\begin{array}{l}\text { Quadro de Operações-Procedimentos de } \\
\text { Implementação }\end{array}$ & \multicolumn{2}{|c|}{$\begin{array}{l}2 \text { quadros (Autoria e Navegação) com procedimentos } \\
\text { de implementação da interface e chamadas à DII }\end{array}$} \\
\hline \multicolumn{3}{|c|}{ Esforço de tempo para recuperação estrutural: $\cong 2$ meses e meio } \\
\hline
\end{tabular}


A documentação funcional recuperada do SASHE é composta por um Modelo de Ciclo de Vida com cinqüenta e cinco (55) sentenças, um Modelo de Operações composto por sessenta e duas (62) operações e dois modelos de objetos, um para cada tema proposto. O número elevado de sentenças do Modelo de Ciclo de Vida é um indicativo da grande interatividade do software e dos muitos estilos de interface (menus, botões, múltiplas janelas) implementados no sistema.

Com o término da recuperação do Modelo de Ciclo de Vida, do Modelo de Operações e dos modelos de objetos, encerra-se a primeira etapa do método Fusion-RE/I, que recupera visões funcionais do software unicamente através da interação com as informações sobre o sistema e sua interface. A conclusão dessa etapa do método deu-se ao final de cerca de dois meses, considerando-se uma dedicação de oito (8) horas/dia para uma (1) pessoa.

A segunda etapa, de recuperação de informações estruturais através da análise do código fonte do software, caracterizou o sistema SASHE com cerca de dez mil linhas de código C++, implementando o gerenciador da hiperbase (71,5\% do código), e cerca de quatro mil linhas de código Delphi, implementando a interface do sistema (28,5\% do código).

Todos os Quadros de Chamadas definidos para os arquivos de código $\mathrm{C}++$ totalizaram setecentos e vinte e dois (722) procedimentos registrados, incluindo protótipos e funções implementadas, sendo que para cento e setenta (170) procedimentos (23,5\%) não foram encontradas chamadas que os ativassem. Esse alto número de procedimentos inativos deve-se ao fato de que alguns objetos implementam métodos que não são utilizados pelo sistema, no entanto, complementam o conceito representado pelo objeto. Também existem procedimentos implementados em versões anteriores que, mesmo deixando de serem utilizados na versão analisada, não foram retirados do código pelos mantenedores. No total, foram analisadas quarenta e sete (47) classes, quinhentas e vinte e nove (529) funções (descartando-se os protótipos), codificadas em oitenta e quatro (84) arquivos de código $\mathrm{C}++$.

Quanto aos procedimentos em Delphi, foram analisados, no total, cento e sessenta e cinco (165) procedimentos, codificados em vinte e um (21) arquivos. Grande parte dos procedimentos analisados não apresentou nenhuma chamada no código. Devido ao paradigma da linguagem, orientada a eventos, já era esperado que fossem encontradas poucas chamadas aos procedimentos implementados em Delphi.

Como resultado, constatamos que aproximadamente $19,1 \%$ do código total do SASHE é inativo, ou seja, não é chamado em nenhum momento. 
Grande parte do trabalho concentrou-se no código $\mathrm{C}++$, por ser a parte em que está implementada a hiperbase, sob o modelo MCA (Casanova et. al., 1991). A construção do Quadro de Chamadas demandou cerca de um mês e meio de trabalho apenas para os arquivos $\mathrm{C}++$. Parte dessa tarefa foi auxiliada pelo uso da ferramenta Understand for $C / C++$ (STI, 1999), da qual foi utilizada uma cópia demo, disponível via Internet. Cerca de dez dias foi o tempo despendido na análise e construção dos Quadros de Chamadas dos arquivos Delphi. Foram necessários aproximadamente cinco dias para a construção do Quadro Índice de Procedimentos, incluindo os procedimentos em C++ e Delphi. Finalmente, a elaboração do Quadro de OperaçõesProcedimentos de Implementação demandou três semanas de trabalho para a sua conclusão.

Assim, podemos resumir o esforço de recuperação, conforme mostrado no Quadro 4.5, em aproximadamente dois meses para a visão funcional (modelos) e 2 meses e meio para a visão estrutural (quadros).

\subsection{Problemas encontrados na realização da Engenharia Reversa}

Por tratar-se de um sistema desenvolvido como protótipo em um projeto anterior (Soares et al., 1995), o SASHE apresenta diversos problemas, os quais nos levou a encontrar algumas dificuldades no processo de engenharia reversa. Conforme já foi mencionado, toda documentação relacionada ao desenvolvimento do sistema encontrava-se em dois relatórios técnicos (Nunes et al., 1996), (Nunes et al., 1997b), sendo que nenhum deles constitui um manual do usuário. Dessa forma, grande parte da informação sobre a funcionalidade do sistema foi conseguida através da interação exaustiva com o mesmo, e com várias entrevistas com alguns usuários, já que não havia uma descrição da mesma.

Outro problema que acarretou um certo atraso na realização das atividades que exigiam interação com a interface do sistema foi a sua instabilidade. Por tratar-se de um protótipo, muitas das funções continham problemas de execução, e também algumas inconsistências foram encontradas. Sendo assim, para determinar o resultado de uma função, a mesma tinha que ser executada várias vezes, pois nem sempre apresentava o mesmo comportamento. Também devido a essa instabilidade, tornou-se muito trabalhosa a elaboração dos documentos com as 
informações recuperadas no próprio SASHE, pois a cada erro corria-se o risco de perder essas informações. Assim optamos por elaborar os modelos e quadros em outras ferramentas de apoio e depois montar o hiperdocumento no sistema SASHE. De fato, essa foi uma das maiores dificuldades encontradas.

Também na análise do código encontramos dificuldades devido ao fato do software ter sido desenvolvido em duas linguagens diferentes, e por não existir comentários descritivos em grande parte desse código. Assim, sem informações que nos orientasse, o código tornou-se um "emaranhado" de comandos a serem desvendados. Esse fato fez com que a tarefa de descrição dos procedimentos fosse demorada e bastante custosa (concentração e lógica de raciocínio).

As próprias características do código $\mathrm{OO}$ foi outro fator que acarretou dificuldade à engenharia reversa. A aplicação de alguns dos conceitos da orientação a objetos traz certas dificuldades à leitura do código, que não são encontradas na manipulação de um código procedimental.

Pelo código ser orientado a objetos, as chamadas aos procedimentos nem sempre são explícitas, sendo feitas através de troca de mensagens. Isso proporciona uma dinâmica ao código em execução que dificulta o rastreamento das chamadas. Dessa forma, embora com o auxílio de uma ferramenta de suporte a engenharia reversa, a Understand for $C / C++$ (STI, 1999), o rastreamento dos ponteiros dinâmicos foi feito manualmente, para que cada chamada de procedimento fosse corretamente localizada. De fato, a falta de ferramentas que manipulassem o código-fonte de modo a auxiliar efetivamente a recuperação de informações durante todo o processo de engenharia reversa também foi um problema enfrentado neste trabalho.

Outro fator que influencia na identificação das chamadas é o fato de objetos diferentes conterem métodos com código diferente e com o mesmo protótipo (mesmo nome, mesmos parâmetros). Devido a essa característica, é preciso identificar o tipo do ponteiro que está referenciando o método, para se identificar a qual objeto pertence o método ativado. Além disso, existem os métodos virtuais, que para se identificar a sua chamada, é preciso saber o contexto (escopo) da chamada, em tempo de execução.

A utilização de métodos por herança também acarreta um trabalho extra ao rastreamento da chamada. Principalmente por se ter o conceito de herança, é que precisamos do Modelo de Objetos Real para a construção do Quadro de Chamadas. Somente tendo o conhecimento desse modelo, torna-se possível rastrear um método que está sendo utilizado por herança. De fato, se 
por um lado a herança poupa o trabalho do implementador, a possibilidade dos níveis de aninhamento de herança são "esconderijos" que tornam o entendimento do código problemático para determinados tipos de manutenção.

Conforme foi descrito nesta subseção, foram encontradas várias dificuldades na realização da engenharia reversa do sistema SASHE, tanto na etapa de recuperação da visão funcional quanto na recuperação da visão estrutural, devido a complexidade e volume inerentes do sistema, bem como pelo nível de detalhes exigido pelos documentos do Fusion-RE/I. Porém, essas dificuldades puderam ser transpostas, de forma que o processo de engenharia reversa pôde ser concluído com sucesso.

\subsection{Considerações Finais}

Neste capítulo foram apresentados os resultados do processo de engenharia reversa desenvolvido, tendo como o alvo recuperar informações estruturais e de análise do sistema SASHE.

Nas subseções da Seção 4.1 foram apresentados detalhadamente cada um dos produtos gerados como resultado da engenharia reversa, sendo que algumas medidas dos produtos e do esforço requerido para a conclusão do processo foram apresentados na Seção 4.2.

Finalmente, na Seção 4.3 foram descritas as dificuldades encontradas durante o processo de engenharia reversa, dificuldades essas devidas tanto a instabilidade do sistema, pois trata-se de um protótipo, como a falta de documentação para o início do processo, a falta de ferramentas adequadas, e até mesmo as características inerentes do código OO.

No próximo capítulo é apresentada uma avaliação geral do método de engenharia reversa utilizado, o Fusion-RE/I. 


\section{Capítulo 5}

\section{Avaliação geral do Fusion-RE/l}

Este capítulo tem por objetivo apresentar a avaliação do método Fusion-RE/I, baseada no estudo de caso realizado com o sistema SASHE. São comentados pontos positivos e pontos críticos encontrados na aplicação do método, bem como aspectos de validação. Finalmente, é apresentada uma nova proposta, adequando o Fusion-RE/I a sistemas originalmente implementados sob o paradigma OO.

\subsection{Discussão dos pontos positivos e críticos da aplicação do método Fusion-RE/I}

O Fusion-RE/I (Costa, 1997) é um método de engenharia reversa que propõe o início do processo pela interação com a interface do software para a recuperação de informações sobre a sua funcionalidade, e posteriormente, em uma segunda etapa, iniciar a recuperação de informações estruturais. Seu objetivo é recuperar a documentação de análise orientada a objetos de um software implementado sob o paradigma procedimental. Dessa forma, pode ser aplicado para a migração de paradigma do sistema (procedimental para OO) (Figura 5.1), assim como o Fusion-RE (Penteado, 1996). Uma das diferenças entre o Fusion-RE e o Fusion-RE/I está na ordem de recuperação das visões. O Fusion-RE inicia o processo pela recuperação estrutural, enquanto o Fusion-RE/I recupera a visão funcional inicialmente. 
Como mencionado no Capítulo 2, o método Fusion-RE/I foi desenvolvido a partir do método Fusion-RE, herdando, dessa forma, a base desse método. Entretanto, durante o andamento do processo de engenharia reversa, constatou-se que a recuperação dos modelos de análise, que descrevem a funcionalidade do sistema, poderia ser facilitada através de uma manipulação mais intensiva da interface do software. De fato, nas aplicações anteriores do método Fusion-RE/I (Costa, 1997) (Quinaia, 1998), ficou evidenciado que os Modelos de Ciclo de Vida e de Operações podem ser totalmente recuperados sem que haja nenhuma manipulação de código. Entretanto, a recuperação do Modelo de Objetos através da manipulação da interface pode ser válida ou não, conforme é discutido adiante.

Como o objetivo da engenharia reversa proposta pelo Fusion-RE/I é a migração de paradigma de projeto e implementação procedimental para orientação a objetos, o método Fusion-RE/I proporciona um bom ganho. Uma vez que a etapa inicial do método é a recuperação do modelo de análise, através da interação exaustiva com a interface, pode-se garantir que o engenheiro de software envolvido na engenharia reversa terá uma visão completa da funcionalidade do software, sem que o mesmo tenha sido influenciado pelos aspectos da implementação, pois até o término dessa etapa, o engenheiro não tem contato com o código fonte do software, tarefa esta que só é realizada após o término da etapa de recuperação da visão funcional.

Dessa forma, garante-se que o modelo recuperado no novo paradigma (OO) contém uma proposta nova, baseada na visão da funcionalidade do sistema, sem “contaminação” do código.

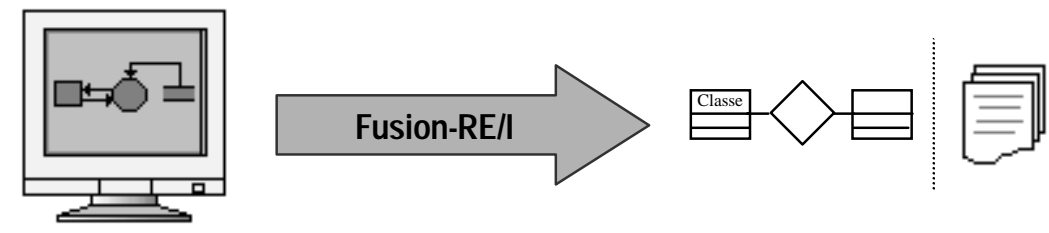

Figura 5.1 - Aplicação do Fusion-RE/I a sistemas procedimentais

Outra vantagem que se obtém com a aplicação do Fusion-RE/I é um ganho de familiaridade com o domínio do sistema já no início do processo de engenharia reversa. Como premissa do Fusion-RE/I, para que o engenheiro de software possa recuperar os modelos de análise de um sistema, é preciso antes reunir informações sobre o mesmo. A documentação existente, a linguagem de implementação, os dados obtidos por meio de entrevistas com os usuários e o domínio do sistema são fontes de informação valiosas (Biggerstaff, 1989). Dentre esses, o domínio do sistema, por ser um aspecto bastante relacionado às informações do mundo real e 
que são representadas de uma forma abstrata no sistema implementado, merece atenção diferenciada.

Domínio do sistema pode ser entendido como a área de conhecimento a qual um sistema pertence, que pode variar muito. Certamente, o domínio exerce influência no levantamento de informações sobre um determinado sistema. Uma vez que o engenheiro de software possui conhecimento (familiaridade) sobre o domínio ao qual o sistema pertence, maior é a chance desse sistema ser melhor entendido (Adelson; Soloway, 1985). E conseqüentemente, maior a chance de se obter uma melhor análise do mesmo.

Dessa mesma forma, sempre que o engenheiro de software possui familiaridade com o domínio do sistema, é de se esperar que isso influencie positivamente na construção do modelo mental desse sistema. O modelo mental permite ao engenheiro de software escolher um caminho particular de pensamento sobre um problema e gerar uma representação deste problema. Quanto mais familiar for o domínio ao engenheiro de software, uma melhor representação do sistema é feita e menos erros surgirão posteriormente (Adelson; Soloway, 1985).

Pesquisas já indicaram que a experiência e a familiaridade do engenheiro em um domínio de software influem diretamente nas etapas do ciclo de vida do software (Adelson; Soloway, 1985), (Greenbaum; Kyng, 1991). Sob a perspectiva da engenharia reversa, DeBaud et al. (1994) realizaram estudos de caso em que descrevem como o conhecimento do domínio pode auxiliar um processo de engenharia reversa e como a engenharia reversa pode ser usada para construir um modelo melhor do domínio de uma aplicação.

Pode-se dizer que, quando um sistema pertence a um determinado domínio, a sua interface é um dos elementos que melhor evidencia esse domínio. Há muito a interface deixou de ser apenas mais um elemento do sistema; é através dela que se dá o conjunto de processos, diálogos e ações entre o usuário e o computador, de forma a resultar em mecanismos objetivos para se obter a funcionalidade desejada.

No Fusion-RE/I, interação com a interface é ponto inicial do processo de engenharia reversa. Uma interação exaustiva com a interface é realizada, tornando o engenheiro de software conhecedor das funcionalidades e características operacionais do sistema. Dessa forma, o Fusion-RE/I possibilita um ganho efetivo de familiaridade com o domínio.

Quanto à recuperação dos modelos de análise, embora se trate de uma tarefa ligada à manipulação do sistema, por meio da sua interface, de forma bastante intensiva, sendo dessa 
forma uma tarefa "concreta", é exigido um grande esforço de atenção e concentração por parte do engenheiro de software (ou mantenedor), ao investigar quase que exaustivamente todos os estados da interface do sistema.

Os Modelos de Ciclo de Vida e de Operações, mesmo exigindo um grande esforço para sua obtenção, fornecem um conhecimento completo da funcionalidade do sistema, revelando as seqüências de comandos permitidas e a descrição das operações do sistema de forma clara e objetiva.

Esses foram alguns pontos positivos que puderam ser evidenciados durante $o$ desenvolvimento do processo. Entretanto, neste trabalho, o Fusion-RE/I foi aplicado a um sistema implementado sob o paradigma de orientação a objetos, o sistema SASHE. O desenvolvimento do processo de engenharia reversa em um sistema com essa característica nos permitiu algumas conclusões sobre o método que não haviam sido abordadas anteriormente.

Os estudos de caso anteriores realizados com o Fusion-RE/I (Costa, 1997), (Quinaia, 1998) foram aplicados a sistemas originalmente não orientados a objetos, e com um estilo de interface diferente do utilizado no SASHE. As informações sobre os estudos de caso realizados com o método são apresentadas no Quadro 5.1. O fato do sistema SASHE ser orientado a objetos, nos permitiu analisar uma série de outros fatores, que são discutidos a seguir.

Quadro 5.1 - Informações sobre os estudos de caso realizados com o Fusion-RE/I

\begin{tabular}{|c|c|c|c|c|c|c|c|c|}
\hline \multirow[b]{2}{*}{ Sistema } & \multirow[b]{2}{*}{ Domínio } & \multirow[b]{2}{*}{$\begin{array}{c}\text { Paradigma } \\
\text { de } \\
\text { programação }\end{array}$} & \multirow[b]{2}{*}{ Linguagem } & \multirow[b]{2}{*}{$\begin{array}{c}\mathrm{N}^{\circ} \text { de } \\
\text { linhas de } \\
\text { código }\end{array}$} & \multirow[b]{2}{*}{ Plataforma } & \multicolumn{3}{|c|}{ Documentação Funcional Gerada } \\
\hline & & & & & & $\begin{array}{c}\text { № de } \\
\text { sentenças } \\
\text { do ciclo de } \\
\text { vida }\end{array}$ & $\begin{array}{c}\text { № de } \\
\text { operações do } \\
\text { modelo de } \\
\text { operações }\end{array}$ & $\begin{array}{c}^{\circ} \mathrm{de} \\
\text { modelos de } \\
\text { objetos }\end{array}$ \\
\hline SASHE & $\begin{array}{l}\text { Autoria e suporte } \\
\text { hipermídia ao } \\
\text { ensino }\end{array}$ & $\begin{array}{c}\text { Orientação a } \\
\text { objetos }\end{array}$ & $\begin{array}{l}\text { C++ e } \\
\text { Delphi }\end{array}$ & 14.000 & $\begin{array}{c}\mathrm{PC} / \\
\text { Windows }\end{array}$ & 55 & 62 & 2 \\
\hline $\begin{array}{c}\text { SAPES } \\
\text { (Quinaia, } \\
\text { 1998) }\end{array}$ & $\begin{array}{l}\text { Apoio à pesquisa } \\
\text { científica }\end{array}$ & $\begin{array}{l}\text { Orientado a } \\
\text { função }\end{array}$ & Clipper & 4.000 & PC/ Dos & 46 & 17 & 4 \\
\hline $\begin{array}{c}\text { Proteum } \\
\text { V1. 1 C } \\
\text { (Costa, } \\
\text { 1997) }\end{array}$ & Teste de software & $\begin{array}{l}\text { Orientado a } \\
\text { função }\end{array}$ & C e X-View & 27.000 & $\begin{array}{l}\text { Estações } \\
\text { SUN/ Unix }\end{array}$ & $\begin{array}{c}\text { Não } \\
\text { disponível }\end{array}$ & Não disponível & 5 \\
\hline
\end{tabular}

A abstração conseguida sem influência do código fonte deixa de ser vantajosa quando o objetivo da engenharia reversa não é mais a recuperação de projeto para a mudança de paradigma, e passa a existir a necessidade de se recuperar o projeto exatamente como está. Em 
sistemas cujo código não esteja sob o paradigma $\mathrm{OO}$, faz sentido construir uma abstração do mesmo, na forma de Modelos de Objetos, através da análise de suas funcionalidades e do seu domínio de atuação, sem que o código implementado interfira na modelagem. Entretanto, quando o software está implementado sob o paradigma OO, a estrutura do Modelo de Objetos já existe e está instanciada no código do software. Assim, a construção de um Modelo de Objetos baseado somente nas visões funcionais do sistema deixa de ser válida. Seguindo-se os passos prescritos pelo Fusion-RE/I, após ter recuperado os modelos funcionais, é preciso construir um novo Modelo de Objetos, que realmente reflita a implementação, pois para que a recuperação do Quadro de Chamadas seja feita, é necessário o Modelo de Objetos realmente implementado. Sendo assim, um novo esforço de recuperação do Modelo de Objetos é requerido.

A recuperação do Modelo de Objetos, sem dúvida, é uma tarefa fundamental na documentação do software, no entanto, para sistemas orientados a objetos, a realização dessa tarefa nos parece mais adequada em outra etapa do processo de engenharia reversa. De fato, na experiência com o SASHE, ao se iniciar a segunda etapa, o Modelo de Objetos teve que ser ajustado às classes implementadas. Um ponto a ser ressaltado é que o ganho proporcionado pela interação com a interface, para a recuperação dos Modelos de Ciclo de Vida e de Operações, permanece, independente da ordem em que essas tarefas de recuperação sejam realizadas.

Quadro 5.2 - Vantagens e desvantagens do Fusion-RE/I aplicado a sistemas OO

\begin{tabular}{|c|c|}
\hline \multicolumn{2}{|c|}{ Início do Processo de Engenharia Reversa pela Recuperação da Visão Funcional } \\
\hline Vantagens & Desvantagens \\
\hline $\begin{array}{l}\text { 个 Ganho de familiaridade com o domínio da aplicação logo } \\
\text { no início do processo. } \\
\text { ^ Na leitura do código fonte existe um conhecimento prévio } \\
\text { da funcionalidade que está implementada. }\end{array}$ & $\begin{array}{c}\downarrow \text { A divisão das funcionalidades em temas pode influenciar a } \\
\text { abstração do Modelo de Objetos de forma errônea. } \\
\downarrow \text { O Modelo de Objetos pode ter que ser recuperado } \\
\text { novamente, a partir do código, para o prosseguimento do } \\
\text { processo. }\end{array}$ \\
\hline $\begin{array}{c}\text { A recuperação dos modelos de análise através da interface } \\
\text { é mais facilitada do que pelo código fonte, pois o nível de } \\
\text { abstração das interações é mais alto. }\end{array}$ & $\begin{array}{l}\downarrow \text { Perde-se tempo abstraindo um Modelo de Objetos que } \\
\text { posteriormente poderá ser descartado. }\end{array}$ \\
\hline
\end{tabular}

Um ponto crítico evidenciado durante a aplicação do método foi a recuperação do Modelo de Objetos, o que nos levou a considerar algumas questões. Uma primeira questão que pôde ser discutida foi a validade da inversão na ordem das etapas de recuperação proposta pelo Fusion$\mathrm{RE} / \mathrm{I}$, isto é, o início do processo de engenharia reversa pela recuperação da visão funcional do 
sistema através da interface, sem interação com o código fonte. Algumas vantagens inerentes a esta característica do método permanecem na sua aplicação a sistemas OO. Porém, a mesma característica acarreta alguns problemas a serem discutidos (Quadro 5.2).

Uma outra questão é a divisão das funcionalidades do sistema em Temas. Os Temas "forçam" uma abstração do sistema particionada pelo agrupamento da funcionalidade em assuntos semelhantes. No caso de um sistema OO, é muito provável que esse particionamento não exista no modelo implementado. Dessa forma, o engenheiro de software é induzido a recuperar uma abstração que não estará de acordo com a implementação.

Na verdade, é bastante discutível a validade da definição de Temas quando a engenharia reversa é aplicada a sistemas OO. A partir do momento que o Modelo de Objetos deixa de ser uma abstração criada a partir das visões funcionais do software e passa a registrar a sua estrutura real, a definição de Temas perde o significado. Nesse caso, pode-se discutir a utilidade dos temas também para sistemas $\mathrm{OO}$, mas não da maneira como é originalmente proposto pelo FusionRE/I. Uma possível aplicação da definição de Temas seria a sua utilização para a organização do Modelo de Objetos extraído do código. Sistemas maiores podem exigir que a estrutura recuperada do código seja dividida em vários Modelos de Objetos. No entanto, nesse caso, os Temas deveriam se adequar à implementação, já que o modelo implementado não pode ser mudado para se adequar aos Temas propostos de acordo com as funcionalidades observadas. Dessa forma, os temas teriam a mesma função de agrupamento, como proposto no Fusion-RE/I, porém em um outro nível de abstração. Nessa nova proposta, os temas seriam então definidos visando o agrupamento de classes e relacionamentos que implementam um determinado aspecto (assunto) do sistema.

As tarefas para recuperação de visões estruturais, segunda etapa do método Fusion-RE/I, foram adequadas, porém bastante trabalhosas, como pôde ser verificado através dos números apresentados no Capítulo 4. Foi constatado que parte dessas tarefas podem ser automatizadas com sucesso.

De acordo com o Fusion-RE/I, a primeira tarefa de recuperação estrutural é a elaboração do Quadro de Chamadas. Parte da elaboração desse quadro foi feita automaticamente, com o auxilio da ferramenta Understand for C/C++ (STI, 1999), conforme descrito no Capítulo 4. No entanto, a descrição dos procedimentos teve que ser feita manualmente, o que demandou muito trabalho para sua conclusão. A informação descrita nesse quadro é bastante significativa, pois através dele 
é possível rastrear a execução de cada procedimento, do momento em que é chamado (Chamado por) aos procedimentos que são disparados no corpo do procedimento (Chama). Além disso, o entendimento da funcionalidade de cada procedimento é apresentado no item Descrição.

Quanto ao Quadro de Índice, a sua geração pode ser totalmente automatizada, já que esse quadro é uma lista de todos os procedimentos e suas respectivas localizações (arquivo/diretório). Neste trabalho, esse quadro se torna especialmente útil, pois será usado na construção de uma página índice da hiperbase contendo links para acesso aos procedimentos de outro quadro.

O Quadro de Operações-Procedimentos de Implementação encerra a documentação estrutural recuperada segundo o método Fusion-RE/I. Esse quadro complementa as informações apresentadas no Quadro de Chamadas, associando a cada operação identificada na interface os procedimentos responsáveis por sua implementação. Um ponto positivo do método é a flexibilidade de se detalhar os procedimentos relacionados a cada operação num nível de profundidade que esteja de acordo com o objetivo final da engenharia reversa, como foi exemplificado no Capítulo 4.

Um ponto a se discutir na elaboração desse quadro (Etapa2-b do Quadro 2.6) é a classificação dos procedimentos em um dos temas definidos na primeira etapa do método, ou como uma implementação da interface. Novamente entramos na questão da validade da elaboração de temas para sistemas orientados a objetos. No caso de sistemas implementados sob outros paradigmas, a classificação dos procedimentos nos temas definidos é importante para que se possa ter uma idéia de onde (em qual classe) cada procedimento ficaria melhor implementado. Isso seria especialmente útil no caso de uma re-engenharia para mudança de paradigma (procedimental para OO). Uma vez que o código é orientado a objetos, essa classificação deixa de ser necessária, pois cada procedimento já é implementado como método de uma determinada classe, permanecendo válida apenas a classificação dos procedimentos que implementam as interações da interface relativas a cada operação.

Tendo terminado o processo de engenharia reversa, concluímos que o Fusion-RE/I não recupera informações de projeto orientado a objetos, uma vez que as informações estruturais recuperadas através do método não são suficientes para a construção dos modelos que constituem o projeto de um software OO. Seguindo-se os passos propostos pelo Fusion-RE/I, recupera-se o modelo de análise do sistema, segundo o método Fusion, e importantes informações estruturais, como o Quadro de Chamadas de Procedimentos e o Quadro de 
Operações - Procedimentos de Implementação. Porém, não são recuperadas informações que fazem parte do projeto $\mathrm{OO}$, como grafo de herança e grafo de visibilidade entre os objetos. Ou seja, características de projeto inerentes à orientação a objetos não são abordadas pelo método Fusion-RE/I.
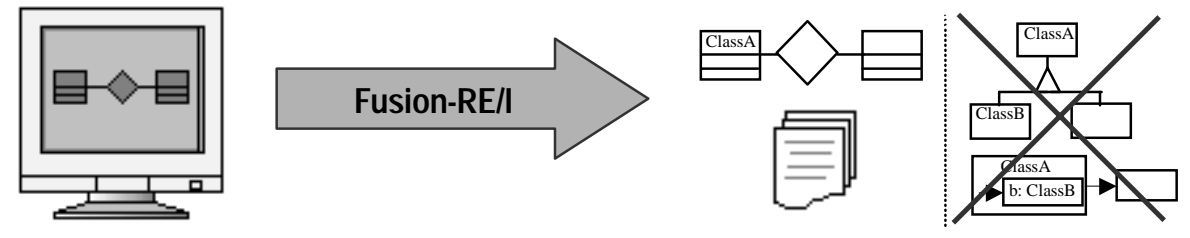

Figura 5.2 - Aplicação do Fusion-RE/I a sistemas orientados a objetos

Sendo assim, podemos dizer que, para sistemas OO, o Fusion-RE/I é um método que possibilita o entendimento e a documentação funcional (OO), e o rastreamento do código do sistema. Porém, essas informações estruturais recuperadas não constituem a documentação de projeto OO do sistema (Figura 5.2).

O diferencial do Fusion-RE/I está na proposta de etapas bem definidas para que o engenheiro de software seja capaz de extrair o modelo de análise do sistema (segundo o método Fusion) sem ter que manipular, em qualquer momento da extração do modelo, o código fonte do mesmo. Dependendo do objetivo da engenharia reversa, esta característica do método pode ser desejável ou não.

No estudo de caso desenvolvido por Quinaia (1998), o objetivo era recuperar apenas a funcionalidade do sistema, pois o código fonte seria todo descartado, a fim de implementar o mesmo sistema sob outro paradigma. Nesse caso, as etapas propostas pelo método foram suficientes, sendo que foi realizada apenas a etapa de recuperação da visão funcional. A aplicação do Fusion-RE/I, nesse caso, proporcionou ao engenheiro um ganho de tempo e esforço, já que foi feita a modelagem de toda a funcionalidade sem nenhuma interação com o código fonte do sistema. Esse é um ponto positivo que será válido sempre que o código fonte for desconhecido pelo engenheiro de software e/ou não existir a necessidade de documentação estrutural, seja o sistema alvo procedimental ou OO. Assim, podemos dizer que, nas condições descritas acima, o método é aplicável e vantajoso.

No estudo de caso realizado com o SASHE neste trabalho, foram encontrados alguns problemas na aplicação do Fusion-RE/I, uma vez que era objetivo do processo de engenharia reversa não só a recuperação da modelagem funcional, como também a modelagem estrutural do 
sistema. A recuperação da estrutura do software era necessária, já que o SASHE não seria reimplementado, e o objetivo era documentar o software para auxiliar em futuras manutenções. Nesse ponto surgiram dificuldades, especialmente relacionadas ao fato do SASHE ser um software $\mathrm{OO}$ e do método Fusion-RE/I não estabelecer etapas para a recuperação de projeto $\mathrm{OO}$ (Figura 5.2).

Dessa forma, podemos concluir que algumas premissas do método Fusion-RE/I devem ser reavaliadas, de acordo com o objetivo do processo de engenharia reversa que se pretende realizar, antes de se iniciar a engenharia reversa. Alguns fatores determinantes para o sucesso da aplicação do método e que devem ser avaliados antes do início do processo são:

• nível de documentação que se espera recuperar (funcional/estrutural);

ـ paradigma de implementação do sistema atual;

๑ desejo de se reutilizar o código fonte original;

• nível de conhecimento do engenheiro de software sobre o sistema alvo do processo.

Esclarecidos esses pontos, pode-se traçar um plano para a aplicação do método, determinando possíveis ações a serem realizadas, como:

- quantas etapas do método serão necessárias para se alcançar o objetivo estabelecido para o processo;

- reorganização das etapas propostas pelo método, caso necessário, de acordo com a necessidade de detalhamento da documentação estrutural; (necessidade do Modelo de Objetos recuperado da estrutura, necessidade da definição de temas, necessidade da classificação em temas no Quadro Operações-Procedimentos de Implementação)

- avaliação do custo-benefício da aplicação do método, caso o engenheiro esteja familiarizado com o código fonte do sistema alvo.

Todos esses fatores devem ser levados em conta, antes do início da aplicação do método de engenharia reversa propriamente dito, para que se possa garantir um processo eficiente e resultados consistentes com os objetivos traçados. 


\subsection{Validação dos Resultados obtidos com o Fusion- RE/I}

Como mencionado anteriormente, no início do processo de engenharia reversa não existia quase nenhuma documentação de análise e projeto do sistema SASHE, sendo que as informações existentes estão em dois relatórios técnicos (Nunes et al., 1996), (Nunes et al., 1997b). Em Nunes et al. (1996) é mostrada uma pretensa arquitetura em camadas para o sistema SASHE (Figura 5.3a), assim como uma breve descrição das funcionalidades inicialmente desejáveis para o sistema. Também nesse relatório é apresentada uma visão geral da máquina HIP (Figura 5.3b), componente do sistema SASHE. Em Nunes et al. (1997b) é feita uma apresentação da interface do sistema e de suas principais funcionalidades. No entanto, em nenhum momento é apresentada uma modelagem do sistema.

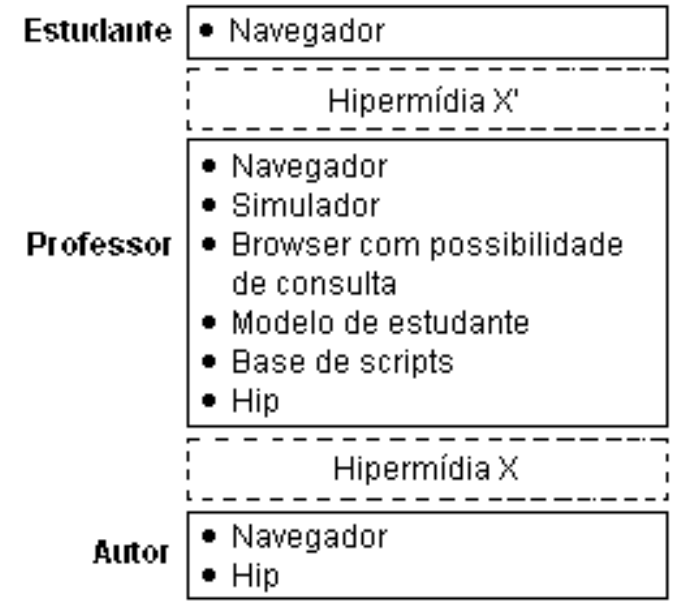

Figura 5.3a - O ambiente SASHE proposto (Nunes et al., 1996)

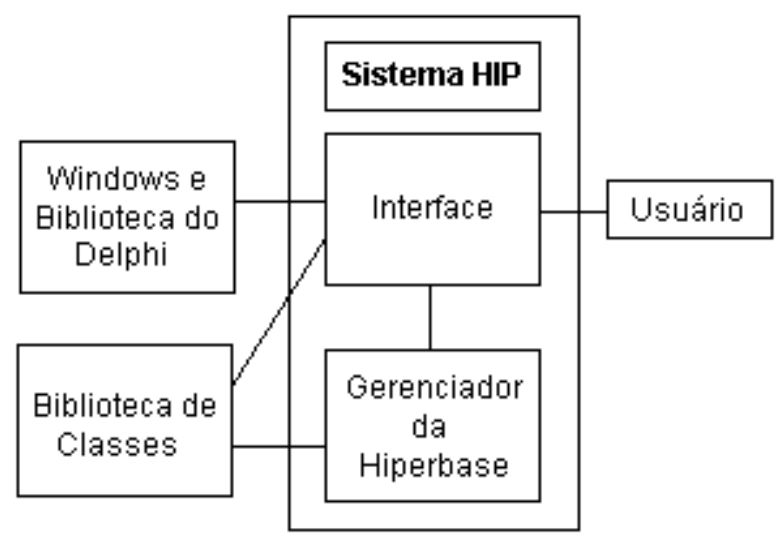

Figura 5.3b - Arquitetura básica do Hip (Nunes et al., 1996)

A Figura 5.3a mostra a proposta feita inicialmente para o sistema SASHE. Nessa proposta, o Autor, que não precisa ser necessariamente o professor, seria o construtor da hiperbase de fato, ou seja, agruparia todos os documentos desejados dentro do SASHE. Essa hiperbase constituiria a camada Hipermídia X. Sobre essa camada, o Professor propriamente dito poderia trabalhar, criando sobre a camada Hipermídia X um roteiro específico para seu objetivo. Para tal, o Professor disporia de todos as ferramentas listadas na camada Professor da figura. A hiperbase limitada pelo roteiro construído pelo professor seria a camada Hipermídia X', ou seja, uma instância da camada Hipermídia X. O Estudante, por sua vez, atuaria sobre essa camada Hipermídia X', utilizando o navegador. 
A Figura 5.3b mostra a arquitetura do Hip/Windows, um sistema para desenvolvimento de aplicações hipermídia, que constitui o módulo de autoria de hiperdocumentos do sistema SASHE. Em Nunes at al. (1996) são descritos os componentes do Hip, conforme mostrado na Figura 5.3b:

【 Interface, responsável pela interação do sistema com o usuário;

- Biblioteca de Classes, que implementa as abstrações definidas pelo modelo MCA (Casanova et al., 1991);

- Gerenciador da Hiperbase, responsável pela manipulação dos objetos que compõem a hiperbase.

As informações presentes em Nunes et al. (1996, 1997b) são muito importantes e serviram como ponto de partida para o processo de engenharia reversa, porém, como já mencionado, não havia nenhuma documentação de análise ou de projeto do sistema que foi efetivamente seguida para a implementação do SASHE.

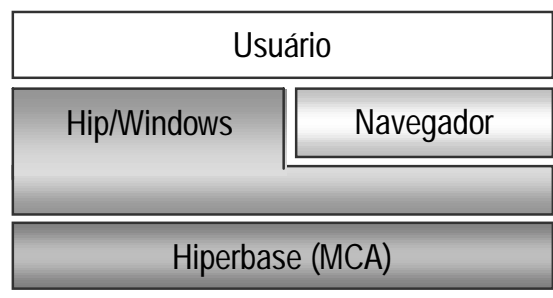

Figura 5.4a - Arquitetura recuperada do ambiente SASHE

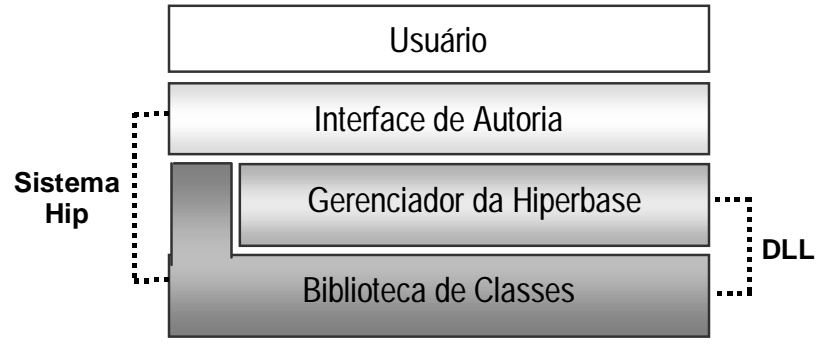

Figura 5.4b - Arquitetura recuperada do Hip/Windows

Dessa forma, a partir do estudo de caso realizado com o SASHE, não foi possível comparar a documentação recuperada com a documentação original do sistema, uma vez que esta última não existe. No entanto, as informações recuperadas através da aplicação do método Fusion-RE/I mostraram-se consistentes com os relatórios existentes, embora a arquitetura proposta inicialmente para o sistema SASHE (Figura 5.3a), não tenha tido todos os seus componentes implementados. A arquitetura recuperada, que retrata a real implementação do sistema SASHE 1.0 é mostrada na Figura 5.4a. Os documentos recuperados confirmaram a arquitetura proposta para o sistema Hip (Figura 5.3b), documentada em Nunes et al. (1996) e totalmente implementada na versão atual. A Figura 5.4b apresenta a arquitetura recuperada do Hip, elaborada em camadas para melhor visualização. 


\subsection{Uma proposta de adequação do Fusion-RE/I a sistemas 00}

Como descrito na Seção 5.1, alguns pontos, na aplicação do método, foram críticos. Isso devido, principalmente, ao paradigma de implementação do sistema utilizado no estudo de caso (SASHE). Como anteriormente o método não havia sido aplicado a nenhum sistema com tal característica, vários fatores que não haviam sido previstos influenciaram o processo.

Nesta seção é proposta uma reorganização das etapas previstas no método Fusion-RE/I, a fim de melhorar a adequação do método a sistemas orientados a objetos. Nesta nova proposta, dois pontos são modificados:

- definição de Temas; e

○ recuperação do Modelo de Objetos.

Tanto no Fusion-RE/I como no Fusion-RE, o objetivo da definição de Temas, que agrupem as funcionalidades identificadas no sistema, é nortear a construção do Modelo de Objetos, pois se pretende recuperar uma modelagem $\mathrm{OO}$ para um sistema que foi originalmente concebido sob outro paradigma. Como foi argumentado na Seção 5.1 (Quadro 5.2), a definição de Temas perde o significado a partir do momento que o Modelo de Objetos deixa de ser uma abstração resultante da análise de funcionalidades e passa a ser recuperado do código fonte, retratando o Modelo de Objetos realmente implementado.

Nesta nova proposta, os Temas apenas serão definidos caso haja a necessidade de se particionar o Modelo de Objetos Real, devido ao seu tamanho e sua complexidade. Assim, os objetos podem ser organizados em vários modelos, consistentes entre si, facilitando dessa forma, a leitura e o entendimento da modelagem. Porém, deve-se ressaltar que embora a divisão do Modelo de Objetos deva levar em conta a funcionalidade do sistema, os Temas devem se adequar à implementação existente. Sob essa nova visão, os temas deixam de agrupar "assuntos" identificados através da interação com a interface, para agrupar classes e relacionamentos que implementam um determinado aspecto do sistema.

Sendo assim, cabe ao engenheiro de software responsável pelo processo de engenharia reversa, determinar a necessidade ou não da definição de Temas durante a aplicação do método. A definição de Temas pode ser a última tarefa da primeira etapa (Recuperação de Visões 
Funcionais), mas pode continuar juntamente com a recuperação do Modelo de Objetos, pois como dito anteriormente, os temas devem se adequar ao Modelo de Objetos implementado.

Outro aspecto observado na realização do estudo de caso com o SASHE é a validade da recuperação do Modelo de Objetos durante a etapa de recuperação de visões funcionais. Retomando, a recuperação das visões funcionais é feita unicamente através das informações já existentes sobre o sistema e da manipulação da interface do software. Dessa forma, o Modelo de Objetos recuperado, segundo o método Fusion-RE/I, é uma abstração construída a partir das informações coletadas nos passos anteriores (ver Quadro 2.6), sem que haja nenhum contato com o código fonte.

Conforme discutido (Seção 5.1), essa modelagem isenta da implementação pode ser vantajosa ou não, dependendo do objetivo definido para o processo de engenharia reversa. Nesta proposta (Quadro 5.3), assumimos que o sistema alvo é orientado a objetos e que é objetivo da engenharia reversa recuperar uma modelagem que seja fiel à implementação, semelhante ao estudo de caso desenvolvido. Sendo assim, a recuperação do Modelo de Objetos passa a ser a primeira tarefa (a.) da segunda etapa do método (Recuperação de Visões Estruturais). Dessa forma, o Modelo de Objetos deixa de ser abstraído da funcionalidade para ser recuperado do código fonte do sistema. Assim garantimos que o Modelo de Objetos realmente reflete o sistema implementado.

Quadro 5.3 - Modificações propostas para o Fusion-RE/I

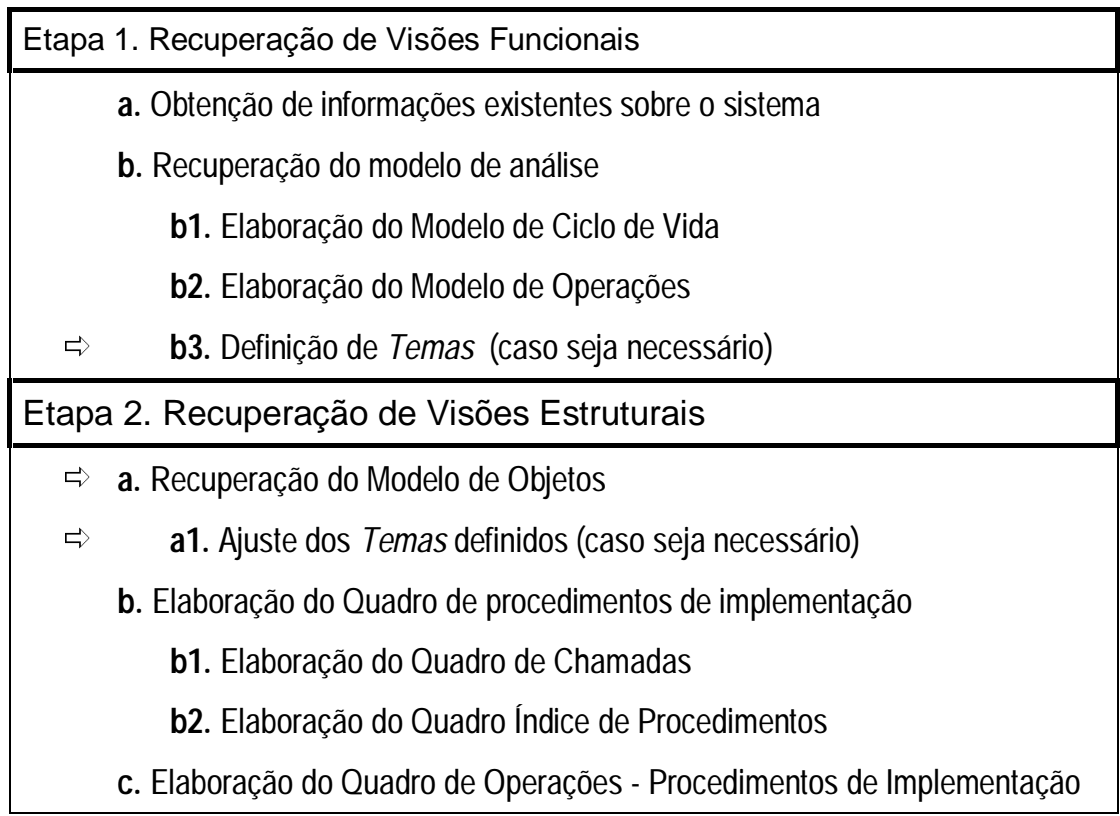


De fato, a tarefa de se recuperar o Modelo de Objetos a partir do código fonte teve que ser realizada no estudo de caso feito com o SASHE, pois para a recuperação do restante das informações estruturais prescritas pelo Fusion-RE/I é necessário ter o conhecimento da arquitetura do código $\mathrm{OO}$.

No Quadro 5.3 é apresentado um resumo das etapas do método Fusion-RE/I com as modificações propostas.

As setas indicam os pontos onde houve modificações em relação à proposta original do Fusion-RE/I (ver Quadro 2.6). Independente da mudança de passos proposta, é fato que a interação com a interface, ao invés da manipulação do código fonte, facilita consideravelmente a recuperação dos Modelos de Ciclo de Vida e de Operações. Além disso, conforme discutido na Seção 5.1, consegue-se um ganho de familiaridade com o domínio do sistema, uma vez que a interface é um dos elementos que evidencia esse domínio.

\subsection{Considerações Finais}

Neste capítulo foram abordados os pontos positivos e os pontos críticos da aplicação do FusionRE/I a um sistema orientado a objetos, assim como os aspectos de validação da documentação recuperada através da engenharia reversa. Também foi apresentada uma nova proposta de adequação do método Fusion-RE/I para sistemas sob o paradigma de orientação a objetos. No

próximo capítulo, são feitas as conclusões deste trabalho e apresentados possíveis trabalhos futuros. 


\section{Capítulo 6}

\section{Conclusão}

Este trabalho teve como um dos seus objetivos principais a elaboração de uma proposta para a adequação do sistema SASHE ao domínio da documentação de engenharia reversa de software, de forma que fosse proporcionada maior agilidade para o acesso dessa documentação e que também fossem estabelecidos links representativos, que "guiassem" o usuário durante a navegação da documentação de engenharia reversa, explicitando os relacionamentos entre os documentos.

Foi realizado um experimento, de forma que a análise dos resultados embasasse essa proposta. Tal experimento consistiu da utilização e aplicação de engenharia reversa ao sistema SASHE, um sistema hipermídia protótipo existente desenvolvido no ICMC-USP. Sendo que o

ambiente SASHE baseia-se no modelo MCA (Casanova et al., 1991), um modelo interno de estruturação de nós que auxilia a organização das informações, esse modelo também foi estudado para que obtivéssemos os subsídios necessários ao processo de entendimento do SASHE.

Para que a documentação atendesse ao paradigma OO, o processo de engenharia reversa orientou-se pelo método Fusion-RE/I (Costa, 1997). Foi realizado um estudo prévio desse método, viabilizando sua aplicação ao sistema SASHE. Também foram estudados os conceitos de uma linguagem padrão de modelagem OO, a UML (Rational, 1997a), cuja potencialidade de ser independente da utilização de qualquer método sob o paradigma OO, pôde ser comprovada. 
Para que a UML pudesse ser utilizada neste trabalho, foram propostos possíveis mapeamentos entre os modelos utilizados pelo método Fusion-RE/I e os modelos propostos pela UML.

Para o início da construção da hiperbase composta pelos documentos recuperados do sistema SASHE, foi realizada uma modelagem conceitual do domínio de engenharia reversa, baseada nas etapas propostas pelo método Fusion-RE/I. Tal modelagem foi feita utilizando-se o método de projeto de aplicações hipermídia OOHDM.

Tendo como base a modelagem em OOHDM, foi iniciada a construção, propriamente dita, da hiperbase no SASHE. Uma vez que o SASHE é baseado no modelo MCA, a modelagem feita previamente teve que ser ajustada para que os nós fossem organizados adequadamente.

A maior parte da documentação recuperada do SASHE foi efetivamente inserida na hiperbase, sendo que essa experiência proporcionou o conhecimento necessário para a sugestão de pontos de ajuste para o sistema SASHE, visando proporcionar um melhor suporte à autoria e navegação de hiperbases contendo documentos de engenharia reversa.

\subsection{Contribuições deste Trabalho}

Durante o andamento deste trabalho, constatamos que, de fato, existe a necessidade de um meio de acesso mais ágil aos documentos de engenharia reversa, isso devido ao grande volume de documentação manipulada durante e após o processo, e também ao grande número de relacionamentos existentes entre os documentos. As modificações para a adequação do sistema SASHE ao domínio da documentação de engenharia reversa propostas, juntamente com as características já existentes no SASHE, viriam suprir essa necessidade, facilitando tanto na autoria da hiperbase, permitindo que os relacionamentos entre os nós fossem estabelecidos já na autoria, como na navegação, provendo controles para guiar o usuário através dos documentos e apontar os relacionamentos entre os modelos, sem que o usuário tenha necessidade de conhecimento prévio da documentação.

Também com a realização da engenharia reversa, foram recuperadas a documentação de análise e importantes informações estruturais sobre o sistema SASHE. No início do estudo de caso com o SASHE, não existia nenhuma documentação de análise sobre o sistema, e pouca documentação sobre sua funcionalidade e sua estrutura. A documentação recuperada e publicada 
em Feltrim e Fortes (1999) poderá servir como guia para novos usuários do sistema e também auxiliar engenheiros de software em futuras manutenções.

Também podemos citar outras contribuições que não eram o foco principal deste trabalho, mas que foram concluídas durante o seu desenvolvimento.

A aplicação do método de engenharia reversa Fusion-RE/I, da sua fase inicial até a sua conclusão, em um sistema orientado a objetos, proporcionou um contexto propício à análise de alguns pontos críticos da aplicação do método a sistemas OO. Também permitiu a constatação de aspectos do Fusion-RE/I que permanecem sendo vantajosos, mesmo quando aplicado a sistemas OO. Foi realizada uma avaliação crítica de todas as etapas propostas pelo método e foram propostas algumas modificações na ordem de suas etapas, a fim suprir os pontos críticos apontados e de favorecer sua aplicação a sistemas OO (Feltrim et al., 1999).

A proposta de mapeamento feita para os modelos do Fusion-RE/I, de forma que fossem representados em UML pode vir a ser o ponto inicial para um completo mapeamento do Fusion-RE/I para a notação UML.

A modelagem do domínio de engenharia reversa realizada em OOHDM pode ser vista como uma apresentação dos requisitos funcionais identificados no processo de engenharia reversa que possam ser suportados por um sistema hipermídia. Essa modelagem foi uma tentativa de formalizar o relacionamento das atividades de engenharia reversa, seus subprodutos e interações (Feltrim; Fortes 1998b). Como base para o estabelecimento das atividades envolvidas e dos modelos gerados ao final do processo, nos apoiamos no método Fusion-RE/I, que viria a ser efetivamente utilizado posteriormente na engenharia reversa do sistema SASHE.

\subsection{Sugestões para Futuras Pesquisas}

Um trabalho futuro que se apresenta bastante interessante é a generalização da interface do SASHE proposta para atender o domínio de engenharia reversa. A nova interface proposta neste trabalho foi baseada na resolução dos problemas encontrados durante a manipulação da hiperbase de engenharia reversa. Sendo assim, está fortemente ligada às etapas e aos produtos gerados pelo método de engenharia reversa utilizado, o Fusion-RE/I. Um estudo aprofundado do processo de engenharia reversa, tendo como foco o estabelecimento de fases genéricas do 
processo e de atributos de nós generalizados, poderia resultar em uma interface que atendesse o domínio de documentos de engenharia reversa sem restringi-la a um ou outro método.

A efetiva implementação dessa interface ao sistema SASHE virá suprir a necessidade de um sistema adequado de autoria e navegação de documentos resultantes do processo de engenharia reversa.

Outro trabalho futuro que ficou evidenciada sua necessidade durante a realização deste mestrado consiste na definição de um método de engenharia reversa para sistemas implementados sob o paradigma de orientação a objetos. Os sistemas OO possuem muitas características intrínsecas ao paradigma que necessitam de um tratamento específico. Embora tenha sido possível a aplicação do Fusion-RE/I a um sistema OO, muitos aspectos de implementação desse sistema não foram recuperados completamente, em função do referido método não apoiar a recuperação de documentos de projeto. A proposta de um método que recuperasse não só os documentos de análise, mas também os documentos de projeto $\mathrm{OO}$, viria suprir uma necessidade de fato comprovada.

Como a aplicação do Fusion-RE/I é iniciada pela manipulação da interface para a elaboração do Modelo de Ciclo de Vida e essa tarefa requer um esforço mecânico de interação exaustiva com todas as opções da interface do software com o usuário, um auxílio automático que capturasse essas interações se apresenta também como alvo de futuras pesquisas. 


\section{Referências Bibliográficas}

ADELSON, B.; SOLOWAY, E. The Role of Domain Experience in Software Design. IEEE Transactions on Software Engineering, v.SE-11, n.11., p.1351-1360, 1985.

BIGELOW, J. Hypertext and CASE. IEEE Software, p.23-27, March 1988.

BIGELOW, J.; RILEY, V. Manipulating Source Code in DynamicDesign. ACM Hypertext' 87 Conf., Proceedings, p.397-408, 1987.

BIGGERSTAFF, T. Design Recovery for Maintenance and Reuse. IEEE Computer, v.22, n.7, p.36-49, 1989.

BULLOCK, J.C.; GOBLE, C.A. TouristT - Conceptual Hypermedia Tourist Information. ACM Hypertext'97 Conf., Proceedings, p.228-229, 1997.

CASANOVA, M.A.; TUCHERMAN, L; LIMA, M. J.; RANGEL, J. L.; RODRIGUEZ, N. R.; SOARES, L. F. G. The Nested Context Model for Hyperdocuments. Third ACM Conference on Hypertext, Proceedings, San Antonio, Texas, p.193-201, 1991.

CASTRO, M.A.S. Infra-Estrutura de Suporte à Editoração de Material Didático Utilizando Multimídia. Revista Brasileira de Informática na Educação, n.1, p.61-70, 1997.

CERQUEIRA, A.A.C. HOOT: Integrando Hipermídia e Bancos de Dados Orientados a Objetos. Dissertação (Mestrado), UFRJ, Rio de Janeiro, Agosto 1997.

CHIKOFSKY, E.J.; CROSS II, J.H. Reverse Engeneering and Design Recovery: A Taxonomy. IEEE Software, v.7, n.1, p.13-17, 1990.

COLEMAN, D. et al. Desenvolvimento Orientado a Objetos: O Método Fusion. Ed. Campos, Rio de Janeiro, 1996.

COLEMAN, D.; ARTIM, J.; OHNJEC, V.; RIVAS, E.; RUMBAUGH, J.; WIRFSBROCK, R. UML: The Language of Blueprints for Software?. ACM Sigplan Notices, n.32, p.201-205, New York, 1997. 
COSTA, R.M. Um método de Engenharia Reversa para Auxiliar a Manutenção de Software. Dissertação (Mestrado), ICMC-USP, São Carlos, 1997. 100p.

DEBAUD, J-M.; MOOPEN, B.; RUGABER, S. Domain Analysis and Reverse Engineering. In: International Conference on Software Maintenance, Victoria. Proceedings, p.326-335, 1994.

ERIKSSON, H.; MAGNUS, P. UML Toolkit. Wiley, New York, 1998.

FELTRIM, V.D.; FORTES, R.P.M. Uma modelagem do domínio de Engenharia Reversa de Software utilizando o método OOHDM. Notas do ICMC-USP, Série Computação, n.40, São Carlos, Junho 1998a. 23p.

FELTRIM, V.D.; FORTES, R.P.M. Requisitos de Hiperdocumentos de suporte ao domínio de Engenharia Reversa de Software. In: Workshop de Engenharia de Requisitos, Anais, Maringá, p.159-167, Outubro 1998b.

FELTRIM, V.D.; FORTES, R.P.M. Documentação do sistema SASHE recuperada por meio de Engenharia Reversa. Relatório Técnico do ICMC-USP, Série Computação, n.90, São Carlos, Julho 1999. 254p.

FELTRIM, V.D.; FORTES, R.P.M.; SILVA, W.F. Aspectos de Validação do Método de Engenharia Reversa Fusion-RE/I aplicado a um Sistema Hipermídia. In: XIII Simpósio Brasileiro de Engenharia de Software, Anais, Florianópolis, p.257-272, Outubro 1999.

GARG, P.K.; SCACCHI, W. ISHIS - Designing an Intelligent Software Hypertext System. IEEE Expert, p.52-63, Fall 1989.

GARZOTTO, F.; PAOLINI, P.; SCHWABE, D. HDM - A Model-Based Approach to Hypertext Application Design. ACM Transactions on Information Systems, v.11, n.1, p.1-26, January 1993.

GREENBAUM, J.; KYNG M. (eds), Design at work: Cooperative of Computer Systems. Lawrence Erlbaum, Hillsdale, NJ, 1991.

HAREL, D. Statecharts: A Visual Formalism for Complex Systems. Science of Computer Programming, v.8, p.231-274, 1987.

HAREL, D.; GERY, E. Executable Object Modeling With Statecharts. Computer, n.30, p.31-\&, 1997.

JUBILEU, A.P.; SANCHES, R. Um Processo de Aquisição de Conhecimento Explícito para Apoiar o Método de Engenharia Reversa Fusion-RE/I. In: IV Workshop de Teses em Engenharia de Software, Anais, Florianópolis, p.79-83, Outubro 1999.

MASIERO, P.C. Análise Orientada a Objetos: Uma Introdução ao Método Fusion. In: IX Simpósio Brasileiro de Engenharia de Software. Documento preparado como apoio ao tutorial homônimo, Recife, 1995. 
MEIRA, S.M.; CABRAL, R.S. Id: Um Sistema de Hipertexto Configurável e Orientado a Objetos para Integrar Documentos de Software. VIII Simpósio Brasileiro de Engenharia de Software, Anais, Curitiba, p.283-296, 1994.

NIELSEN, J. Multimedia and Hypertext - The Internet and Beyond. Academic Press, London, United Kingdom, 1995.

NUNES, M.G.V.; HASEGAWA, R.; VIEIRA, F.M.C. Hip/Windows: Um Ambiente de Autoria de Hiperbases Multimídia, Relatório Técnico do ICMC-USP, n.38, São Carlos, 1996. 34p.

NUNES, M.G.V.; FORTES, R.P.M. Roteiros em Aplicações no Ensino: a Questão do Controle do Leitor. In: Workshop em Sistemas Multimídia e Hipermídia, III., Anais, São Carlos, p.15-27, 1997.

NUNES, M.G.V.; FORTES, R.P.M.; NICOLETTI, M.C. Flexible Guided-tours in Hypertexts: a way of controlling the user in learning applications. In: World Multiconference on Systemics, Cybernetics and Informatics SCI'97/ISAS'97, Proceedings, Caracas-Venezuela, 1997a.

NUNES, M.G.V.; HASEGAWA, R.; VIEIRA, F.M.C.; SANTOS, G.H.R.; FORTES, R.P.M. SASHE: Sistema de Autoria e Suporte Hipermídia para Ensino. Notas do ICMC-USP, n.33, São Carlos, 1997b. 22p.

OXFORD, Dictionary of Computing Oxford, University Press, 1986.

PENTEADO, R.A.D. Um método para Engenharia Reversa Orientado a Objetos. Tese (Doutorado), IFSC-USP, São Carlos, 1996. 251p.

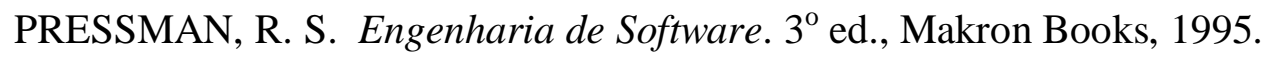

QUINAIA, M.A. Diretrizes para Reengenharia de Software com Características de Software Legado. Dissertação (Mestrado), ICMC-USP, São Carlos, 1998. 111p.

RATIONAL Software Corporation. UML Summary, 1997a. (http://www.rational.com/UML)

RATIONAL Software Corporation. UML Notation Guide, $1997 \mathrm{~b}$. (http://www.rational.com/UML)

RATIONAL Software Corporation. UML Semantics, 1997c. (http://www.rational.com/UML)

RATIONAL Software Corporation, 1999. (http://www.rational.com/rose).

RIZK, A.; SUTCLIFFE, D. Distributed Link Service in the Aquarelle Project. ACM Hypertext'97 Conf., Proceedings, p.208-209, 1997.

ROSSI, G. Um Método Orientado a Objetos para o Projeto de Aplicações Hipermídia. Tese (Doutorado). Departamento de Informática Pontifícia Universidade Católica, Rio de Janeiro, 1996. 205p. 
RUGABER, S. Program Comprehension for Reverse Engineering. In: AAAI Workshop on AI and Automated Program Understanding, San Jose, California, p.106-110. July 1992. (http://www.cc.gatech.edu/reverse/papers.html)

RUMBAUGH, J.; BLAHA, M.; PREMERLANI, W.; EDDY, F.; LORENSEN, W. Object Oriented Modeling and Design. Prentice Hall, 1991.

SALEH, K.; BOUJARWAH, A. Communications Software Reverse Engineering: A SemiAutomatic approach. Information and Software Technology, Oxford, n.38, p.379-390, 1996.

SCHACH, S.R. The Economic Impact of Reuse on Maintanance. Journal Software Maintanance: Research and Practice, v.6, n.4, p.185-196, 1994.

SCHNEIDEWIND, N.F. The State of Software Maitanance. IEEE Trans. on Software Engineering, v.13, n.3, p.303-310, 1987.

SCHWABE, D.; ROSSI, G. The Object-Oriented Hypermedia Design Model. Communications of the ACM, v.38, n.8, p.45-46, 1995.

SCHWABE, D.; ROSSI, G.; BARBOSA, S.D.J. Systematic Hypermedia Application Design with OOHDM. In: Hypertext'96. Proceedings. Washington DC, USA, p.116-128, March 1996.

SOARES, L.F.G. et al. HyperProp: Uma Visão Geral. In: I Workshop em Sistemas Hipermídia Distribuídos, Anais, ICMC-USP, São Carlos, p.1-12, 1995.

STI. Scientific Toolworks, Inc., 1999. (http://www.scitools.com)

TILLEY, S.R.; SMITH, D.B. On Using the Web as Infrastructure for Reengineering. 5th Workshop on Program Comprehension (IWPC'97), Proceedings, p.170-173, Michigan, 1997. 